Portland State University

PDXScholar

$1-4-2021$

\title{
Decolonizing Healthcare: a Black Feminist Analysis of Sisters Informing Sisters on Topics of AIDS (SISTA)
}

Joy Mutare Fashu Kanu

Portland State University

Follow this and additional works at: https://pdxscholar.library.pdx.edu/open_access_etds

Part of the Public Health Commons, and the Sociology Commons Let us know how access to this document benefits you.

Recommended Citation

Mutare Fashu Kanu, Joy, "Decolonizing Healthcare: a Black Feminist Analysis of Sisters Informing Sisters on Topics of AIDS (SISTA)" (2021). Dissertations and Theses. Paper 5626.

https://doi.org/10.15760/etd.7498

This Dissertation is brought to you for free and open access. It has been accepted for inclusion in Dissertations and Theses by an authorized administrator of PDXScholar. Please contact us if we can make this document more accessible: pdxscholar@pdx.edu. 
Decolonizing Healthcare: A Black Feminist Analysis of

Sisters Informing Sisters on Topics of AIDS (SISTA)

by

Joy Mutare Fashu Kanu

A dissertation submitted in partial fulfillment of the requirements for the degree of

\author{
Doctor of Philosophy \\ in \\ Sociology
}

\title{
Dissertation Committee: Aaron Roussell, Chair \\ Amy Lubitow \\ Julius McGee \\ Lisa Weasel
}

Portland State University

2020 
(C) 2020 Joy Mutare Fashu Kanu 


\section{ABSTRACT}

This mixed methods project combines the conceptual insights offered by institutional ethnography, the deductive and inductive attributes of content analysis, semi structured interviews, and quantitative data analysis to study Sisters Informing Sisters on Topics of AIDS (SISTA), a social skills training program designed for sexually active, heterosexual African American women. This progressive program serves as a site to examine the complex relationship the U.S. state has had, and continues to have, with marginalized populations, particularly African Americans. The program reveals how the state, through the public health service, partners with scholars, researchers, and community-based organizations to produce, reproduce and perpetuate problematic discourses regarding the sexual lives of Black folks. As a former participant in this training, I juxtapose the theory of gender and power, upon which the program rests, to standpoint feminist theories like Black Feminist Thought to show the ways class and colorblind racism work together in well-intentioned programs to ensure the survival of controlling images. I argue that though SISTA offered a variety of benefits to the community, it is still a valuable source of data into the ways harmful stereotypes about the sexual lives of Black folks concerning HIV/AIDS exposure persist even in the face of opposing discourse like Black Feminist Thought. 


\title{
DEDICATION
}

This work is dedicated to HIV/AIDS combatants, those who fought bravely and those still in the trenches. It is on your brave shoulders that I stand. This dissertation is also dedicated to those who feel like giving up on anything - those who have been told they could not do it (fill the blank). It is therefore also dedicated to they who made life hard for me, denied me access this just became fuel for me. Thank you, otherwise I certainly would have given up.

\author{
A luta Continua!
}




\section{ACKNOWLEDGMENTS}

I acknowledge Dr. Arthur Paris who, through my struggles, reminded me that "You were purchased by blood" - meaning that giving up was not a luxury I could afford. To this end, I honor all who shed their blood for me to walk this land, to walk the halls of academia and produce this intellectual/spiritual work. Thank you, Pepe Sutton and the Sutton family. The lives of the children of Zimbabwe whom we support though Project It Takes A Village, Inc. are being positively impacted because you appreciated my talents, took a chance on me, and changed my life.

I acknowledge Dr. Aaron Roussell for agreeing to advise me and help restore that which was previously shattered, for being intellectually invested in this project and helping re-envision its possibility. I acknowledge my committee of Dr. Amy Lubitow, Dr. Julius McGee, and Dr. Lisa Weasel for your brilliance and your mentorship in and out of the classroom! Thank you for allowing me latitude to be intellectually creative in producing this work that I care deeply about. I hope I have made you proud. I acknowledge Dr. Joel Bettridge for being adventurous enough to read work outside their discipline yet providing outstanding feedback. I acknowledge Dr. Winston Grady-Willis, for being a brother and a mentor. I thank and acknowledge you, Bahar Jaberi. I cannot count the many ways you made life manageable. Thank you so much for increasing the reasons I am glad I came to PSU.

I acknowledge my family, the innocence with which my children regard me, the quiet (and sometimes not so quiet $\odot$ ) patience with which they have watched me work throughout the years and their unconditional love. When I started at PSU in 2016, Thabela, then 9 yrs. old, asked when I would graduate. I told her, "Not until I write this 
huge document called a dissertation with about 200 pages.” I acknowledge you, Thabela, because when I finally started writing in 2019, you'd ask, "What page are you on now, Mommy?" I was on page 4 when you first checked in and one page at a time, I knew I did not want to still be on page 4 when you ask again. Surely, the next time you asked I was on page 38 and so the document got written, one page at a time.

Thank you also, Thabela for putting the note, "Wake up, mommy!! I love you” on my alarm clock (Appendix A). Whenever I saw that note on my alarm, my mindset changed immediately, and my morale boosted because you helped me remember what's important and worth waking up for. My last born Yinka, thank you for stopping by the desk to kiss me occasionally when I wrote. Thank you, Yinka for writing me notes, for sitting on my lap and writing with me sometimes. You are precious to me, Yinka and O, what a gift you have been to me. Thank you for reminding me of what it is that is important in life. Thank you our first born, Sammy, for your gentle spirit, reminding me to find that quiet peace even when the world can be very loud. As they say, your babies are like pancakes, you usually burn the first one. Thank you, Sammy, for your resilience and for keeping me accountable. Thanks, Munya! You were there from the start and remained faithful! Thank you for telling me you are proud and encouraging me to keep it moving and now we are almost done. I say "almost" because the fight for "complete health” for BIPoC is ongoing. I thank my children for their unconditional, redeeming love. Seeing myself through the eyes of my children has given me permission to believe in myself again and trust myself because they trust me. In a word of competing and sometimes ugly voices, thank you, babies for being the voice of truth, the wind beneath my wings. 
I acknowledge my mother, Constance Sithole (Elder Jongwe). Thank you, Mom for giving me life and for teaching me about God. You taught me that when things do get tough, I can look to loving Heavenly Bodies and I wouldn't have to carry any life load on my own. You taught me that if I can see myself through the way Heavenly Bodies see me, there was nothing I couldn’t accomplish. O, how I miss you! Thank you for encouraging me to seek spiritual guidance wherever I am. I thank you, therefore my newfound church family who gave me fellowship and helped me stay focused on what matters.

I acknowledge my birth family. When I lost faith, you were there to restore it. Joseph Sr. and Babamunini Leslie - my father figures who faithfully sowed into my life! To Sekuru Shepherd, Mbuya Anna, my child said most appropriately of you, “They practically raised you!” - and you did and continue to. I look back now and realized you were 22-23 then when you took me into your home for seven years! Sekuru Wellington, carrying me on your shoulders to Mutambara Hospital when I got sick- that is a good sixmile hike! Mbuya Chipo, for telling me about Bassanio and Shylock and planting the love of literature in my heart! Mainini Charity, Mainini Ella, my mom’s sisters to whom I send my children even when I am not there. My children have had the blessing of drinking from the fountain that is your love. Sekuru Gladwell, you have loved me, and you took the trip to go visit Munya when you heard he was in Musami. Mainini Charity Jr. and Babamunini Frank, Sekuru Kuda! Thank you! Sekuru Albert, you have our grandfather's name, and you wear it well!! I acknowledge my family in Nyanyadzi. Growing up with you folks as my family is priceless to me and I love you all so much! Joseph, Hendrix Alexio Sam, Jackie, Peshi, I exist because you exist. Growing up 
surrounded by you has served as sauve for my soul. Even when they tried and I let them, they could break me because you are my pillars. Mhuri yangu yekwa MuBekapi woye! Dissertation iya yaibva, anhu nayi. Tichava vanhtu!

I acknowledge the family I married into. Alvin, thank you so, so for reminding me not to get distracted and remember why I came to Portland! "Keep your head down, finish your program and think of the kids who look up to you” - you said! Thank you, Mainini Danai for being a friend and for being a sister.

My amazing friends, Chem, Abigail! What can I say! We came a long way. Thank you for taking the time to know me, to love me, and to support me intellectually, spiritually, and emotionally. Rudo \& Joanna, though we don't talk as much, when we see each other it's like time just collapses. Emily, Jackie and Lillian, you have become sisters and gave me a second family. Thank you for your love and for all my nieces and nephews. Mandi and Abby! Thank you for joining our family and continuing to remind me that I matter. The time and energy you have invested in me has not gone unnoticed. Thank you, Abby for reminding me, "His grace is sufficient.” That reminder has seen me through some surefire tough times.

Dr. Gisela Rodriguez thank you for editing this 200-page document! What! You have been a colleague, a comrade, and a friend. To all my old friends of 30 years and over, my middle friends of 15 years, and my new friends of the last 3-5 years, how do I thank you. Thank you, Ian, and Nouf for working next to me. We have motivated each other to a 2020 completion which seemed an impossible milestone to imagine.

I thank my friends from the sociology department for coming to my on and off campus affairs and continuing to sow into me and my family. Wynn, Shah! Thank you 
for your intellect and being willing to share it with me. My friends and the Jim and Nancy Boyle, thank you for asking me, "how is the dissertation going?" The more you asked, the more I realized you actually expected me to complete this document, and I did! Dr.

Micere Mugo for being a mother to me. I acknowledge the Africans living in the diaspora and those at home for reminding me of the kinds of people I am descendant from!

I acknowledge Dr. Wingood! Thank you for providing this tool for Black women, thank you for talking with me about it, thank you for the opportunity to appreciate and critique it as I grow as a scholar. Thank you to all my respondents for taking the time to speak with me and calling me a "colleague.” Thank you, Portland State University. Thank you, editors, for working tirelessly to make this document better. This has been a tough section to write because I cannot name everyone here but by golly people, we have done it!!!!!! 


\section{TABLE OF CONTENTS}

ABSTRACT
DEDICATION
ACKNOWLEDGEMENTS
LIST OF TABLES
LIST OF FIGURES
LIST OF ABBREVIATIONS
PREFACE
INTRODUCTION
Purpose

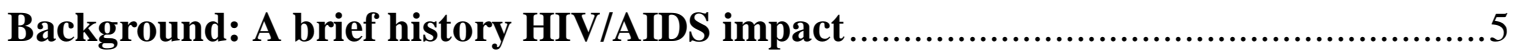

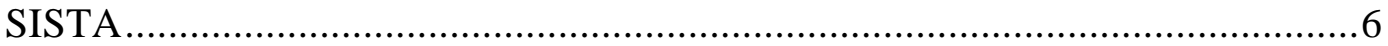

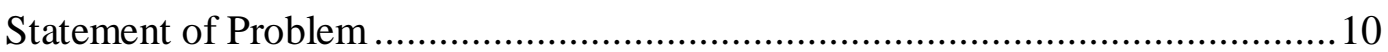

Organization and structure of this dissertation ................................................14

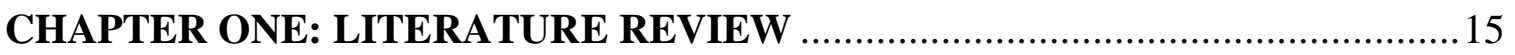

1.1. Health Behavior Models.......................................................................15

1.2. Theory of Gender and Power, Social Cognitive Theory ...............................20

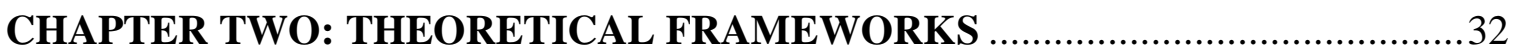

2.1. Feminist Theories ......................................................................................32

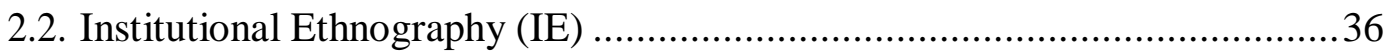

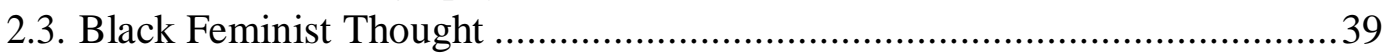

2.3.1. Black Feminist Thought in the context of HIV/AIDS ................................42

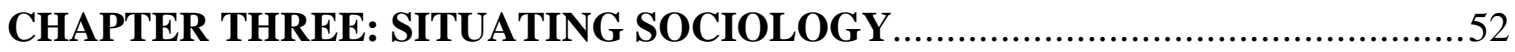

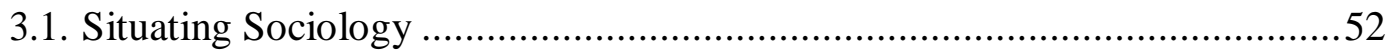

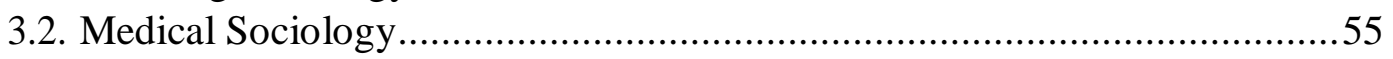

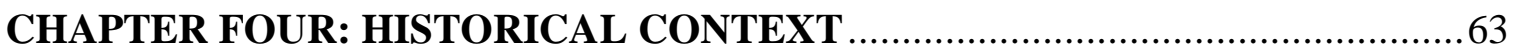

4.1. Historical context ....................................................................................63

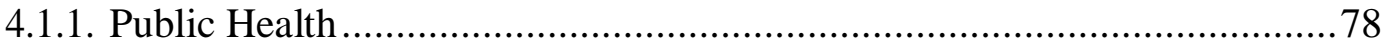

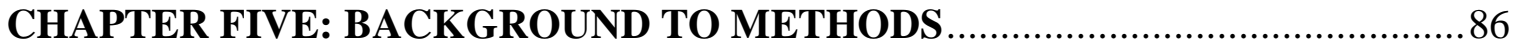

5.1. Research Philosophy: IE and Black Feminist Thought ..................................8

5.2. Summary of mixed methods approach ..........................................................90

5.2.1. IE and Development of Personal Standpoint..................................91

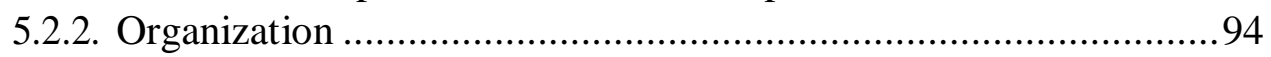

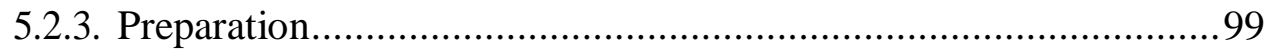




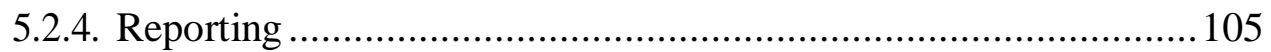

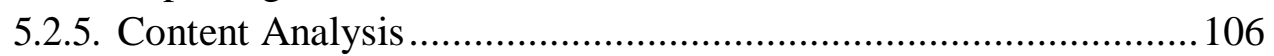

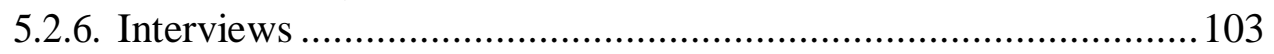

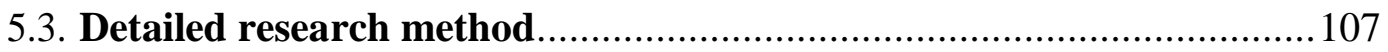

5.3.1. Content Analysis - SISTA Training manual.................................106

5.3.2. The Insider Standpoint: Experiencing and Embodied Subject......112

5.3.3 Point of entry ............................................................................113

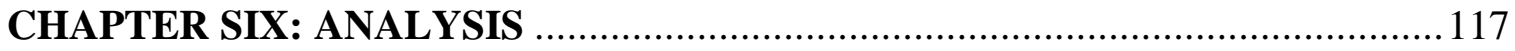

6.1. Relations of Ruling .............................................................................117

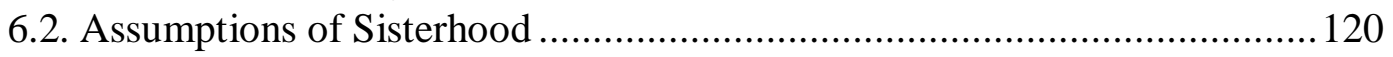

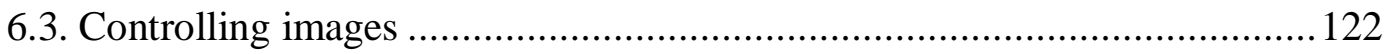

6.3.1. The welfare queen...................................................................125

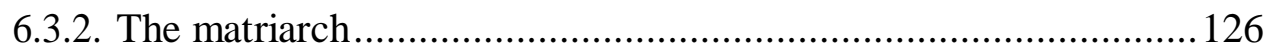

6.3.3. The angry Black woman............................................................ 127

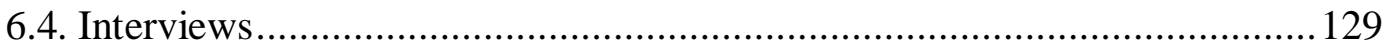

6.4.1. Academia as a ruling apparatus .................................................134

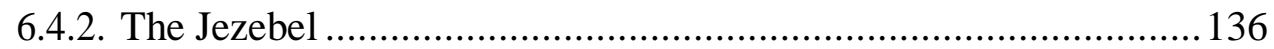

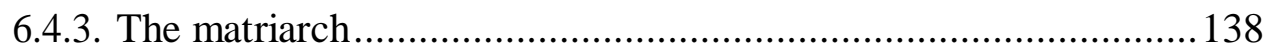

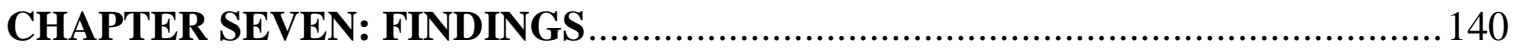

7.1. Class and reproduction of controlling images.............................................141

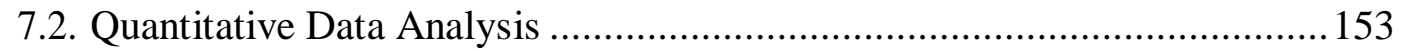

7.2.1. Black women as objects .............................................................158

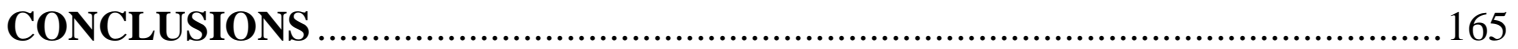

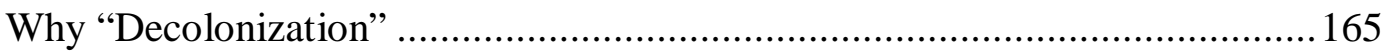

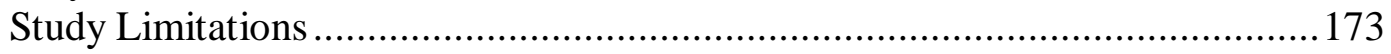

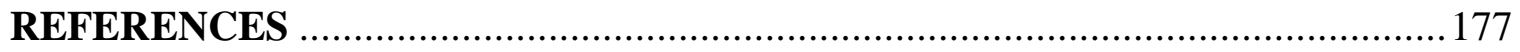

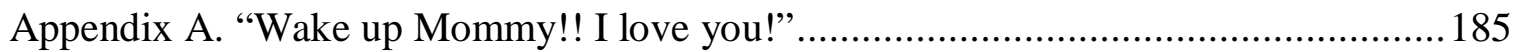

Appendix B. SISTA Training Manual Front Page and page 2, 2005 .............................186

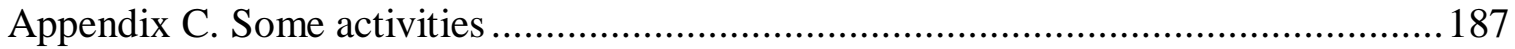

Appendix D. Core elements .................................................................................190

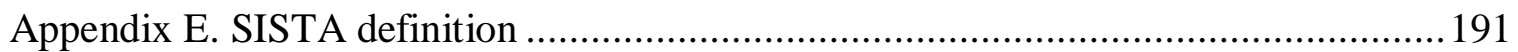

Appendix F. Description of Theory of Gender and power .............................................192

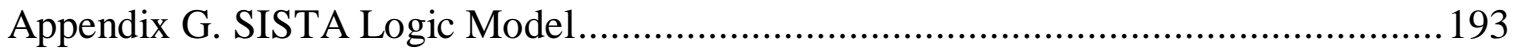

Appendix H. Conceptual model for the Theory of Gender and Power ............................195

Appendix I. Rationalization for Theory of Gender and power .......................................196

Appendix J. Excerpt from the movie "It's Like This"................................................197

Appendix K. Sample of work speaking to sexual lives of Black folks............................ 198 
Appendix L. Patricia Hill Collis’ Controlling images (1991) ....................................203

Appendix M. Verbal script for recruitment...................................................... 204 


\section{LIST OF TABLES}

Table 1. Summary of mixed methods approach ...........................................98

Table 2. $\quad$ Schlobohm examples of "Black tropes" (2016) ................................... 100

Table 3. Examples of vignettes containing "controlling images" .......................130

Table 4. Pseudonyms, self-reported gender, and occupation of respondents........133

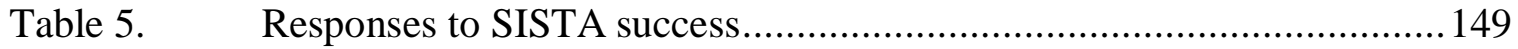

Table 6. $\quad$ Responses to CDC shift in funding priorities ..................................151

Table 7. Parameters of women under study in Broaddus et al (2016) study.........156

Table 8. $\quad$ Responses to “... condom use in your relationship?” ..........................158

Table 9. Sites quantitative data was collected from...................................... 159 


\section{LIST OF FIGURES}

Figure 1. Zimbabwe Life Expectancy 1950-2019 …….......................................... xix

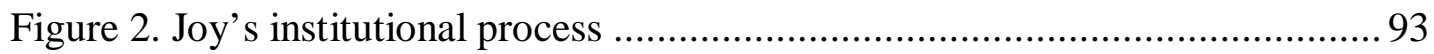

Figure 3. Race, gender, educational and occupation make-up of respondents ...... 160 


\section{LIST OF ABBREVIATIONS}

DEBI(s).......................... Diffusion of Effective Behavioral Intervention(s)

CBO................................ Community Based Organization(s)

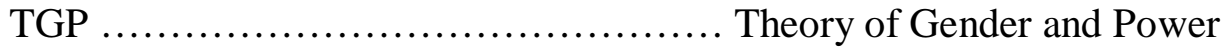

BFT .............................. Black Feminist Thought

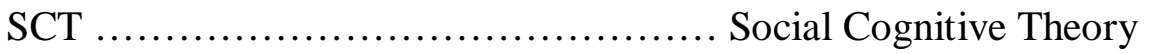

CDC.................................. Centers for Disease Control

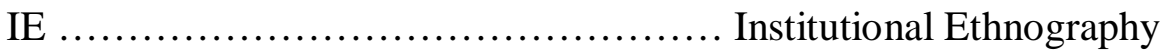

TRA.................................... Theory of Reasoned Action

HBM ....................................Health Behavior Models

BIPoC ................................. Black, Indigenous, People of Color

PLWAs.................................People Living with AIDS. 


\section{PREFACE}

Conceptualizing and producing a dissertation amidst mourning for George Floyd, Tony McDade, Breona Taylor, and in the midst of remembering Jonathon Tubby, an Oneida man killed in police custody nearly two years ago as well as all the missing and murdered indigenous women has been humbling and challenging, humbling because it is on the shoulders of these lives Black, Indigenous, People of Color (BIPoC) lives that I stand. Further, writing during the era of COVID and its devastating impact on the US, particularly the disproportionate deaths among African Americans, ${ }^{1}$ has made it even more obvious why this work is important. From this vantage point, I examine Sisters Informing Sisters on Topics of AIDS (SISTA), a social skills training program developed for sexually active, heterosexual African American women during the earlier years of the HIV/AIDS pandemic. As a participant in the program and a sociology student, I was intellectually stimulated by its theoretical framing. It raised within me critical questions regarding the relationship between the US government and Black folks, particularly Black women. My literature review revealed that much of the work written about SISTA speaks of its positive attributes. Allison Schlobohm's 2016 dissertation is the first work I have encountered that offered a critique of SISTA and a genealogy of race and public health in the United States. Schlobohm (2016) characterizes SISTA as a "program that relies on longstanding tropes of blackness to describe the lives of Black women.” She further writes about SISTA as a "mechanism for the production of anti-black sentiment that ultimately reproduces the conditions that make black women disproportionately

\footnotetext{
${ }^{1}$ COVID-19 and racial disparities Shah Monica, Sachdeva Muskaan, and Dodiuk-Gad Roni P., 2019.,
} Journal of the American Academy of Dermatology. 
likely to die from HIV/AIDS” (Schlobohm 2016 146). Schlobohm contends that she did not arrive at this conclusion lightly and acknowledges that a part of her perceives her dissertation as a "disrespectful discredit to SISTA's creators and disseminators who have devoted enormous efforts to curb HIV/AIDS in the African American community” (2016 146). Regardless of her misgivings about performing this work, Schlobohm brings to light complexities and contradictions contained within public health where public health officials are tasked with ensuring the health of all on the one hand, yet on the other, they consciously or unconsciously reproduce the isms responsible for health inequalities.

My work parallels Schlobohm's and affirms and recognizes her thorough outline of the problematic 100-year history the public health sector has had with historically marginalized peoples of the US, particularly African Americans. One major difference between our work is that whereas Schlobohm's work traces the 100 years of public health history from the time she was writing, my work goes a little bit beyond 100 years to the actual founding of public health sector as a formalized government mandate. Further, while Schlobohm's work is located in communications and rhetoric studies where they employ this academic discipline’s specific analytical tools to critically examine language, meanings, and symbols of Blackness as they are employed by SISTA, mine is located within sociology, is interdisciplinary and explores the US public health sector as a power structure not directly concerned with how its racist and classist history continues to impact the lives of Black folks to date.

My work also echoes New York Times correspondent, Neil Irwin, who, in a March 17th 2017 article "What if Sociologists Had as Much Influence as Economists?” wrote urging the policy makers in Washington DC to consider creating policy rooted in a 
sociological understanding of social structures because sociology is better equipped to serve populations than economic models.

Irwin advocates for sociology because sociologists generally spend the bulk of their time studying various aspects of how societies work. My work examines the role of medical sociologists, in particular, who use unique theoretical and methodological explanatory tools to understand persistent health disparities while offering sustainable solutions for these disparities. Using this premise for my dissertation, I examine how psychology dominate public health discourse and HIV/AIDS interventions as has been the case, has provided only partial, and sometimes devastating solutions for the impacted. While critical sociologists do not necessarily undermine nor diminish the importance of individual responsibility in determining health outcomes, an elevated role for sociology in influencing health policy and accompanying interventions provides more comprehensive recommendations for the prevention of the further spread of infectious diseases like AIDS. With theoretical tools like C.W. Mills' sociological imagination, the sociological perspective places appropriate focus on social factors to equip those who use it to adequately discern those societal patterns accountable for unequal health outcomes (Weitz 2007).

I arrived at this conclusion in 2006 when I accepted a friend's invitation to participate in the SISTA training. It was while I was in the midst of mourning for friends and family as well as volunteering with several organizations within my community that I had begun to assess my own country's micro and macro-level responses to the epidemic that I received this invitation. This friend, whom I shall refer to as Toziwa in this dissertation, worked as a Prevention Specialist at a local HIV/AIDS agency whose work 
focused historically marginalized populations. She was both optimistic and excited because, she said, in the face of HIV/AIDS, there was finally a program "for Black women, by Black women.” These words spoke directly to me as I was coming from Zimbabwe where AIDS had so devastated my country, and indeed my continent of Africa. The impact of HIV/AIDS was so significant it left Zimbabwe reporting a life expectancy of 44 by 2001 as depicted in Figure 1.

In this crisis, though my academic training was in the field of business administration, I found myself intellectually but unwittingly using sociological tools to process my thoughts regarding what I considered to be my country's problematic responses to this pandemic. Amongst the top problematic micro-level responses was a general linking of HIV/AIDS to individual [lack of] morality. Another one of Zimbabwe's macro-level responses I was most critical of was the government's silence or slow reaction to misinformation such as the linking of condom use to promiscuity. Yet another was the population's general discomfort with condom commercials on TV and a call for the banning of such commercials.

My 1997 immigration to the US did not diminish the curiosity I nursed as I had expected it to. Instead, this exodus shifted and expanded my critical gaze towards the global. Here I thought that I was in a new world learning new things. While this was true, to a large extent, it was disheartening to note that Black people in the US were also experiencing disproportionately large numbers of HIV/AIDS infection and incidence. It is in this context, then, that I was asked to train as a participant in the SISTA education program and I gratefully agreed. My entrée into the SISTA training coincided with the start of my academic career as a sociology student. Equipped with a few theory classes 
under my belt, I recognized that the sociological lens was becoming useful in allowing me to comprehend the socio political and historical dynamics responsible for the proliferation of the HIV virus. However, I had not become fluent enough in the disciplinary language to clearly articulate the questions rising within me regarding my role, the role of the state, and other players to mitigate the causal and correlational factors responsible for the rise in HIV/AIDS statistics among Black folks. However, I also became conscientized to the complicity of academia in spreading stereotypical and onesided messages about the spread of HIV/AIDS through my anthropology class "Culture and AIDS." Here, a one-sided view of how Black men considered "on the downlow" responsible for the high rates of HIV/AIDS among heterosexual African American women was presented and the women in one video were screaming, "they are killing us." The discussion on "men on the down low" barely scratched the surface of the complexity of African American lives, or the contexts within which sexual practices occur and are interpreted. What further infuriated me was that the teacher was considered by the school as an expert on AIDS and expert of AIDS in Africa, particularly Ghana. Again, I felt insufficiently educated to critique the premise, but I knew it was unsettling and I also knew that I was getting a more critical lens from sociology and I was glad to be there. Therefore, challenges I have encountered notwithstanding, I chose not to give up on this story and I now offer this study as my way to explore the ways academia partners with the government in simultaneously exacerbating inequalities while attempting to reduce them. I explore the role of class privilege as it comes to bear in the analysis of SISTA as a program for "us by us". 
Further, I use institutions ethnography (I.E.), a tool known as "a sociology for women” developed by Dorothy Smith to investigate how SISTA was created and how the women experienced the program. For starters, because the program was said to be "for us by us” or specifically for African American women, I felt uneasy being there. I reluctantly considered the practicality of limited resources to be a factor for these parameters. It made sense that, with HIV/AIDS ravaging Black communities, there would be a scarcity of resources available to target all the populations under threat. Be that as it may, I also observed that the language sounded contradictory. I began to wonder that if the stipulation was that this program was for African American women only, why then was I, a Zimbabwean immigrant woman, invited into the training? It became apparent that though the manual specified that it had to be followed as stipulated, the women on the ground interacted with it as was most expedient for them.

Further, the more I peered into the manual, the more I noticed several other elements emerging which needed some unpacking. I perceived these elements only as glaring because this training manual specifically stipulated that for the program to work, it had to be administered exactly as it was written.

In conclusion, I offer that my approach to this project is influenced by the above and in the current climate of CoVID-19, I emphasize that my work is significant because while Black, Indigenous bodies and bodies of color continue to suffer disproportionately, those in leadership, including the President of the United States, declare that they do not understand why the statistics show that African Americans are disproportionately impacted by the epidemic. This project highlights the tragic implications of the inability or unwillingness to center race, racism, racial inequality, and continued violations BIPoC 
bodies. How long can we afford to live in this form of conditioned oblivion? (McIntosh 1989) Can we afford to remain oblivious to sociohistorical political forces initiated by colonialism and slavery and advanced through racial, class privilege and colorblind racism? By failing to properly account for the role of systematic and structural racism on in our work, we remain complicit in perpetuating structural inequalities. 


\section{Life expectancy at birth, total (years) - Zimbabwe}

(1) United Nations Population Division. World Population Prospects: 2019 Revision, or derived from male and female life expectancy at birth from sources such as: (2) Census reports and other statistical publications from national statistical offices, (3) Eurostat: Demographic Statistics, (4) United Nations Statistical Division. Population and Vital Statistics Reprot (various years ), (5) U.S. Census Bureau: International Database, and ( 6 ) Secretariat of the Pacific Community: Statistics and Demography

Programme

License : CC BY- 4.0 (

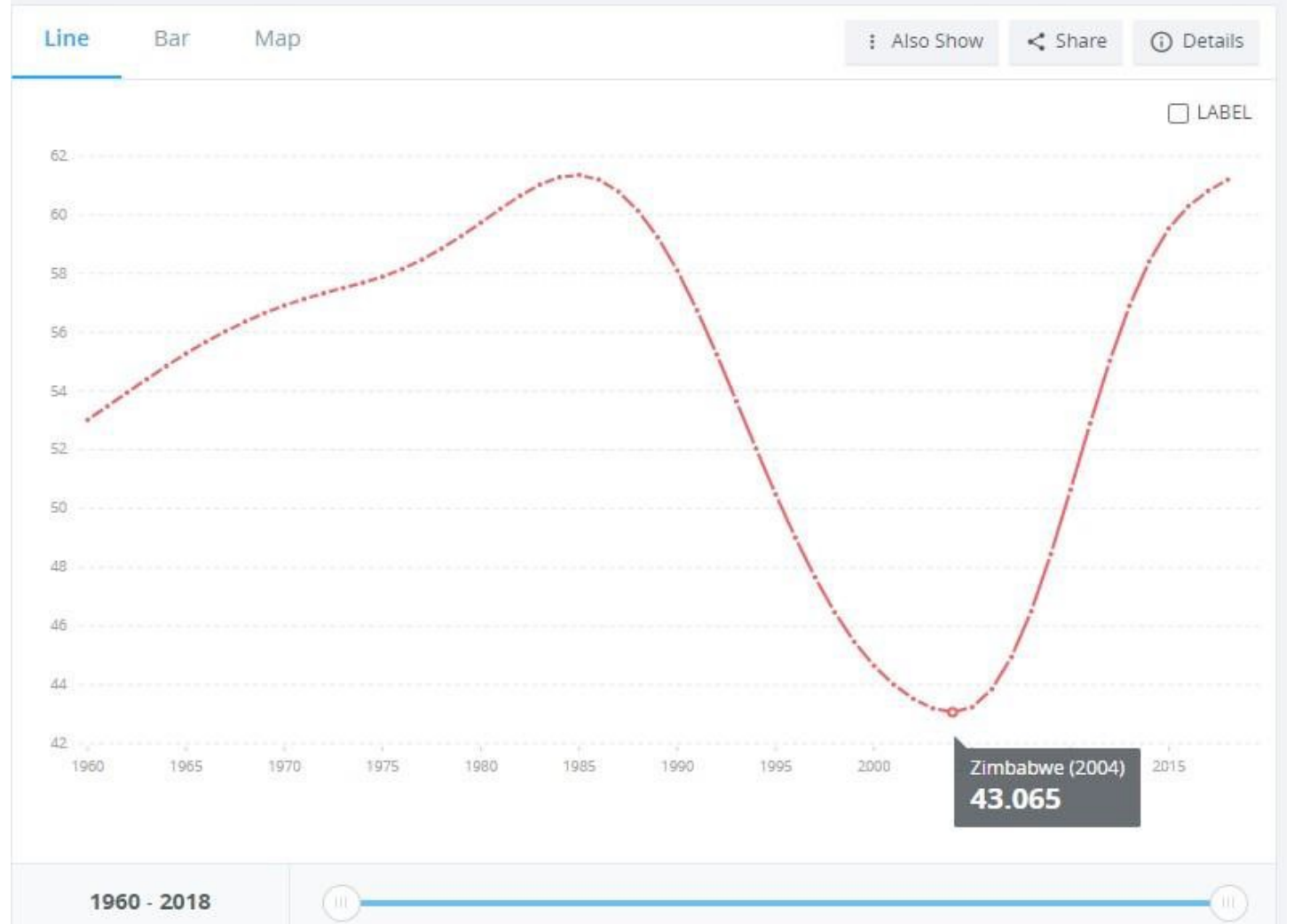

Figure 1. Zimbabwe Life Expectancy 1950-2019 - source, World Bank 


\section{INTRODUCTION}

"... for the problem of the Twentieth Century is the problem of the color line"

W.E.B. DuBois 1903.

"Transfusion of blood is a simple matter compared with the transfusion of civilization; yet that is precisely what is going on between us and the Negro race."

Charlotte Perkins Gilman 1908.

The World Health Organization defines health as a "state of complete physical, mental and social well-being and not merely the absence of disease or infirmity” (Barr 2013). Health indicators for African Americans remain lower compared to the white, Asian, and Hispanic populations (Baciu, Negussie, Geller \& Weinstein, 2017). I situate HIV/AIDS and SISTA as the unit of analysis in this study to investigate the partnering of activists, academia, community-based organizations, and the US government around HIV/AIDS. I investigate the use of theories surrounding its spread and prevention as proxy to analyze the concepts of the subject, power, and knowledge creation.

Rooted in sociology, this dissertation spans across disciplines and relies on a wide variety of bodies of literature to present a landscape that reveals how these concepts of power and knowledge creation continue to complicate the relationship the US state has had and continues to have with the marginalized, particularly African Americans. My project thus situates the Public Health Service in this analysis because it stands as a state agency devoted to promoting and protecting the "health of people and the communities where they live, learn, work and play” (American Public Health Association). The project also acknowledges that "promoting and protecting the health of people” as a public health agenda is a contentious one, complicated by the emergence of the medical community as a mechanism of social control and a site of power (Zola 1972). This is also a contentious issue because well-meaning public health 
officials work within an environment that is marred by public health and state violence on colonized and formerly colonized folks. Now it is with this background that dedicated well-meaning folks occupying public health offices work to promote health. I argue that the extent to which they acknowledge how medicine and public health have failed to shed their racist and classist roots is the true measure of success for any program.

In this work, therefore, I explore the ways class continues to ensure that racialized discourse concerning health behaviors of Black folks circulates persistently in the US, particularly through seemingly progressive public health programs such as Sisters Informing Sisters on Topics of AIDS (SISTA), a social skills training program designed for sexually active, heterosexual African American women as an intervention devoted to containing HIV/AIDS, Hollingshead (1941) says although the social sciences field is responsible for pioneering the concept of power and social control, over the years the discipline has still shown little interest in studying this process empirically. Since Hollingshead’s critique, scholars have indeed responded to the call by developing theoretical and methodological tools to understand this complex issue. Therefore, I lean on some of these tools, particularly conceptual frameworks such as feminist standpoint theories like Dorothy Smith’s $(1978,1987)$ institutional ethnography (IE), Monica Prasad's (2018) problem-solving sociology and medical sociology to reveal themes of knowledge creation, power, and social control contained the SISTA. I emplace SISTA within a historical trajectory of well-meaning governmental responses to tackling social problems within the US. Projects like the war on drugs and the war on poverty reveal the extent to which the US state continually avoids solutions that are 
committed to addressing structural violence which is at the root of continuing health and other disparities.

\section{Purpose of study}

The project is characteristic of Nader's (1972) “studying up” concept where researchers seek to understand the processes through which power is exercised in the United States. In this project, I use explore the ways this exercise of power and authority over others is linked to the perpetuation of African American tropes and stereotypes and how these manifest in the US government's effort to curb unequal health outcomes. This project answers the call by Pulido (2000) for scholars to engage in work that substantively interrogates the ways racism contributes to inequalities. The project also answers the call by Paul Farmer for graduate students to continue to be protagonists for social change (Weigel 2010). In this social change conversation are also Griffith and colleagues (2007) who argue that because racism is so embedded in institutions such as healthcare, scholars bear a deeper responsibility to adapt a "systems change” approach to addressing health disparities in their work. My research seeks to

join this conversation because infectious diseases continue to threaten lives, particularly the lives of the poor and vulnerable as shown by the Ebola crisis and now the coronavirus.

As scholars, it behooves us to remain critical of the lenses we deploy in speaking about the impacted. Farmer (1999) warns against work that makes "immodest claims of causality” regarding the distribution and course of infectious illnesses. He defines "immodest" claims these as conclusions by scholars that erroneously substitute rampant structural violence against the impacted for "culture" while ignoring the 
political, economic, and historic reasons for the spread of the disease and adds that these claims unfortunately rest on patterns of blaming the individual and on stereotypes. In this regard therefore, the purpose of this study is to analyze how programs like SISTA project represent work that removes attention from the historical and contemporary forms of structural violence responsible for unequal health outcomes of African Americans. It is my hope to add to work that continues to make visible these ongoing institutional patterns of stigmatization and how these patterns continue to disenfranchise communities of color.

This study does not gloss over the volatile gender relations within the Black community, or any other community that exists within a patriarchy for that matter. It also recognizes that the goals of SISTA are noble and well-intentioned. However, it follows the argument that SISTA remains a vital tool to examining the relationship between Black folks and the US state. Studying SISTA sheds light on how the women targeted by these programs actually interpret and experience these programs.

Further, scholars like political scientist Jeremy Shiffman (2008) have argued that the HIV/AIDS epidemic attracted too much financial commitment at the risk of other (treatable) diseases such as malaria, with mixed results. With as much financial commitment HIV/AIDS attracted, what were manifest and latent benefits of SISTA to the community? What were any missed opportunities? Further, this study recognizes that SISTA remains significant as health disparities still persist and so, with as many resources devoted to it how is it that HIV/AIDS has remained elusive to containment effort despite the fact that HIV is fragile and difficult to transmit (Wilton 2011). 


\section{Research Questions}

As I had participated in the SISTA training three times, I discovered that feminist methodology and standpoints like IE and Black Feminist Thought are useful because they treat the standpoint of the researcher as data. I use these frames to explore the research questions below.

1. What controlling images about Black women are present in a program like SISTA which is meant to serve them?

2. How do controlling images prevail even in the presence of alternate theories like Black Feminist Thought?

3. To what extent are the constructions of SISTA accepted or rejected by African American women?

In summary, the question of controlling images, can be best addressed by revisiting SISTA as well as the theory of gender and power upon which it is based using both Black Feminist Thought and Institutional Ethnography. As a former participant in this training, I use my experiences to methodologically lean on content analysis, semi structured interviews, and quantitative data analysis to investigate what the SISTA program is saying about ways the state, scholars, researchers, activists, and community-based organizations, have theorized, written about, and worked to support African American men and women in the context of HIV/AIDS.

\section{Background: A brief history HIV/AIDS impact}

The pattern of disparities in HIV/AIDS outcomes began to show sometime in 1981 when the Centers for Disease Control and Prevention (CDC) recorded the first death they attributed to complications associated with what is now known as AIDS (Morbidity and Mortality Weekly Report 2001). From that time until 1986, statistics emerging from the CDC indicated a steady disproportionate rise in AIDS incidence and prevalence for African Americans and Hispanics compared to other racial groups in the 
US and, by 2010, over 230,000 African Americans were reported to have died of complications related to AIDS (Alcena 2012). A 2014 report from the New York Health Department showed that African Americans represented the highest number of all new infections in Brooklyn, and in 2015, the CDC reported that more than 17,500 African Americans were newly diagnosed with HIV in the US (13,070 men and 4,524 women). Over half this number, 58\% $(7,600)$ identified as gay or bisexual men and 38\% (1,500) were between 13 and 24 years of age (CDC Surveillance Report 2015).

It is in the context of trying to curb AIDS in the Black community that the CDC, at the recommendation of the Institute of Medicine (IOM), adapted a behavioral intervention strategy known as the Diffusion of Effective Behavioral Interventions (DEBIs). These interventions gained notoriety because they were considered by CDC guidelines to be scientifically proven to effectively curb HIV/AIDS among African Americans (Collins 2016). The overall DEBI strategy was aimed at developing trainings, coordinating intervention resources, developing technical assistance, and supporting other capacity-building activities to community-based organizations (CBOs) and health care.

In 2015, a total of 29 interventions, all serving different segments of marginalized communities of color, were disseminated to 11,300 agencies throughout the US. They were designed to be disseminated by trained facilitators to a group of African American women, usually in five sessions within a five-day period (Fuller et al 2007). Target audiences for the interventions included African American women who were living positively with HIV/AIDS who received the Women Involved in Life Learning from Other Women (WILLOW) program. The other program was Choosing 
Life: Empowerment! Action! Results (CLEAR), and yet another was Sisters Informing, Healing, Living, and Empowering (SIHLE) (Collins et al. 2016).

The above-mentioned interventions were not the only programs offered and while their focus was mainly on training Black women, these EBIs were also adapted for and disseminated to Hispanic populations, select African populations, trans men and trans women, as well as Black men who have sex with men (MSM). According to results from a set of randomized controlled trials that measured reported behavior modification and according to financial commitment from the CDC, the most widely disseminated and most successful EBI was SISTA (Collins et al. 2016). 


\section{SISTA}

SISTA was created as a social skills training program to reduce "sexual risk behavior [in] African American women” (Collins and Sapiano 2016). The program was developed in 1995 by Gina Wingood and Ralph DiClemente, both renowned behavioral health researchers and intervention specialists with extensive training in psychology and behavioral health. Using the social cognitive theory and the theory of gender and power, SISTA was born out of the larger search for the most effective ways to mitigate the impact HIV/AIDS was having on communities of color. One conclusion emerging from this discussion was that heterosexually active Black women needed social and behavioral skills training to change their risky sexual practices (Wingood and DiClemente 1996). The creators of SISTA, Wingood and DiClemente (2010), have placed a call for scholars to evaluate SISTA and I answer this call here.

To offer a brief history of SISTA, Wingood reports that her work with lowincome Black women in San Francisco led her to discovered that standard talk about condom use, HIV transmission, sexually transmitted diseases, and safe sex was not working for African American women (Sasso 2009). While Wingood does not expand on the definition of "standard talk" in this interview with Sasso, she says though, that during her time working in the population, she discovered in this San Francisco neighborhood that "women in power imbalanced relationships tend to depend on their male partner because men usually bring more financial assets” (Sasso 2009).

Wingood also concluded that the prevalence of condom use in these scenarios was low. It was here that Wingood sought to gain further insight into the phenomenon and recruited 128 Black women from the San Francisco Bayview-Hunters Point 
neighborhood in 1995 for a randomized control trial. Basing the study on trends within the gay community where she noted that condom use was low, she similarly tailored her study to identify the correlates of non-condom use among African American women and thus selected condom use in the Black community as the dependent variable with "frequency of vaginal sex," "age of sexual debut” and "number of sex partners”, "substance use”, "partner abuse," and "history of abuse as a result of asking for condom use from a partner" and "beliefs regarding promiscuity" as independent variable items (Wingood \& DiClemente 1998).

From the original 128 women, 100 returned to complete the follow up interviews. Her findings from this randomized trial showed that women in the social skills intervention demonstrated increased consistent condom use compared to those with the delayed HIV education control condition. Results also showed that the women had greater sexual self-control, sexual communication, assertiveness, and increased partners' adoption of norms supporting consistent condom use (Wingood and DiClemente 1995). SISTA emerged as a result of these findings. It is in SISTA, its theoretical framing, and my experiences with it where I ground this dissertation project. This program and other government programs like it, have raised questions regarding the conceptualization and dissemination of EBIs to Black women. Thus, I situate SISTA as an avenue to explore questions raised by scholars such as Treichler (2004), "What is the role of theory in the face of an epidemic like AIDS?"

As mentioned earlier, to date, the global and national incidence of AIDS has slowed and the CDC expects that the introduction of Pre-exposure prophylaxis (PrEP), a daily pill that can prevent HIV infection, will support this downward trend. However, 
my work, influenced by Michel Foucault, one of the most celebrated and cited thinkers devoted to understanding the history and genealogy of the concept of power and governance, explore how SISTA fits into scholarship that engages with the dialectic emerging from the creation and dissemination of prevention education programing that seeks to protect the marginalized and prevent disease while simultaneously reproducing the -isms responsible for health inequalities. This work is important because HIV/AIDS was, and continues to be, one of the major health concerns for communities of color in the US and globally. Further, as infectious diseases continue to disproportionately impact historically marginalized communities, I seek to add to literature urging scholars, activists, health practitioners, and community-based organizations to deliberately engage in how health behavior models continue to miss opportunities to completely understand how structural racism makes people ill and how we ought to rethink the impact the work we do has in reproducing oppressive and hegemonic structures that keep people sick.

\section{Statement of Problem}

SISTA, with its good intentions, unfortunately rests on the assumptions about the health of US Blacks that is embedded in a history of racism and oppression. This leads Clatts to say,

To continue to pretend that a two-hour session with an AIDS educator can measurably increase 'self-esteem' in a person who has lived in a context of violence, discrimination, and abject poverty .... is completely to miss the mark (1995 250).

My dissertation places SISTA at the center of an analytical framework where I examine the ways class privilege and colorblind racism are responsible for transmitting harmful stereotypes through well-meaning programs targeted at African American 
women. This project recognizes the contradictions presented by the history of a racist public health sector and the well-meaning folks who work in it. I propose that these tensions and disjunctures result partly from scholars' and researchers' use of theory. I, therefore, juxtapose the theory of gender and power as it is used in SISTA against emancipatory theories such as Black Feminist Thought to examine historical and the present-day relationship between the state and Black folks. I investigate the ways the halls of academia remain complicit in perpetuating beliefs about Black women's vulnerability and how these beliefs are then either taken up or resisted by state agencies such as the CDC and circulated through community-based organizations. I argue that SISTA oversimplifies factors contributing to the disproportionate impact of HIV/AIDS on historically marginalized populations. I also analyze the role of Black elites in formulating explanations of AIDS transmission among Black folks. The dissertation thus, examines data collected from my own experiences as a SISTA participant, from the women who undertook the training with me and the 2071 from Tennessee, Texas, Missouri, and New Jersey who answered survey questions relating to SISTA. The aim is to discuss the tensions between the state's view of Black folks' behavior and the ways Blacks view and understand their own health and their own vulnerabilities.

Additional to Black Feminist Thought in my work is Smith’s (1987) institutional ethnography. In combination with each other, these two lenses are useful to explicate the tensions between what Black women say about ourselves and the way the state presents us. It is through these lenses that I came to make sense of my experience in the SISTA program and it is through this lens that as Black women, we came to discuss how the state controls our lives, how academia tries to understand our struggles, 
and how we come to tell our own stories and tell of our victories. It is also through the Black Feminist lens that I analyze how the theory of gender and power presents the image of the Black women and juxtapose this image to the alternate ways Black women speak of and imagine ourselves. Questions arise pertaining to the sufficiency of the theory of gender and power to fully account for the contexts within which Black women make sexual choices. For example, the theory of gender and power, in conjunction with social cognitive theories influencing SISTA, argues that power imbalances within the Black community, especially those between Black men and women, render Black women susceptible to infection because of our inability to negotiate condom use in our sexual relationships on the one hand. Black Feminist Thought, on the other, contends that the TGP lens ignores the "matrix of domination." The "matrix of domination," defined as those multiple ways Black women experience institutional discrimination and the interplay of a myriad of larger forces that work against us, stand as more significant explanatory factor for the prevalence of HIV/AIDS in the United States (Gentry 2007).

Black Feminist Thought also argues that the lives of women are further complicated by academic work that homogenizes the experience of Black folks and ignores our subjectivity (Collins 2008). Further, because the theory of gender and power was imported from an Australia sociologist who developed it from a study of European women, its use in the context of the lives of Black women is seen through the Black Feminist lens as representing the "add and stir" construct. This construct is considered as single-axis, simplistic, and fails to consider the multidimensionality of Black women's experience (Crenshaw 1989). Therefore, while Wingood and 
DiClemente (2000) recommend that efficient community-based interventions need to focus on developing community support that will strengthen "women's influence and control over their sexuality,” Black Feminist Thought argues that while this premise has merit, it does indeed conflate the experiences of Black folks and ignores the power we possess to influence and control our sexual lives. The premise of "empowering” or "strengthening” women’s positions also ignores the practical complicated lives we negotiate daily.

These arguments by Black women come in light of others studies whose results illuminate the intricacies relating to Black women's sexual patterns as well as the contexts within which we make sexual decisions. For example, an ethnography conducted in an Atlanta neighborhood called “The Rough” revealed these complicated and nuanced ways gender dynamics factor in forming patterns of sexual encounter within this community of African American women. Gentry Quinn (2007) found that though the women in this study exhibit what is termed as high-level risky behavior; particularly a lack of condom use, they reveal intricate details that usually remain ignored as relevant when sexual decision making is discussed in the context of African American women. From her data Quinn was able to identify recurrent themes which she used to identify a pattern of five stages in the development of relationships formed by the women. Quinn argued that these stages; courtship, commitment, conflict, compromise, and conclusion had remarkable implications on the spread of HIV in communities of color (2007:99). 


\section{Organization and structure of this dissertation}

In order to unpack the historical context surrounding HIV/AIDS and SISTA this dissertation will be organized in seven chapters. First chapter sets the stage for the discussion by presenting literature that situates SISTA within a frame of other problematic initiatives such as the war on poverty. This section also introduces health behavior models and presents arguments to support propositions by some scholars that these theories be revisited and revised. In this section, I also present the literature on feminist standpoint theory and Black Feminist Thought to discuss my entry into the field of medical sociology as an immigrant woman from Zimbabwe, studying work surrounding the African American community. I locate myself within this study as a woman who shares a history of violence and oppression with the African American community though I am not directly from the community.

Chapter two and three contains literature reviewing sociological theories and their contributions to my discussion and also situates public health within a history of ignoring Black folks' health outcomes, the role of government in defining health and prescribing normative standards of health and finally, chapter four describes in detail my approach to data collection and analysis as well as methods used to answer to each of my research questions. Chapter five and six describe the ways I interpret the findings in the context of the theoretical framework I chose. Chapter seven highlights the themes and the findings as well as any limitations in my framing and implications for further study. 


\section{CHAPTER ONE}

"I am pointing at the moon and you are looking at my finger" - Pilani, AA, male. LITERATURE REVIEW AND THEORETICAL FRAMING

\section{Health Behavior Models (HBM)}

While studying HIV/AIDS and early responses to it, Treichler (2004) observed that the ways scholars, researcher, activist wrote about and organized around AIDS made visible the struggle occurring between theory and practice. In these early days of studying the epidemic, Treichler says she and other activists became increasingly distressed at this dichotomy, particularly because these struggles to effectively theorize and practically support the impacted were allowed to continue at the expense of dying human bodies (2004).

According to Treichler, she and other activists who were in the "trenches" fighting AIDS were forced to face the realities of the dead and dying while scholars and researchers allowed themselves to remain stuck in a battle of trying to theorize about it, analyze it and define it. In addition to being an activist, Treichler was fascinated as a scholar by the ways HIV/AIDS stringently tested current taken-for-granted knowledges and beliefs about its spread, its prevalence, and impact. HIV/AIDS also provided Treichler with a lens through which to view the connections between the intellectual work produced by scholars in academia and the everyday humans who are impacted by the work produced within these walls. She thus used Stuart Hall's notion of "terrain of struggle and contestation,” to pose a challenge to academics that they answer the question, "is there room for theory in the face of an epidemic such as HIV/AIDS?" (Treichler 2004). 
Using war as a metaphor, Treichler deploys this metaphor to illustrate this struggle she sees, the struggle involved in trying to make sense of the epidemic while also trying to put an end to it. For Treichler, the virus represented a variety of symbolisms which all contained various interpretations. Treichler (2004) says that as real and as tangible as AIDS is in killing people, so are the realities it represents as an “epidemic of meanings.” These meanings or interpretations of HIV/AIDS infection, prevention and range from reasonable to ridiculous. What is more visible is the impact meaning had in determining the ways the state legitimizes widespread invasion of people's lives and sexual practices (2004). Treichler increasingly became agitated with scholars who continually philosophized while in the middle of what she regarded a war zone. She saw this constant need to theorize as a betrayal to the practitioners as it leaves these activists and practitioners exasperated. She acknowledges that HIV/AIDS created confusion about how to deal with it and it left medical professionals to scramble for sufficient theories that describe accurately what they thought was going on with human sexuality. This confusion left those fighting in the trenches feeling exasperated and thought of this struggle for theory, these ongoing debates for language while people's lives hung in the balance as a form of betrayal. AIDS activist, Martin Delaney (19452009), is quoted as saying, “This isn’t an argument about how many angels can dance on the head of a pin. People's lives hang in the balance of this decision” (Treichler 2004 4).

This dissertation follows Treichler discussion and reflects on the ways health belief models created by health behaviorists, social psychologists, and psychologists like Albert Bandura, Martin Fishbein and Icek Ajzen have gained epistemological 
control of HIV/AIDS discourse. I evaluate HIV/AIDS prevention strategies born out of such behavioral theories including theories of reasoned action (TRA), theory of planned behavior (TPB), and social cognitive theory (SCT) continue to survive even in the face of opposing discourse.

Glanz is an example of a renowned behavioral scientist and researcher who has used HBM in her work successfully, boasting of a glowing 68-page single-spaced research CV accompanied by millions of dollars in research grants and prestigious positions at research institutions, universities, and hospitals. Glanz's definition on theory, unlike Treichler's, takes a less critical approach. Per Glanz (1997), while theories allow for systematic ways of understanding events or situations,

They are, by nature, abstract, and don't have a specified content or topic area. Like empty coffee cups, theories have shapes and boundaries, but nothing inside. They become useful when filled with practical topics, goals, and problems (4).

Glanz's approach is definitely less jarring and graphic than Treichler's in her definition and use of theory. While Glanz regards theory as “abstract,” Treichler uses Stuart Hall to describe theory as concerned with people's lives. The difference apparent in the ways scholars talk about and utilize theory sets the stage for my work. I am interested in exploring these questions and discussions of how theory is defined and used across and within academic disciplines as well as the real-life implications of the use of theory in addresses infectious diseases. Per Treichler, scholars must take a deliberate reflection on the use of theory because the meanings scholars construct sometimes survive in wrong, harmful ways.

I juxtapose Glanz and Treichler because the two scholars use theory differently. Health behavior models arose as a way to help public health practitioners empirically 
understand health behaviors and provide, develop, and evaluate interventions (Glanz 2002). They became popular in the 1950s when public health social psychologists wanted to understand reasons people ignored programs to prevent and detect tuberculosis. This was of concern because of 1) the nature of the illness, and 2) the screenings were free as Public Health Service was sending mobile X-ray units out to neighborhoods. Their findings led them to theorize that people did not believe they were susceptible to disease. It was this belief, the social psychologists theorized, that influenced people’s readiness to act (Glanz 1997). These models inform practitioners on how the health of individuals and communities can be developed, improve, and evaluated.

HBM usefulness also lies in the insight they offer in studying deep-seated cultural norms that interfere with health strategies. This insight helps practitioners assess habits such as eating, smoking, and assess various attitudes of patients after cancer diagnoses in order for public health to improve health behaviors such as diet and exercise, physical activity, and substance use. In addition, practitioners rely on HBMs to determine the level to which patients adhere to treatments and screening guidelines. However, these HBM have come under harsh criticism pertaining to addressing infectious illnesses such as HIV/AIDS and the disproportionate impact of infectious diseases has on historically marginalize peoples such as Black folks and the LGBTQIA2S+ community.

This is primarily because these models focus mostly on individuals' perceptions, on the individuals' motivation to change as well as on "improving” individuals' cognitive and behavioral as skills. While there is merit to this approach, it lends itself to 
blaming those mostly impacted by illness for their health status. Further, it ignores the larger social context within which individuals make health related choices and decisions. For example, in the above cited tuberculosis case, questions of race, class and the ways in which people of color have been betrayed by Public Health Services did not take center stage in the psychosocial analysis of why "people” did not utilize the provided machines to scan for the disease. I put "people' in quotes here to highlight the fact that the public health service used a one size fits all model to account for why folks did not utilize the service. This event was a missed opportunity to discuss community perceptions and mistrust of the health services which may have led to the underutilization of the machines.

Noar and Zimmerman (2005 and others within the health psychology field such as Weinstein (2007) have warned against overreliance on misleading tests of health behavior theories. They have noted that over the year, there has been a significant overlap in these health behavior theories. Thus, they question whether an increase in research using health behavior models has necessarily correlated to additional "substantive cumulative knowledge to this area of research.” Noar and Zimmerman (2005) have argued that while health behavior theories have increased in number their overlap raises questions of how much knowledge they have actually contributed to the field. Weinstein (2007) has also been a critic of cognitively oriented theories of health behavior. He argues that because these theories rely mostly on correlational data, sometimes based on biased tests, they tend to provide misleading conclusions. 


\section{Theory of Gender and Power}

It is in this conversation that I situate the theory of gender and power and social cognitive theory used by Wingood and DiClemente (1995) to account for low condom use among African Americans. The social cognitive theory is taken from Bandura's 1986 Social Foundations of Thought and Action: A Social Cognitive Theory. Bandura's work is based on the premise that in order for individuals to exercise personal agency and change unhealthy behaviors, they need self-efficacy, self-confidence, and must possess expectations for a healthy outcome. As a leading behavioral psychologist, Bandura studied human behavior and reviewed the current theories to add the social cognitive theory. He went further to argue that this theory, if used effectively, has longterm benefits to behavioral change so desperately needed by society to change. Further, Bandura says for this alteration in behavior to occur and be maintained, a set of collectively enforced sanctions that can produce this shift must be manufactured within individuals. Bandura is well known for promoting self-efficacy and applies this concept as a way to measure how confident an individual feels in their ability to be successful in health behavior change (Bandura, 1994; Wingood et al., 2000).

It was because of these attributes that the social cognitive theory became attractive to SISTA, particularly the quality it has to teach condom use. In addition to social cognitive theory, the creators needed a more comprehensive theory on gender inequality to account for factors inhibiting condom use. They quote Perkins Gilman (1911) and de Beauvoir (1949) for some foundational work on gender inequality. Because HIV/AIDS impacted Black women, gender imbalance became a significant unit of analysis for Wingood and DiClemente (2000) as they created SISTA. They 
reference Perkins Gilman’s (1911) argument that most problems of humankind are rooted mainly in these patriarchal systems that regard women unfairly. Perkins Gilman (1911) indicts these systems for the ways they consider woman only as an accompaniment of and subordinate to man, reducing women's purpose to reproduction only. Further, their search for appropriate theory found de Beauvoir’s 1949 androcentrism argument in The Second Sex whose main premise is that it is these masculinist frameworks that are largely responsible for the subordinated position of women. While these theories were useful, what Wingood and DiClemente (2004) required was a theory that specifically explains HIV/AIDS prevalence in the Black community. This fact, combined with Wingood and DiClemente's critique of public health models that heavily relied on psychological theories to explain health behavior, led them on a quest for a more suitable and better equipped theory that would analyze the connection between sexual politics and gender inequalities in health. More specifically, they needed a theory that would also take into consideration an "ethnic component” to health inequality (Wingood and DiClemente 2000).

Gender and Power: Society, the Person and Sexual Politics by R.W. Connell offered the theory of gender and power (TGP) as the invaluable theoretical contribution that Wingood and DiClemente were seeking (Wingood and DiClemente 2000). This 1987 book and the theory of gender and power it espoused, were based on Connell's ambitious 10-year longitudinal global study. In this work, Connell’s theory analyzed sexual inequality, particularly gender and power imbalances in sexual relationships and the implications on women's health. Wingood and DiClemente appreciated its integrative look at the connections between the lives of women, sexuality and sexual 
politics, and health outcomes. Among its numerous strengths, the theory of gender and power possesses a uniqueness in examining the contribution of the sexual division of labor, the sexual division of power, and the structure of cathexis to the shaping of the nature of relationships between men and women (Wingood \& DiClemente 2000). It is worthy of note that Wingood \& DiClemente regard these as three distinct but separate institutional and societal level structures that make African American women susceptible to health disparities. This worthy of note because these institutional structures of oppression are argued by others not as distinct but as intersecting as we shall see later.

Wingood and DiClemente (2000) contend that because extensive work has already been done using the sociological concepts of the sexual division of labor and the sexual division of power argument to explain persistent gender inequalities, they would focus instead on the more concept more appropriate to the African American context. The "structure of cathexis" better explained the unequal health outcomes experienced by African American women. Pioneered by Freud, "cathexis” was used to explain what Connell argued to be that instinctual energy or psychic charge people are said to get from being attached to any particular object. Connell, in turn, connected cathexis to hegemonic heteronormative relations where those constraints are inherently present when people create emotional attachments to each other. Connell explains that these attachments typically translate into hostile feelings especially in those circumstances where one partner feels threatened. Ultimately, Connell concluded that while the systematic nature of gender relations varies widely, the fact that remained 
clear was that where a "structure of cathexis" exists it is usually followed by inequality of power and subsequently the inferior health outcomes of women (Connell 1987).

The "structure of cathexis" was relevant to Wingood and DiClemente (2000) because to them, the concept explains the nature of sexual relationships within the Black community and how these relationships were tied to higher HIV incidence among US Blacks. For Wingood and DiClemente (2000), the fact that there is, within the Black community, a variety of issues such as unequal power relations that are entangled within African American sexual relationships is the major contributor to disproportionately high prevalence of HIV/AIDS among African Americans. They redefined this phenomenon, this cathexis, and renamed it "affective and social exposures" (2000 545). Their argument was that these "affective and social exposures" within the African American community such as promiscuity among African American men, make it harder for heterosexual

African American women to form meaningful relationships with men (Wingood and DiClemente 2000). Also, these "affective and social exposures" in the African American community are not limited only to sexual relationships for Wingood and DiClemente argued that African American women's relationships were further complicated by African American women's relationships to the church, relationships with their children, as well as the sex ratio imbalance in the African American community. All these were factors that contribute to the inability of African American women to keep themselves healthy (Wingood and DiClemente 2000).

Overall, Connell is pleased with the reviews on the book, Gender and Power: Society, the Person and Sexual Politics, as well as the wide acceptance of this 
publication and the theory it espouses. As stated on the author's website, the work "seemed to find an audience, since that is my second most cited publication."2 However, Connell has since revisited the 1987 conclusion reached in the book, admitting that while the book was indeed timely and much needed, it also was an ambitiously large project, perhaps even too ambitious. The ramifications of the scale of such a project were that since "this was the work of only one individual" it inevitably faced backlash. Connell (2015) adds,

I continued to think about the conceptual model, especially its unsatisfactory treatment of culture. When my UK publishers asked for an introductory book for students, I tried to make a systematic revision of the model.

Suffice it to say, Connell has admitted the numerous flaws contained with this work specifically pertaining to the theory's treatment of culture and gender, and lack thereof. Connell added that she has since had to rethink some of the conclusions from this longitudinal study because Connell says the work failed to recognize gender as a "multi dimensionally, historically changing structure of social relations.” She also adds that she failed to factor the fact that gender relations are constructed in active and dynamic social practices (Connell 2015). Even before making these admissions, Connell had already stated in the 1987 book that some parts of the analyses were "thin, some ... abstract and others ... speculative” (1987 x).

Wingood and DiClemente (2000) are silent regarding these shortcomings. For their purposes, the theory of gender and power was usable to the understanding of HIV/AIDS in the African American community. It is this failure to recognize gender as

\footnotetext{
${ }^{2}$ Raewyn Connell wrote an editorial on their website regarding their reasons for revisiting the theory of gender and power. http://www.raewynconnell.net/p/gender-sexuality.html
} 
a "multi-dimensionally, historically changing structure of social relations," that guides my research. Noar and Zimmerman (2005) suggest that since behavioral health is so theory based, there is need for the field to “audit” itself. Connell's revisiting the theory of gender and power is arguably an example of what it looks like when theorists audit themselves.

Connell (2015) recognizes that the theory of gender and power misses the “multidimensionality” required in an analysis that speaks to population’s susceptibility to illness. Hill Collins (1990) calls this the "matrix of domination."

The "matrix of domination" stands as a rejection of what Black feminists see as "additive modes of thinking about oppression" and subsequent inequality. Per Hill Collins, a true commitment to better health outcomes for Black folks must rest on a social justice lens that resists and challenges "Eurocentric masculinist” ways of thinking about the lives and behaviors of Black folks. This involves a critical interrogation of how the intersecting structures of race, class, gender, and other heteronormative, able-bodied constructions function to impact health outcomes of Black folks. Black Feminist Thought warns against these monolithic and sometimes stereotypical ways of thinking of, writing about, and speaking of the health behaviors of Blacks. What a Black Feminist analysis of SISTA entails, therefore, is that 1) the theory of gender and power was devised after a study of European women and their sexual lives; 2) it was imported into the US and made to fit into the lives of Black women and, thus, 3) ignored the racialized history of the United States and its impact on the health outcomes of Black women. 
This critique comes in light of the above arguments and those advanced by Black Feminist Cathy Cohen (2014) who charges us, as a future generation of scholars, to ask questions that align with the questions the people we are studying are asking about themselves, about their own integrity and wellbeing. Regarding our research, Cohen also charges us to ask ourselves whether our politics are bigger than the skirmishes we have been "asked to enter and integritist enough to be enlarged by them." Ultimately, Cohen wants us to ask ourselves ... "Have you worked to build foundations for something new, useful and beautiful on otherwise dry and fallow fields?” (Jafari Allen 2004) Jafari Allen presented Dr. Cathy Cohen, with the annual Kessler award from CUNY CLAGS: The Center for LGBTQ Studies in 2014. In his introduction, he relayed the message Cohen had given him regarding the direction research should take and the questions critical scholars must ask in doing research. The full quote was, "Are your research questions aligned with the questions the people you are studying are asking about their own integrity, and wellbeing...? Are your politics bigger than the skirmishes you were asked to enter and integritist enough to be enlarged by them? ... Have you worked to build foundations for something new, useful and beautiful on otherwise dry and fallow fields?”

Here, I believe Cohen is challenging scholars to resist normative ways of understanding our research subjects. This view is shared by Dorothy Smith whose work is devoted to analyzing academia as a ruling apparatus that determines and restricts work scholars produce. Per Smith, these restrictions by academia on the works produced sometimes leads to scholars producing work that further oppresses women. I expand on this discussion in subsequent chapters but for now, I lean on my experiences 
as a SISTA participant to ask the necessary questions of health behavior models. I examine HBM rely on social cognitive theory and theory of gender and power, how they have been deployed in the context of SISTA as tools to understand and explain the lives of Black folks. In the end, I seek to explore the consequences of such a lens on policy. I will offer multiple alternate lenses to discuss the implications of the use of theory to the lives of those who experience these programs. I offer that SISTA follows in the footsteps of other programs, both programmatically and theoretically.

I offer also that the academic conversation regarding what is best for Black folks is not new. W.E.B. DuBois's The Philadelphia Negro, published in 1899, is applauded as the first decent institutionally sanctioned inquiry by the University of Philadelphia into racism and its link to unequal health outcomes for Black people. Before and since then, the US government has attempted a few more programs aimed specifically at erasing inequality and bringing socio-political and economic status of Blacks closer to the mainstream. These programs continue to be short-lived and frustrating for those involved, particularly those "in the trenches". Quadagno (1994) has argued that when these programs fail to produce desired results, their failure is placed on the shoulders of the target population who mostly are ill-equipped to take advantage of them. Quadagno further argues that while programs like these are useful, they "represent a well-intended but poorly executed effort to address the malady of structural racism” (4). It is my hope that by the end of the dissertation, I will have shown how such programs are well intended but ill executed. First, because they do little to acknowledge structural violence, and second, they are based on ignoring the subjectivities of the people under study. 
Looking back to the Civil Rights era shows the "War on Poverty" as a notable example of a well-intended federal program aimed at reducing inequalities. Like SISTA, this program is also said to have produced mixed results and its effect is still a matter to debate to this day. In an address to the nation regarding the "war on poverty," President Lyndon Baines Johnson (LBJ’s) remarked and recognized that “negro poverty is not white poverty” and that there indeed was a need to address the poverty of Black folks, in the same speech he simultaneously said “...the solutions were the same” (Katz 1990). This dissonance characterizes how the US state has failed to address racism in the creation of programs to serve Black folks. I reference the "War on Poverty" and the attitude guiding it to situate SISTA in this frame where I examine well-meaning government initiatives and discuss the various perspectives on their "success," keeping in mind, of course that "success" is a debatable matter of perspective. Others believe that "War on Poverty” was a "failure.” For example, on one PBS news hour panel discussion, question was posed on whether the "failure" of the war on poverty was due to the theories upon which the war was based, the implementation of it or possibly because of a lack of economic vision from the beginning. Panelist Glen Hubbard responded, "I think it was incomplete from the beginning ...." From there, he goes to discuss why he thinks this economic vision was incomplete.

The same question is asked to Angela Blackwell, founder, and chief executive officer of PolicyLink, a national research and action institute interested in advancing economic and social equity. I note her credentials here as they factor into my expectation that as a Black woman well researched in equity issues, would speak poignantly to the issues of intersecting structures of oppression. Blackwell's response 
was general, offering a mere, "I agree with all that has been said” only adding “... and we really need to focus on this problem of inequality. We have had growth in America, but it has only benefited one part of the population...”" My emphasis here is because she does not name that "one part of the population.” This way of glossing over racial and heteronormative privilege is commonplace in US discussions on inequality. In this conversation, Blackwell eventually gets to the more significant topic on race as the discussion progressed:

“....and let's not forget, with the shifting demographics and the people of color quickly becoming the majority in this country, we need to remove racial barriers ...make sure people who have been incarcerated get work, we need to deal with low-income communities that are holding people back. So many people are poor because they are living in communities that are not connecting them to work and opportunity...."

According to critical scholars, therefore, LBJ’s “War on Poverty” was a missed opportunity for the US to make much headway among Western democracies in national welfare systems, health indicators and childcare (Quadagno 1994). Historian Robert Dallek, who was also a panelist on this same PBS News Hour, acknowledges that LBJ was frustrated by some of the outcomes of the program and the backlash it received.

Williams (2004) takes on this challenge of framing the "war on poverty" within the intersectionality lens to highlight how race and gender made it impossible for Blacks and particularly Black women to benefit from the program. Williams (2004 4) argues that African American women and their families were offered a mixed bag of opportunities and discrimination, of possibilities and restrictions, and of freedom and surveillance due to the fact that race, gender, and class combined in insidious ways to 
promote unequal citizenship status, meaning, Blacks could not access this program in the same ways white folks could.

I highlight this conversation to reveal my reaction to it as an observer and consumer of the media. As a critical scholar, I came to view this conversation as revealing of ways talks such as these that tend to gloss over the role of structural violence in program failure were not only isolated to the field of academia but extended to the media as well. In this television discussion, I concluded that Blackwell and others understated the role of racism and missed the opportunity to critically examine the legacy of racism in limiting Black people's access to available resources. Thus, from Williams' and from a Black Feminist standpoint, the "war on poverty” stands as a good example of the US continued failure to recognize the limits Black folks have in accessing readily available resources that white people can. The panel did eventually manage to reach one unanimous agreement, that LBJ would be pleased that we are still having these debates.

I locate SISTA in this context, in a world where health is a human right that is not being realized by all, and certainly not by historically marginalized folks. I locate SISTA in a world where people of color are still disproportionately impacted by unequal health outcomes and I charge that as scholars, we must continue to name problems correctly for more appropriate solutions. As scholars, activists, and community-based organizations, we continue to lag in making headway in social change if we fail to acknowledge the root causes of social problems.

As I enter the conversation regarding the state response to HIV, I consider the extent to which the state views as significant the intersecting issues of race, sexuality, 
poverty, and marginality in accounting for health behaviors. In the case of HIV/AIDS, I too question, for a delicate a pathogen as HIV, how did humanity lose the battle to it? I ask the same questions advanced by Hubbard: "could we have done better still?” What were the gaps left by our initiatives to prevent its spread and what lessons did we leave for future generations? So, as we face four decades of AIDS, I refer to AIDS activist and musical artist Bono, commenting in a 2003 documentary, A Closer Walk, that history is going to be unkind to our generation because of the way we allowed this fragile pathogen to devastate humankind. 


\section{CHAPTER TWO}

\section{THEORETICAL FRAMING}

\section{Feminist Theory - “The Personal is Political”}

I locate myself in this project and come from the premise the "personal is political.” This is a term coined by second wave feminists to reflect the conditions of subordination feminists felt at the time in the 1960s. The term is adapted from Carol Hanisch’s 1969 essay that appeared in the publication “Notes from the Second Year: Women's Liberation.” The essay was based on Hanisch's observation that though some activist groups were progressive in ideology and opposed the Vietnam war and Civil Rights, these groups ironically oppressive to women. This was because the folks who volunteered for these groups would tell women to separate personal troubles from political ones by leaving their personal issues at home and not bring them into the office.

This caused Hanisch to challenge those within the women's movement to examine their own personal ethics and behavior regarding social justice work. She argued that work that is supposed to change the world must come from a premise where we, as scholars and feminists question our own behavior. We must be conscious of the ways we silence others as we strive to give voice. Hanisch (1969) coined the term to protest oppressive nature of these times she found herself in and to bring attention to the fact that when women faced what were seen and described as individual women problems that must stay home, they were indeed reflecting that their problems were tied social ones and hence political.

Because the "personal is political,” therefore, my entree into conversation surrounding the health outcomes of people, particularly women of color, is filled with 
trepidation, insecurity, and fury. While the image of the "angry Black woman" has been deployed stereotypically to dismiss this anger, this fury, or to control it and normalize our behaviors, work analyzing why it is that Black women are in fact angry remains under appreciated. I offer, in this work, that I embody and embrace the "angry Black woman” label to engage with my anger towards the lack of honest empirical investigation into this "Black woman's anger” in mainstream academic literature. My biography, which includes, but is not limited to caring for, sometimes watching helplessly, mourning for, and cheering for comrades personally affected by HIV/AIDS motivates this work. Also, in my personal narrative exists my battle against the imposter syndrome and to begin believing that I am well positioned to carry out this work. I credit earlier work by BIPoC scholars and writers in my position whose life stories are similar to mine who have given me permission to place myself squarely in the middle of my work and count my story as a legitimate source of knowledge.

I began as a new graduate student who was tasked with thinking of structuring a research project. To undertake this endeavor, I had decided that my research would focus on polygamy in Zimbabwe. My teachers were pleased with this decision, but it was not until 2005 when I returned to Zimbabwe that I changed my research focus to study the US power structure. This was because while I was in Zimbabwe, I lived close to a cousin and his two wives. With my western thinking, I had initially concluded that it was only a woman with a few options who would choose to share a husband and expose herself to HIV/AIDS.

However, my proximity to the family allowed me to observe more closely that the women my cousin married were not powerless at all and that they were indeed in 
charge of their sexual choices. For instance, the women in this home decided when my cousin ate, what clothes he wore to work, and what he ate. They had their lives organized in a way that worked for all involved, and more importantly, in the context of HIV/AIDS, I realized that sexual acts performed within this union were safe. Upon my return to the States, I informed my teachers of my intent to change my focus from Zimbabwe to the US and use IE to center SISTA in an analysis that interprets the language in HIV/AIDS prevention discourse. My interest shifted to US public health and behavioral health’s framing of the lived experience of African Americans concerning HIV/AIDS exposure. I did not get as much support from faculty as I had anticipated given that my department had a medical sociology focus and claimed to have a critical scholarship lens. In 2007, for example, this department hosted a "HIV/AIDS, Gender, and Sexuality in a Globalized World” public lecture attended by such prolific scholars as Judith Auerbach and Lesley Doyal. I certainly was out of my depth at this symposium though I was exhilarated and could not stop gushing at the caliber of scholars present, scholars whose work I had read. However, as I tried to raise my voice to articulate that I found some of the work presented there, work on "the researched" (or "subjects" as it were) as well as recommendations for male circumcision, to be paternalistic, I was drowned by my then teachers who claimed they had no idea what I was talking about.

Of course, I quickly shut up because I thought who am I to question these esteemed scholars and because I respected them immensely, I did not want to continue the discussion. Additionally, I just had not been immersed in sociology long enough to confidently use the language of the discipline to stand my ground and defend my 
argument. As I succumbed to the sheer intimidation I felt, I did manage to grab Dr. Auerbach during the break and relayed my concerns that work like this obscures the deeper issues of colonialism, imperialism and how, as scholars, we run the risk of perpetuating these -isms. What gave me the courage was a claim by one scholar that male circumcision did not work in the African context because either the men did not know how to clean themselves properly after the procedure or that they did not have soap. I was outraged and decided that I could stay quiet no longer.

I approached Dr. Auerbach and in my communication her, she acknowledged my concerns, and this gave me confidence to speak to more guests. I talked to Anastasia Gage, originally from Sierra Leone, whose study in child marriages in Ethiopia also took center stage. Again, because at that time, HIV/AIDS rates in Ethiopia were at only $4 \%$ at that time, I thought it unnecessary to conflate of child marriages and HIV/AIDS. I spoke with her after, and once again expressed the fact that though HIV/AIDS and child marriages were indeed issues of concern and needed to be explored, conflating them in this manner was disconcerting and may lead to misinformed resource allocation. In summary, she concurred, adding though, that at time scholars are confined in their work because of funding parameters. This affirmation was encouraging, leading me to take my arguments to faculty within my department. I expressed discomfort at the ways these scholars had spoken of their participants as well as how I found some of the comments made at the symposium regarding research respondents patronizing and paternalistic. To the faculty who worked closely with me, I expressed similarities between these narratives and the language contained in the SISTA literature and wanted to further explore Prof Gage's comment that sometimes 
scholars can only do their work according to the stipulations of the funding they

receive. My desire was to use institutional ethnography to situate SISTA in this context of epistemological authority and again, I did not receive much encouragement. It was not until Dorothy Smith herself came to my school, when again, I stole a few minutes of her time to ask if she thought my project could qualify as an institutional ethnography project. Her confirmation was all I needed.

\section{Introduction to Institutional Ethnography}

Having been trained as a sociologist working in the sociology department, Dorothy Smith experienced marginality and perpetual invisibility in academia. Smith (1987) recounts how unsettling it was when the department constantly undermined her work. She attributes this dynamic to her bifurcated identity, as 1.) a mother and 2.) as a scholar. For the men in the department, they did not consider Smith as a serious scholar and thinker because of her role as mother to two children. Because academia constantly delegitimized her work, she retaliated by focusing her study on academia. She coined the term institutional ethnography (IE) to describe her work (Smith 1987). Through IE, she concluded that academia stands as a ruling apparatus, a "text mediated" structures which possesses specific and predetermined modes and methods conducting research. As a power structure, academia has specific methods of deciding and determining which people were deemed fit to advance to prestigious positions within the institutions of higher learning. These modes and processes often ensured that women remained in non ladder positions or forced those who are in ladder positions, such as tenure track positions, to deal with a system that controls who gets admitted and whose work counts as proper scholarly work. 
Because women were excluded and/or were included only as subordinated research objects, she offered IE as neither a method nor a theory but rather, as an alternative analytical tool for researchers who appreciate “women’s agency, women's authority, and the valuable knowledge this perspective provides” Smith (1987). I found my voice through IE, a method that has come to be regarded by critical scholars as a revolutionary mode of inquiry because it offers scholars a tool to protest and resist mainstream sociology's objectifying ways of knowing and speaking of / for the marginalized. IE has been hailed as a welcome alternative to posivist methods and theories of the day by prioritizing the experiences of women and other marginalized populations. Mykhalovskiy and McCoy (2010) add that,

Unlike forms of conventional sociology whose aim is the production of theory, IE investigates 'what actually happens' in the realm of practices and relations through which societies and people are governed (20).

While hers is work that remains heavily Eurocentric it offers tools useful for me in my analysis of SISTA. Where IE falls short in its discussion of race, I add Black Feminist Thought to frame themes of power and knowledge production for this project are based. Using the SISTA training manual, peer reviewed journal articles and combining IE’s concept of the problematic, Black Feminist Thought's concept of intersectionality and content analysis, I provided a broader view not just of the culturally available knowledge about Black sexuality, but also to thematically expose the conventional, mainstream methodologies responsible for arriving at this knowledge.

Timothy Diamond (2009), Liza McCoy (2006, 2009), Susan Marie Turner (2003), George Smith (1990), Eric Mykhalovskiy (2010), and other institutional ethnographers have produced work aimed at revealing these significant socio political, 
economic, and cultural forces shaping and constraining the activities of people in the US and Canada, particularly regarding their contact with the health care system. Additionally, Mykhalovskiy and McCoy (2010) offer that IE has extended beyond being a "sociology for women" and has found use in studies about discrimination against the LGBTQ community, the disabled, and in environmental justice movements. They also say that while IE research has continued to gain notoriety in these areas, it is also now being used to bring universities and their intellectual resources into relation with other public spheres such as community-based organizations. Starting from my own experiences as a researcher I tap into this aspect of IE, that is, to study how communities interact with the SISTA training manual, its accompanying documents, and published journal articles.

This study uses IE to reflect on how these documents organize women’s participation in HIV/AIDS prevention programming. Ranking (2017), quoting G.W. Smith (1995), also speaks to the attributes of IE research. For most scholars, IE emphasizes the problematic, not so much as a problem but as a mode of thinking that begins by appreciating the everyday events in people's lives, and in appreciating that there sometimes is a conflict in reconciling what people know about their circumstances and the dominant narrative that ignores these personal experiences and chooses instead, to frame people's problems in a different way.

Finding this attribute of IE was liberating for me intellectually. It gave me permission to incorporate my experiences as a graduate student who had been invited to participate in SISTA training who was unsettled by knowing that the subjectivities of women's sexual activities were being ignored through this training. It was also 
unsettling to make the determination that the program objectified Black women and men yet my sociological training, like Smith's, limited me to a value-free sociology that espouses objectivity. This disjuncture, or point of rapture as Smith calls it, occurred while I was pondering my research design and questions. I felt as though I was betraying the discipline by drawing conclusions about the program

\section{Black Feminist Thought}

Black Feminist Thought allowed me make sense of this disjuncture. I was able to combine the discovery of my cousin's wives' independence, my attendance at this conference, meeting and talking to Dorothy Smith, and my contact with Chandra Mohanty’s “Under Western Eyes: Feminist Scholarship and Colonial Discourses” into the frame of studying such programming and its implications on Black women. In my toolbox also was Chandra Mohanty's class, Transnational Feminisms, which introduced me to concepts of power and privilege that made me wonder why these modes of inquiry were not mainstream. I found I was now engaged in the politics of identity, carving out my own identity as a scholar who, in the case of my cousin, found herself as an African scholar potentially producing work about my own family from a Eurocentric normative way and codified my cousin and his wives as the Other (Mohanty 1988). At the same time, I was seeing SISTA through the same lens, where working class or unemployed "at risk sisters" were seen as the Other, whose behaviors needed transforming (Mohanty 1984).

After I completed the SISTA training as participant, I felt compelled to attend the SISTA facilitator training to gain firsthand insight on the nuts and bolts of this training including how messages about Black women are transmitted and internalized. I 
completed this weeklong training of facilitators, I graduated with a poster, a certificate, and my own manual. At the training, I was unsettled at what I thought was a condescending use of Ebonics to read skits and other training resources available there by some facilitator trainees such as myself. I wanted to voice my discomfort with the othering of low-income women for whom the program was meant but I felt paralyzed by a sense of intimidation that crept up again as I began to question whether I was qualified to take offense at the dynamic. Because these were African American women mimicking other African American women, I questioned how qualified I was to critique this dynamic. Thus, I opted to take a back seat and let it play out as it would. Further, I was too preoccupied with my own sense of guilt over the fact that I was benefitting from gathering data to attain my degree.

Minh-ha (1988) says that these questions of identity tend to reopen the "I - Not I" duality that colonized and formerly colonized women feel. She argues that there is a space in theory making for this feeling adding that these questions are usually present where power relations exist. In these situations, Minh-ha says, women of color are usually caught in the struggle to identify their true authentic self apart from the place where the colonizer has deemed appropriate for us. This is what Minh-ha sees as "the colonial mind" which is always struggling to find its proper place within these artificial but very significant categories of race and nation placed by the colonialist. One of the effects of this has been the divide and conquer strategies used by "the master" that has caused this duality. Here, she describes the ways women of color have lost the ability to see difference as a source of creativity and instead we succumbed to the training by hegemonic forces to see difference as a tool for segregation. 
Minh-ha's and works from similar feminist work on positionality have infiltrated academia and now scholars before me have helped me understand the phenomena I was struggling to put into words. To begin, as an immigrant, I felt uncomfortable around my African American sisters, let alone question the ways they spoke of others. Minh-ha (1988) says many of us "still hold on to the concept of difference ... as a tool of segregation” when instead we ought to see it as a tool for creativity. Reading the Combahee Collectives and the founding of Black Feminist Thought gave me more confidence and here I stand now, a little more confident and less likely to downplay the value of my work. I use Black Feminist Thought for its ability to traverse the feminist landscape in order to discuss what SISTA represents to scholars, researchers, activists, community-based organizations, and the communities they represent.

Black Feminism credits its roots to the National Black Feminist Organization’s (NBFO) regional conference held in 1972 where the Combahee River Collectives were created. As a critical social theory, BFT was officially codified in The Combahee River Collective Statement: Black Feminist Organizing in the Seventies and Eighties (1972). Barbara Smith (1986) calls the Combahee River collective statement "a progressive, multi-issue activist Black feminist organizing." The "organizing” spoken of here by Smith (1986) began a few years prior to the publishing of the Combahee River collective statement. For a number of years Smith, along with renowned feminists such as Audre Lorde, report that they consistently maintained a long tradition of gathering regularly as Black scholars to discuss issues pertaining to Black women’s scholarship. These meetings eventually led to the Combahee River Collective as a statement to define and clarify Black women’s politics (Combahee River Collectives 1981). In 
addition to defining and clarifying their politics, these scholars wanted to also clarify their activist work not just within their own group but also "in coalition with other progressive organizations" (1981).

Among the achievements of Black feminist scholars was this Combahee River Collective Statement which was collectively produced to respond to a male-centered and male-dominated academic field that continually suppressed their work and also as a rebuke of white women colleagues in academia and in the mainstream feminist movement who continued to ignore the work of women of color. These Black feminists, therefore, sought to carve out a unique intellectual space for themselves because they were frustrated by white scholars who consistently failed to cite the work of Black scholars. The latter regarded this omission as deliberate and also as a means through which white scholars could avoid acknowledging the "violent and non-abstract realities of race and class oppression” commonly experienced by women of color (1981). At this time, it was apparent to these Black feminists that white women primarily ignored Black women's positionalities and their work centered mostly on the plight of a "group of educated, middle and upper class married white women - housewives, bored with the home, with children, with buying products, who wanted more out of life" (hooks 1984). Black scholars have been fighting for self-determination and this fight continues. At the National Black Feminist Organization where they brought attention to their continual invisibility, they also brought attention to what they considered as “pejorative stereotypes attributed to Black women” (Brown 2014). This movement thus spurred Black women to political and scholarly action, and codified Black Feminist Thought as a tool to focus on the socio-political realities of people of color that are 
continually misnamed, manipulated, or ignored completely. Therefore, while the intellectual and activist work of Black women predates The Combahee River Collective Statement, it was here where Black feminists took collective intellectual ownership of the fact that they "have a very definite revolutionary task to perform” (1981). It was also here that they resolved that though their work may be open to critique, they would unwaveringly stand and struggle for nonhierarchical distribution of power in the arena where they lived and worked.

Contemporary Black feminists like Cathy Cohen call this hierarchical power a “normalizing power” and they regard it as one that needs to be confronted. Quoting Adrienne Rich, Cohen (1997) names this normalizing power as a white middle class, heterosexual standard against which the lives of Black women are measured. In summary, the work of Black Feminists acknowledges, recognizes, and appreciates how the US stands as a heteropatriarchal state that upholds a dominant understanding of gender, race, and sexuality of Blacks.

\section{Black Feminist Thought in the context of HIV/AIDS}

Cohen (1990) offers a look into the practical uses of the Black Feminist framework in the context of HIV/AIDS. Utilizing HIV/AIDS as her site to study the gap in literature regarding how the US in general and the Black community in particular responded to AIDS in the 1990s, Cohen observed that there was indeed a proliferation of literature regarding a national response to the HIV pandemic in the 1990s. However, this literature centered primarily on the experiences of whites and it was these experiences that were used to serve as baseline for theoretical analyses of how various cultures in the US responded to disease. Cohen's purpose was to point out the 
complications presented by using the white experiences as baseline to study emotions associated with how people impacted by HIV/AIDS were coping (1997 10). She pointed out that attempting to address HIV/AIDS through the lens of white experiences is problematic because not all issues experienced by US Whites are easily transferable to the Black community. Cohen says unique "cross-cutting" issues found in the Black community, such as the collective delay by Black leaders in dealing with the epidemic, contributed to the disproportionate impact of HIV/AIDS on the community (1997 8). She contends, therefore, that to discuss AIDS in Black communities is to discuss a multiplicity of identities, definitions of group membership, locations of power, and also to discuss the strategies for the political, social, and economic survival of the community as a whole.

In keeping with the aforementioned mandate to consider the political, social, and economic survival of the Black community as a whole and in considering the health of women of color as a social justice issue, Hill Collins (2008) contends that controlling images of African American women that are usually forwarded by institutions outside African American communities should be confronted. Hill Collins charges emerging scholars to critically assess the work coming from educational institutions that speaks about Black women and challenged these were necessary. Additionally, Hill Collins acknowledges that the visibility of Black women and the issues they deal with, makes them especially open to objectification (94).

In her chronicle of the work of Black women Hill Collins (2000) opens with an excerpt from Zora Neale Hurston’s 1937 “Their Eyes were Watching God.” Here, the character Nanny explains to her grandchild her viewpoint of what the place of Black 
women is and likens the work of Black women to that performed by mules. Hill Collins (2000), as well as Angela Davis (1981), Gerda Lerner (1972) and other prolific scholars have meticulously researched the forms women's work have taken in the US and have also critiqued the work of other Black women without devaluing it. Being that SISTA is hailed as a program for Black women by Black women, it is the intention of this project to use the lens of Black Feminist Thought to interpret not only the claims made by theory of gender and power regarding the work of Black women but also critique image of the Black woman presented by SISTA. This is because this current project understands health outcomes for African Americans as a social justice concern.

Patricia Hill Collins’ work and the work of Black Feminists preceding hers has become even more crucial in powerfully and rigorously clarifying the complexities that exist in creating scholarly work rooted in the everyday lives of US Black women. Historians such as Hine and Thompson (1999) have chronicled the enduring efforts of Black women to remain relevant and to have their stories be properly told in all of their complexities. Hine and Thompson (1999) reveal how the characters of African American history have refused to disappear, and how scholars and poets like Maya Angelou and Rita Doves have preserved the voices of African American women from the times they landed on the shores of America whether in shackles or of their own free will.

Given these aforementioned arguments, I offer that my dissertation uses these works to get at the main question of what the SISTA training manual says about the socio-economic, sexual, and political lives of Black women and juxtapose this to what Black women say about themselves through the lens of Black Feminist Thought in 
order to determine the gaps and the overlaps for the purposes of identifying any lessons learnt. In doing this work, Hill Collins cautions against devaluing the work of other Black women and simultaneously notes that not all work produced by Black women that claims to be feminist work is indeed feminist work. Hill Collins (2008) offers that some work by those who claim to be feminists actually looks more like white feminism in Black face.

Rather Hill Collins proposes a model closer to the one proposed by Angela Davis, Kimberlee Crenshaw, and others at the Combahee River Meeting in 1982; one that recognizes and explores the interconnectedness of the multiple dimensions that work simultaneously to produce social inequalities. Additionally, the Black Feminist model does not render Black women as hopeless and helpless but rather, recognizes that quite simply, the way Black women approach life works. It cannot overcome all obstacles, but it has enabled Black women to shape the raw materials of their lives into an extraordinary succession of victories, small and large. (Hine \& Thompson 1999).

I seek what the Black Feminist lens would offer regarding the arguments connecting sexual behavior to the disproportionate exposure of people of color to HIV/AIDS. The work by Hine and Thompson and others does indeed highlight that the raw materials needed to overcome obstacles lie within the ways Black women live life. Unfortunately, Black women, despite their efforts for self-determination, have continually been misrepresented with devastating consequences. Patricia Hill Collins posits "controlling images" as a conceptual tool to analyze the problematic constructs of Black women. Hill Collins (2008) quotes Harris as saying, "the US society, including the dogs, have instead, proceeded to try and explain the Black woman, even 
to herself” (Hill Collins 2008). According to Hill Collins, this means that "white men and their representatives” have historically maintained an epistemological position that manipulates already existing symbols about Black women or continually create new ones. This means that while the controlling image is traced back through the times when Black folks were enslaved in order to keep us subjugated, the new form of controlling image is more subtle yet still serves the purpose of absolving white America of the unequal health outcomes of BIPoC.

In this project, I hope to provide literature as well as data that sheds light on the mechanisms through which controlling images combine with colorblind racist norms to downplay the significance of sociopolitical and historic forces in determining our inferior health outcomes. It is my hope to discuss the implications of these images and how they are reinforced and perpetuated through seemingly progressive programs like SISTA.

While Black women continually fight for self-representation and selfdetermination, there is much work pointing to the historicity of the harmful ways images of Black people in general and Black women in particular have continually been appropriated or misappropriated in American culture. For example, while Hine and Thompson (1999) present largely difficult to read contemporary and slave narratives, they simultaneously present narratives of triumph, narratives where, in the cruelest of times, Black women would weave new communities whose code would endure through the abolition movement to the 20th century where they organized to provide services where the US government did not. 
During the times of brutal lynching of the Negro, activist, researcher and journalist, Ida B. Wells-Barnett (1895) appealed to "the humanitarian spirit” that lifts its voice on the subject of violence against treatment of "the Russian Jews, the Armenian Christians, the laboring poor of Europe, the Siberian exiles and the native women of India” to denounce lynching of Black people. She questions when and how the US lost its humanity and laments the double standard of a country that professes to be Christian yet stands by silently while Blacks are burnt alive. The brutalizing of the Black people was tied to many factors, one of which was the construction of the Black body as barbaric. It was this construction that Simm (2001) addresses. He analyzes early slave narratives to argue that slave owners constructed Black women as "animalistic" and "inferior" for purposes of violating them and subjecting them to inhumane treatment. Simms’s analysis utilizes Hill Collins’ concept of “controlling images” to reveal how constructions of African American women as the "mammie," the "jezebel” and the "mule" was used to subjugate slaves. These images were the prevailing dominant ideology used to justify the extraction of unpaid labor from women of African descent.

The constructions of Black men and women have somewhat evolved since then and US boasts of being in the post racial era where Blacks are no longer being publicly lynched or where racial disparities are being blamed on the inept work ethic of Black, or having too many babies, even by other Blacks described as progressive such as Will Smith and Bill Cosby (Nilsen and Turner 2014). This means the paternalism with which Black women are regarded in the US persists to date. This project, therefore, wants to connect the physical violence against us to the structural violence that manifests even in academic work. 
Contemporary forms of structural violence are revealed in Kelly's (2010) study of welfare reform. She uncovers various and contradicting public perceptions of Black women by analyzing mainstream television news coverage of U.S. welfare reform from 1992-2007 to highlight the contemporary and tangible implications of these constructions. Her study shows the effects prevailing stereotypical representations of US Black women have on present day policy and makes connections with the continual marginalization of Black women. In this study, Kelly reports that first, Black women are portrayed as welfare mothers who are hyper fertile, lazy, or too unintelligent to find work and that it is because of these attributes that the Black woman finds herself “trapped” on public assistance (2010 80).

Kelly (2010) find that these same scripts which simultaneously present Black women as clueless, childlike mothers yet also present them as conniving welfare mothers who defraud the welfare system. Kelly's conclusions are that these representations ultimately serve to justify a move to control Black women's reproduction and fertility by tying welfare benefits to number of children, among other things. Kelly's work mirrors that of Simms in acknowledging that images of Black women have since evolved from the fat mammy and/or the Aunt Jemima to a more subtle justification of racism. Kelly’s presentation also mirrors Hill Collins' argument as well as those numerous thinkers who argue along these same lines that Black women's sexuality and reproductive rights are continually politicized. Weaving through the work of these scholars is confirmation by Angela Davis of numerous and largely problematic ways the sexuality of Black women has been deployed for various purposes. They are examples of studies that show the ways the media and policymakers 
continually reframe and detract debates away from the structural realities leading to Black women needing assistance in the first place or an HIV prevention program.

To this end, Black women activists and scholars like bell hooks call for intellectual projects that deconstruct and dismantle these degrading ways of speaking of Black women. hooks (1984) challenges Black critical thinkers to break with the hegemonic modes of being, thinking, and seeing that block our capacity to see ourselves oppositionally. hooks says we must imagine, describe, and invent ourselves in ways that are liberator, ways that resist "hegemonic forces of sexism, racism and classism” (1984). From before the slave ships to this day, she says, we are a part of a legacy and so it remains dangerously unproductive for Black folks to not question the projects we produce. We ought to question those who stand to benefit from our projects the most and how. With this in mind therefore, I centered my work the ways controlling images prevail even in well-intentioned programs and how this then continues to perpetuate a hegemonic status quo that continually impacts Black folks’ health negatively.

In my quest for literature that critically analyzes SISTA, I came across Collins and Sapiano's analysis of SISTA's effectiveness. Their safe conclusion was that SISTA's effectiveness was significantly impacted by the fact that community-based organizations did not receive it well because of the communities' misgivings about initiative not being "homegrown”. Because Collins and Sapiano do not elaborate on how they define "homegrown", this project will explore how "homegrown" as a concept is understood and deployed in the context of behavioral intervention to determine what, if anything, is missing from that definition. While Collins and Sapiano 
(2016) invoke "homegrown" in their analysis of lessons learned from SISTA, this analysis glosses over the complicated history the US has had with race and does not address the ways race, class and gender oppression is perpetuated in overgeneralized ideologies responsible for the birthing of top-down programs like SISTA.

My project also uses Black Feminist Thought framing inductively and deductively to explore my thesis that SISTA reads like a tool kit for black women to conform their behaviors to a white heterosexual norm. In addition to the quest for identifying the ways SISTA may maintain this white, heterosexual norm, the project also seeks to uncover the ways SISTA may help explore Black feminist arguments that white scholars, being culturally conditioned by racist assumptions, have distorted the history and experiences of African Americans (Lerner 1972). Lerner’s work is consistent with Black Feminists in its endeavor to highlight these distortions and the ways Black women have been denied a fair telling of their history, how they have been denied legitimacy and how profoundly this has impacted Black women’s lives today. 


\section{CHAPTER THREE}

\section{SITUATING SOCIOLOGY}

"...people do not usually define the troubles they endure in terms of historical change and institutional contradiction.” C. Wright Mills

It is with this framework that I chose to interrogate my work and my studies. Racism, sexism, and all accompanying isms in sociology notwithstanding, I unapologetically locate myself within sociology because of the discipline’s focus on issues of inequality and poverty. Prasad (2019) explains that it is the discipline's deep understanding of the structural cause of inequities that draws students to sociology. More importantly, it is the tools within sociology such as her newly coined "problem solving sociology" that attract students to the discipline. Prasad explains that "problem solving sociology" is unique in its ability to provide insight to specific mechanisms that induce change. For example, within problem-solving sociology students study strategies to change racist discourse instead of merely studying structures that produce racism. Additional strengths of problem-solving sociology are its abilities to shift students beyond just describing the problem under study to focusing on "villains rather than victims.” This means in studying poverty, for example, problem solving sociology is more interested in studying the villains who create conditions conducive for poverty to flourish and benefit from it. Prasad (2016) offers that this approach of studying the villains leads to better policy solutions than studying the "victims."

It is with all these questions and suggestions that I enter academia to perform this work. Armed with C. Wright Mills’ “sociological imagination” as a tool to critically analyze the connections between public issues of social structure and personal troubles of milieu, I aspire my work to add to those modes of inquiry that involve the 
recognition of the interplay of biography and history to make sense of the world and in changing it in meaningful ways. Therefore, as we approach five decades of dealing with HIV/AIDS, I argue that the role of sociology in HIV/AIDS prevention has been grossly undermined in overall disease prevention discourse and in HIV/AIDS prevention. I argue that sociological tools in general, and medical sociology in particular can provide insight into how the virus eluded containment and to prevent further spread of this and other epidemics. Extensive work has been invested in providing a comprehensive understanding of the roots and effects of health inequalities in the U.S., particularly on populations of color. This section will add to the field of medical sociology by presenting a brief, systematic sociological analysis of interdisciplinary writing on major individual level contributing factors to the disproportionate impact of HIV/AIDS on vulnerable populations, specifically African Americans. In addition, while this dissertation utilizes a broader and sociological lens it also leans a more specific medical sociology lens to enhance the discussion connecting the disproportionate spread of HIV/AIDS in the African American community to the lethal interconnectedness of a variety of individual and structural level factors.

Washington (2006) remarks that if Dr. Martin Luther King was alarmed at the health disparities in 1965, his concerns would have redoubled today. Though the incidence of AIDS as slowed down, patterns of disparities in HIV/AIDS incidence and prevalence persist. Some advances and innovations have erased the "death sentence" stigma attached to an HIV/AIDS diagnosis. However, new infections still occur at a rate higher among the people of African descent with gay young African American men and heterosexual African American women reporting a significantly higher incidence of 
infection than other communities (Valdiserri 2013). For this reason, debates persist among scholars, activists, community-based organizations, and the general population on how to organize available financial and other resources most effectively and efficiently towards combating the rampant spread of this virus among marginalized communities.

My choice to situate this work in sociology is influenced by Cockerham (2017) who defines sociology as a discipline “...concerned with the social causes and consequences of human behavior.” Sociology's theoretical and methodological tools that are instrumental in challenging the elevation of health behavior models and theories such as social cognitive theory, theory of reasoned action (TRA), and theory of planned behavior (TPB) as dominant explanatory frameworks in identifying risk factors for major diseases and for determining delivery of care. While these theories are useful in some contexts, sociologists critique them as incomplete because they place the burden of “complete health” on the individual level (Barr 2013). Individual-based theories such as social cognitive theories argue that in order for a person to change their unhealthy risky behavior, they need not only conform to desirable social norms but must also possess the desire and commitment to adopt healthy behaviors (Bandura 1986).

For sociologists, however, the assertion above by Bandura and colleagues above may work in some milieu but in others they fall short because they shift the burden of disease primarily to the individual while ignoring the political, historical, and socioeconomic contexts within which day to day decisions are made by individuals. Sociology transcends individual analyses, qualitatively and quantitatively analyzes 
micro and macro level social interactions within any given health/illness context to allow scholars to recognize and appreciate the weight of social, economic, and political historical forces on individual behavior and how these forces create more enduring patterns responsible for disparities. Thus, a sociological analysis better equips societies with a more comprehensive and solid understanding of how these micro and macro level social phenomenon and dynamics interconnect and interact to impact health outcomes. This approach supersedes the individual based explanations for inequities given by other disciplines (Cockerham 2003).

HIV/AIDS has made it necessary to retell the story of HIV infection among marginalized populations such as the African American community. Robert and House (2000) add that sociological methods can enhance and complement methods from other disciplines by taking into serious consideration the role of race, age, and gender as significant in determining health outcomes. Doing so provides a better analysis of variables responsible for social stratification and how social stratification is accountable for the disproportionate impact HIV/AIDS has had in the African American community. Biomedical and psychological approaches do not do this; hence Robert and House warn against merely depending on these forms of knowledge as they tend to present a one-dimensional or monolithic representation of those most impacted by HIV/AIDS.

\section{Medical Sociology}

Sociologists were not always this critical in their analysis of factors leading to health disparities. Medical sociology emerged in the 1950s and 1960s when the Parsonian functionalist sociological perspective was the dominant lens through which 
scholars were discussing the structural and institutional links between health, healthcare, and illness. American sociologist Talcott Parsons (1902-1979) is credited with coining the term "sick role” as an analytical tool to discuss the role of health and illness in social life. Parsons popularized the argument that the health of an individual is to be cherished since "illness incapacitates the effective performance of social roles" (1951). He controversially proposed that that illness is a "form of medically sanctioned deviant behavior,” that if they did not seek help, the ill person was effectively jeopardizing social order (Bird 2010).

In a sanitary environment uncomplicated by a racialized and violent history, there could be some merit to Parsons' “sick role” arguments. In the US context though, he is heavily critiqued for arguing that illness was not merely a biological condition, but a function of deviance (Bird 2010). Therefore, while Parsons is considered as one of the founding medical sociologists, critical scholars within the field overtook his arguments to offer an alternate mode of thinking. Scholars would argue that the "sick role", as a model, was too simplistic and could not account for all conditions such as chronic ones which would impede a person from appropriately embodying the "sick role”. Further, the "sick role" was criticized for its classist connotations because only the upper-class people with resources could afford to play this role (Bird 2010). Therefore, while Parsons was using "the sick role" to argue against the dominance of the medical model of health in determining illness, medical sociologists were simultaneously fighting to change this way of thinking of health and illness.

In this regard, sociology, as a broad encompassing discipline, allows us to ask and answer socially significant questions while providing theoretical and 
methodological avenues through which we can answer these questions. Medical sociologists focus on the broader concepts within healthcare and consider the dominance of medicine as a profession as well as how this bureaucratization, professionalization, and institutionalization impacted communities’ ability to readily access medical services. Because pioneers of medical sociology as a subfield determined that illness and health did not just occur haphazardly, the subfield also emerged as a tool with which sociologists can critically study the health care system and health care organizations and how individuals within the US society interact with them (Bird, Conrad, and Fremont 2000). For example, medical sociology serves the purpose of providing the much-needed framework with which to understand how societies construct illness. The expectations are that medical sociologists can better provide advocacy and reform recommendations regarding the ways in which biomedicine incorporates (or not) the social components of health and illness (Bloom 2005).

It is within this context that we can fully appreciate the ways in which African Americans have negotiated the healthcare system, how they have been regarded by the US health care system, and the consequences of such dynamics to their overall health outcomes not just HIV. The role of medical sociologists, therefore, is to examine how access to healthcare, accurate information and treatment are all linked to a population's ability to enjoy superior health outcomes. For example, Link and Phelan’s (1995) hierarchy stresses a fundamental social cause approach to explain why HIV/AIDS is disproportionately high in the African American community. Link and Phelan further argue that people who find themselves further down the social hierarchy, such as 
African Americans, possess an immense health disadvantage. In the case of the African American community, (Link and Phelan 1995) identify the hierarchy stress and fundamental social cause approach as one that can highlight the ways in which stressors presented by the inferior material conditions and hierarchical positions of African Americans impacts the overall health picture within the community. Much like Du Bois’ argument in The Philadelphia Negro, Link and Phelan's hierarchy stress argument emphasizes that mere existence in a racialized, socially, and economically marginalized body depresses the immune system, a condition perfectly conducive to HIV infection.

Through his causal pathways theory, Smaje (2000) investigates the impact of one's existence within a racialized body. This theory stipulates that from slavery to the Civil Rights movement, racialized minorities such as African Americans have been systematically prevented from accumulating advantages and because they continue to face discrimination, they have also been unable to amass social capital. This social capital, per Smaje, is both a causal and mediating factor in the disproportionate health outcomes of people of African descent. Access to social capital is causal to unequal health outcomes. Evidence of this is found in the fact that as it varies significantly among distinct racial groups within the U.S., as with African Americans, so do the health outcomes of those groups. It is also mediating because any disadvantages associated with a lack of social support prevents the African American population from accessing those same resources and advantages enjoyed by the dominant members this society who have been allowed access to social capital (Smaje 2000). Hence hierarchy stress, fundamental cause, and causal pathways theory become major contributions of 
medical sociology because they bring to light the sociological dynamics that are largely ignored or undermined.

Mirowsky, Ross and Reynolds (2000) are medical sociologist whose rendering of social capital theory enumerates specific social capital components required for a person to access the prestige, power, avoid risk, and enjoy optimal health. Mirowsky et al (2000) say education, employment, work, and economic standing are factors helpful for communities to access prestige but communities of color been deprived access to these through a chain reaction of historical event responsible for the continued violation of these communities. This chain reaction has also ensured that health outcomes have remained compromised. However, our African American community, particularly those in structurally damaged communities, are also facing a weakened causal chain because they find themselves trapped between low rates of education and high school dropout rates. This leads to limited access to the job market, access to healthcare and so the chain continues.

As people of African descent in the U.S. we battle more chains of disadvantages as highlighted by the life-course and population health model London and Myers’ (2006). The life-course complements Mirowsky’s causal chain argument by uncovering the reinforcing effect of incarceration on the life-course trajectories of African Americans. For London and Myers (2006), the added burden of prison or jail time into an individual's life prevents them from attaining the cumulative advantage that other races have which inhibits them from accessing the means and resources to prevent disease. In addition to not being able to access the means and resources to prevent disease, incarceration also has tangible physiological impacts on the incarcerated. 
Chronic stress due to incarceration leads to compromised health outcomes that can manifest in what has been termed blunted cortisol responses related to length of incarceration. Cortisol is responsible for regulating stress hormones and lengthy incarceration exacerbates this condition particularly for Black folks (Johnson, Mikolajewski, Shirtcliff, Eckel, and Taylor (2015).

Without doing this work of interrogating these deep-seated racist ideologies, well-meaning programs like SISTA find themselves falling into this legacy of American efforts to integrate Black folks into the mainstream while simultaneously ensuring that we remain on the margins of the US society. Numerous other practices that came after Reconstruction such as blockbusting added to the already challenging environment for African Americans. Blockbusting involved numerous mechanisms but the most common was the splitting up of houses in the suburbs into apartment units to accommodate African Americans. This was done in an effort to integrate Black people into white neighborhoods but what resulted "white flight," subsequent deterioration, dilapidation of the neighborhoods due to a drop-in investment in these neighborhoods, and an unwillingness for racist whites to live near Black folks (Orser 1994).

Though these housing practices, also known as blockbusting and redlining, were not necessarily sponsored by the US government, they were blatant and racist at best and to this day, African American communities continue to experience the consequences. Other theorists like Browning and Cagney (2003) suggest, through the social organization theory, that the psychosocial stressors of living in structurally damaged neighborhoods may also lead residents being emotionally detached. They argue that this detachment can lead to apathy and deter residents from forming social 
attachments to their own communities. In the context of HIV/AIDS, I add Browning and Cagney (2003) here to highlight the fact that these factors are vital to consider when crafting programming. It is necessary to consider that ill health is directly linked to living in socially hazardous environments and also to a lack of social attachments to a community.

Krieger (2000) sums this up by saying, “Discrimination hurts”. She reaches this conclusion from her use of the ecosocial theory where she measured the ways state and non-state institutionally sanctioned discrimination directly and indirectly impacts population health outcomes. Her analysis was not limited to racialized minorities but to all population groups that are at the intersection of one form of sexual, gender or racial oppression. Krieger urges scholars to provide a "full accounting of societal health patterns”, in order to make effective recommendations towards equitable populations health. She emphasizes special attention be paid to the ways the human life course trajectories respond to and are determined by an interplay of sociohistorical factors (2000).

The above factors allow sociologists to make direct links between the contemporary health status of people of African descent with how our lives are entangled in the larger context of U.S. history of violence and oppression (LaVeist 2005). All the above causal and mediating factors are deeply rooted in a period of intense enslavement of people of African descent where, for centuries, our people have experienced untold harsh living conditions in addition to ascribed diminished social status. The end of slavery brought little relief for our population group, despite the Reconstruction era whose main intent to improve the outcomes for African Americans. 
SISTA follows the history of these programs and ignores the fact that our people's lives have been shrouded in a history characterized by white people's obsession with power and control, despite other white people's willingness to see Black people become full citizens of the US (Gao 2000). The reconstruction placed Black folks in a position where we had to assimilate against our own self-consciousness while whites had to find a way to harmonize their superiority complex with the call to share power. Gao's work is vital in helping reveal how an incomplete interrogation of the ideologies of the dominant race is a disease has remained troublesome in America. Authors like Gao call for scholars to critically analyze dominant ideology responsible for why Blacks were enslaved to begin with and a more in-depth look into how these ideologies persist still (Gao 2000 xiv).

Therefore, while blatant discrimination has been outlawed in the U.S., its residual effects within the African American community are still felt today and continue to have a bearing on how people of African descent in America not only access the healthcare services but also live-in areas not well served by public health services. Theories such as social cognitive theories conflate communities and fail to factor in the fact that when residents tend not to have reason to value their community, they, in turn, lose value for themselves and may need an additional intervention other than those based on condom use. 


\section{CHAPTER FOUR}

\section{HISTORICAL CONTEXT}

In view of Krieger's argument above, it is fitting to engage the human life course of Black folks in topic of HIV/AIDS. It would be myopic and irresponsible not to do so, for this specific conversation speaks directly to overall health. This topic takes on diverse forms depending on the locales of the people engaged in discussing the current effects of centuries long enslavement of people of African descent and their standpoints. Scholars and even politicians continue to remain fragmented on the best way to productively discuss the longstanding impact of slavery and how to correct the ills of the legacy of slavery on the lives of people of African descent. For this reason, the issue of properly supporting our communities remains contentious, remains mired by incomplete and even problematic analyses and recommendations, and more significantly, and sometimes is ignored altogether. As mentioned earlier, the campaign against poverty waged through a "War on Poverty" is a case in point. Though this initiative was not especially targeted towards US Blacks, its critics have argued that it certainly could have benefited our communities better were it done properly.

Part of the problem of governments is that they ignored the perspective of those folks who stood to benefits from it the most. In the case of the "War on Poverty" those who benefit were disenfranchised whites and Black folks (Katz 1990). Before this “war”, however, the US government had previously attempted to address inequality through the Freedman's Bureau and as mentioned earlier, Reconstruction. Again, while progress was made in terms of uplifting the condition of Black folks in the United 
States, other challenges, such as lynchings of mostly Black men as well as other threats of violence impeded that progress and drove Black folks back underground, afraid to participate in mainstream American politics (Wiegman 1993). It is can be argued therefore, that historically, Black folks have been systematically prevented from participating in the politics that directly impacted our lives. The debates regarding the best way to achieve equality on all the fronts have thus remained contentious and emotion inducing.

Talks on how to best draw the disenfranchised closer to the American mainstream have also has been divisive on some levels, yet necessary and on other levels has sometimes even proven to be productive. One of the most disheartening characteristics of these conversations in America is that those engaging in this topic seem to continually speak past one another. This may be because of disciplinary constraints, opposing political and religious viewpoints, or a slew of other factors that combine to contribute to contribute to the slowing down of progress on topics surrounding social justice. It is my hope in this dissertation, therefore, to use the above sociological tools to weave these conversations together to reveal the benefits and the need for a more encompassing and interdisciplinary approach to research. It is my hope that scholars, researchers, activists, and community-based organizations intertwine their otherwise similar interests to foster approaches to problem solving and policy formulation that actually changes lives.

For my part in this struggle, I use this dissertation process as an opportunity to participate in these meaningful debates and work like this continue to drive my passion for future projects aimed at improving the lives of others. I am spurred by the fact that 
the trends from the $19^{\text {th }}$ century to date continue to reveal the ways public health appears to continually fail to shake its classist and racist heritage at the expense of those who patronize their services the most. It is most disheartening for me that to see change taking place so slowly yet obviously there are folks who work in this sector who are genuinely invested in supporting positive health outcomes as evidence by the wide array of public funding, programing, and policies devoted to pursuing some equity within the United States. Therefore, though it can be argued that African Americans have gained considerable traction towards an improved socio-economic status (SES) and health outcomes, this conversation is still relevant as all major markers continue to see Black folks lagging behind those of people considered as white.

Where health is concerned therefore, the state, scholars, activists, and community-based organizations must no longer ignore that the contemporary issues of HIV/AIDS and SISTA are imbued in this complex socio-political and historic context. As far back as early $20^{\text {th }}$ century, W.E.B. DuBois, among others, spoke to this complexity and used the account of his life as evidence of the traps he experienced living in America as a Negro. DuBois (1903) expresses disillusionment at realizing that his own country considers him and people of his race as a problem to be fixed, rather than as a valuable source of knowledge and as a priced resource for the nation. Throughout his writing career, DuBois continued to reflect in his work a passion for Pan-African movements as an activist, scholar, and journalist, and continued to indict America's racist practices. As he is personally impacted by this racist legacy, he expresses his exasperation by asking, "Why did God make me a stranger in my own house?” (1903). DuBois redeems this situation by recognizing that his life story is a gift 
to him as it provides him with vision to see how these invaluable experiences can provide him with a unique lens with which to analyze the various attitudes within American society regarding the affairs of Black people. He dubs this gift a "double consciousness” (1904)

For DuBois, thus, “double consciousness” means that though his country has ignored his humanity, his identity as an American who lives in America remains intact and not being seen or valued stimulates his creativity and has permitted him to creatively weave all his identities to arrive at a truer sense of himself. Through this struggle he has managed "to attain self-conscious manhood" and argues that if America could value the Negro as a source of knowledge, the country and indeed the world would gain from the power of his genius as a Black man equipped with this "double consciousness” (1903). From his standpoint, however, DuBois sees with clarity an America that has taken to denying the Negro "self-consciousness, self-realization and self-respect;” and America that has thwarted his self-worth and subsequently has led him to lose his creativity. Though Dubois was been accused by some of elitism, he is but one of a myriad of Black folks who have raised their voices to speak of their value in knowledge creation, who they have noted and rejected the monolithic ways they have been presented in literature, in research and in the media, and who demand that they be spoke to, spoken with and not spoken about. Black folks know all too well that we possess the knowledge and input needed and necessary to improve our lives.

Public health is not the only sector that has been accused of reproducing problematic ideology. The work of Gilman, a sociologist, produces racist scholarship 
on the lives of Black folks, regarding the factors believed to contribute to our inferior health outcomes and how to manage the lives of Black folks. "We have to consider the unavoidable presence of a large body of aliens, of a race widely dissimilar and in many respects inferior, whose present status is to us a social injury" (Gilman 1908). In this offering of how to improve the lives of Black folks, Perkins Gilman suggests that the Negro population needs to be taught to be entirely self-supporting and well behaved so that it ceases to be a "problem" and a menace. With all its xenophobic rhetoric, Perkins Gilman briefly presents a rather sound argument: that the status of the US Black race is indeed an embarrassment to the United States and that collective action needs to be taken to address this status. Gilman acknowledges that the negative effects of stealing Black folks from Africa and subjecting them to massive exploitation for centuries are now even more glaring because the emancipated population that are faring rather poorly by all markers, are now free to mingle and live side by side with whites. Gilman also argues that with emancipation also came the removal of the veil that cover the fact that the wealth enjoyed by whites came at the exploitation of the Africans and other groups. With this realization, however, Gilman Perkins’ overarching arguments, conclusions, and proposed solutions to the problem of "Black inferiority" remain racist and problematic.

This shows that while Gilman is willing to discuss the effects of racism on the outcomes of our folks and though she believes that America is responsible for thwarting the socio-economic standing she Black folks, she suggests that America should have left the Africans in the jungle where we were happy. She posits also, that now that the African is in America, it is America's responsibility to root out this lack of civilization. 
Literature is never clear whether DuBois was responding directly to Gilman since they were contemporaries. What is clear is that Gilman's arguments were not isolate. W.E.B. DuBois insists that the role of racism must not be understated when it comes to discussing the disparate status of African Americans, and not any assumed genetic inferiority as suggested by Perkins Gilman. Where DuBois and Perkins Gilman seemed to agree, however, is the fact that per DuBois (1903) there was a sizable improvement in the wellbeing of African Americans since emancipation. DuBois notes, an increase in the number of African Americans who own real estate, assets and even some political leverage. He differs with her because he recognizes that the status for Black Americans is still inferior, that for the majority of Blacks issues of voting rights, justice, and equal standing as American citizens are still evasive.

Rabaka (2018) and Morris (2015) regard DuBois to be a misunderstood and innovative sociologist, noting and recognizing that DuBois's scholarship spans a few decades and much longer. They argue, therefore, that this time span allowed for a significant shift in his intellectual journey that should not be ignored. Morris (2015) cautions against judging DuBois on a select few phrases and instead offers an analysis of the entirety of DuBois’ work to reveal DuBois' genius as a sociological scholar. Thus, both scholars give DuBois credit for returning to edit his work in 1948 and to answer the controversy the work raised by critics (Rabaka 2018). Further, in his assessment of DuBois' work Morris (2015) differs from his contemporaries who argue that DuBois had a contempt for Black folks. DuBois (1903) is indeed quoted as describing some Black folks as being "of a primitive kind” but reading this within context reveals that this description was particular to a group of Black folks North 
Carolina may have appeared to some people who were blind to the value of the “Negros.” This resonated with DuBois’ own words where, as a Black man, bemoaned the ways his intellect was repeatedly ignored, undermined, and underutilized in the United States.

The conversation surrounding the welfare of African Americans was not limited to DuBois and Gilman. Chestnutt and Booker T. Washington were other thinkers and writers of DuBois' time who had some suggestions and ideas about the overall wellbeing of Black folks. Chestnutt is seen by others as a pioneer in thinking about the color line in the US and its impact on Black folks who main focus was on voting rights (Ellis 2015). He offered that the biggest ills being suffered by colored people of his time was that of "taxation without representation." This lack of representation exhibited itself in the denial of voting rights and throughout these challenges, Chestnutt still envisioned a future where the Negros would prevail. Chestnutt had faith in the constitution, "The Negro will, in time, attain to full manhood and citizenship throughout the United States” (Chestnutt 1899).

When critics write about DuBois' suggestions for our advancement and for the ending of inequality, they usually compare him with Booker T. Washington. Some of the scholars defend his position and others have regarded them as paternalist and classist (Rabaka 2018). Rabaka (2018) says when Dubois speaks of “The Talented Tenth” as a solution to improve the socioeconomic standing for Black folks, DuBois strikes some listeners as an elitist scholar influenced by European idealism. This is because some heard DuBois argue that slavery left the Negro "uneducated and 
ignorant" and that the future for our people would be in an educated elite group of leaders. Some saw this view as espousing aristocratic philosophy.

Washington, on the other hand, suggested that Blacks were not to start at the top as slavery had left us too subservient to whites. He offered, instead, that in order to fix the plight of Negroes, we ought to abandon our lofty aspirations of seeking leadership and political offices. He added that it would be in our best interest to know our place and not aspire for positions we had not yet become accustomed to nor had experience in. His solutions were to give Blacks intensive industrial training and he advised Black folks to accept our positions at the bottom because that is where we belonged. The more Booker T. Washington suggested that we would be happier serving whites and the more he suggested that we must not be seen to threaten whites, the more palatable he became to white audiences (Morris 2015).

I quote the above to note that these were conversations taking place within and outside the discipline of sociology. Though they were not canonized as founders of the discipline, both Gilman and W.E.B. DuBois as sociologists use the tools provided by the discipline disparately to discuss slavery and its ramifications from a more intimate experience with it and its ramifications than Marx. I evoke Marx here because is his one of men canonized as the founding father of sociology whose work on exploitation is mostly related to the work DuBois is doing. Marx is applauded for providing theoretical "weapons needed to attack the mystifications of capitalism and the vision needed to mobilize the masses for struggle,” (Buroway and Wright 2002). However, by arguing that slaves were a proletariat, Marx may have been viewed by some as a class 
“reductionist with little awareness of or sensitivity to race,” (Lee 2011). Others have defended Marx's analysis of race but of course, DuBois, as an insider, provides a more intimate analysis of the generational physical and psychological impacts of slavery on the Black body. Further, Marx is also critiqued because his analysis of capital was devoid of a gender lens. For example, Hartmann (1979) argues that the though Marx’s lens into how capital works is useful, it also had limitations with respect to discussing sexism.

My use of Marx in this discussion is to acknowledge and advance Marx’s argument that in a capitalist society like the US where there is exploitation of labor, those oppressed must properly recognize and identify our oppression in order to resist it and improve our outcomes. I weave my work from Marx to Gilman and DuBois, Patricia Hill Collins, and Foucault whose scholarship analyzes life within capitalist societies. Theirs is work I use to situate my work because, while Marx and Foucault have been indicted for not properly accounting for the interplay of race and gender in determining the socio economic and political outcomes, they provide a solid beginning point. The scholars above offered suggestions from their various perspectives on how to mitigate poverty, racial discrimination, and high mortality rates, among others. Some of the conversations were based on rigorous research (Du Bois 1903) and others were opinions centered based on white supremacist rhetoric (Gilman 1911), but all in all, the significant take away from this is that our struggle as Black folks continues till today. Therefore, Perkins Gilman and DuBois speak to the jarring ramifications of centuries of a slave labor economy on our socio, economic, political, and ultimately health status, Foucault's analysis of social structure, also spanning a few decades, 
centered on revealing the genealogy of how state power is exercised on the human body. While Marxism posited that power operates through the mode of production and its relationship to the dominant class, Foucault said the focus on mode of production and the subsequent class struggle as the unit of analysis was insufficient to deduce everything scholars need to know about the operation of power in a capitalist society. Foucault's analysis of the penal system, on religion, on the clinic for example, described the ways state control as a strategy to discipline and punish the subjugated human bodies has evolved over the years to supersede the class struggle based on the means of production. Foucault studied those in power and concluded that their control evolved from being physical to the exercise of forms of knowledge, to what became accepted as scientific understanding and 'truth'. For example, the penal system was eventually transformed by those in power from being an external form of control over the human body through the prison system to inventing technologies through which humans would be trained to self-regulate internally by using a set of strategies I shall discuss later.

There is extensive scholarship dedicated to analyzing the merits and demerits of each of the proposals raised by the scholars above. I cite this work to bring into view the diversity of thought regarding the condition of Black Folks and the proposed remedies for this condition. I have highlighted through the work of Chestnutt, Dubois, Booker T. Washington and other early $19^{\text {th }}$ century thinkers and scholars as representative of scholarly and activist efforts to engage with the government at the macro level and with the general citizenry of the US at the micro level regarding eliminating the subhuman condition of Black folks. I therefore bring into view the traits these remedies had in common, that they all spoke about the status of the Negro, spoke 
for the Negro and not with the Negro. Further, it is important to note that, the work of DuBois and Booker T. Washington is highly recognized and cited numerously, even by me indicating the extent of their influence and authority to speak for us. I am not entering the debate about the merits and demerits of each scholar's viewpoint. Instead, I pursue the theme of epistemology, or the creation of knowledge and seek to unearth how SISTA fits into this tradition of talking about Black folks.

Foucault leads me to Patricia Hill Collins whose Black Feminist lens also pursues the issue of epistemology or knowledge creation as a mechanism that led to this internal regulation. The Stanford Encyclopedia of Philosophy speaks of the different uses and different facets of epistemology, from Plato's $4^{\text {th }}$ century epistemology to, Locke's and Kant's epistemology. It is Foucault's epistemology and feminist epistemology that drives this paper. Whereas the scholars and activists quoted above focused their attention on studying what was best for Black folks, Foucault came along to radically and politically argue that knowledge seeking is motivated by the need for power and social domination (1972). Much like DuBois who studied the ways racism produced inequalities, Foucault's genealogies trace the ways the penal system disciplined and punished the bodies of those condemned by law. Slavery and Foucault's prison system are different in various ways but similar in that the body and power exist within in a disciplinary regime.

In Discipline and Punish, therefore, Foucault examined the ways human bodies where made docile or passive by the prison system, schools, the military whose job was to control the movements of the body. Foucault (1977) also examined the ways prisons controlled how the individual experienced space and time and it was also through 
making executions public that the King asserted his authority and power. Per Foucault (1977) it was through this form of disciplinary power that three forms of technologies emerged to enable what Foucault sees as "the docile body." In this regard, one of the external technologies was the hierarchical observation of prisoners in the form of a panopticon, a circular prison with cells that could be monitored by a lone watchtower in the center visually inaccessible to the prisoners.

Through his genealogical study of power, Foucault noted that the desired effect of disciplining was to create a separate individual from the masses, an individual who could stand out from others with a goal of turning the body into a "productive cog in the social machine” (Donovan 2019). To achieve this goal, the second form of technology used by institutions to control the human body was "normalizing judgment." Normalizing judgment is a tool to rate each body's performance against desired norms of behavior and make people more efficient. The knowledge produced classifies, ranks, and establishes norms and standards against which each individual is judged.

Lastly, the technology of "examinations," used in conjunction with normalizing judgment in prisons, is used to determine prisoner condition while documenting their progress toward some specific set objective. Translated to the medical field, the technology of "examinations," functions by credentialing and giving undue power to medical practitioners to deduce a diagnosis. This becomes central to disciplining, controlling, and homogenizing individuals. This means, in addition to using these technologies to study the prison, Foucault says this lens is useful to examining the role of the clinic and the role of religion in society to critically analyze what task knowledge performs in society and whose interests are advanced by this form of knowledge. 
My interest in Foucault's work and the way he studies technology is because of its instrumentality in understanding this systemized knowledge about human behavior. Narrowing Foucault's argument into a coherent summary has been a challenging task because of the width, breath, and sheer magnitude of Foucault's work. The ultimate purpose for Foucault that of looking ahead to a new scholarship attracts me. He says that this new scholarship needs to begin by "taking the form of resistance against different forms of power” (1982 779). He does indeed contend that studying power can be rather complex, but he urges those humans who are objectivized by power relations to engage in, bring light to, and locate their positions within these relations and "find out their point of application and methods used" (Foucault 1982 780). The result of this kind of work and this kind of inquiry is that scholars, activists, and community-based organizations can begin and continue to interrogate the power relations they are imbued in and the power relations they are participating in advancing. We must conduct our work consciously as we navigate our privileged / oppressed positions in relations to power and as we gauge our attempts to dissociate / embrace these relations in order to find out what they have in common or how we perpetuate them. Hill Collins (2000) also argues that Black Feminist Thought creates space for "other groups engaged in similar social justice projects" and does not lend itself to the binary argument of whether work is Black Feminist or not. Therefore, we are increasingly being urged to pursue work that takes on a social justice lens, or an emancipatory lens.

This argument connects with my work as I enfold the SISTA HIV/AIDS training program within the arguments laid out here determine the ways this program reveals some of the main themes of these schools of thought. The connections that I 
draw from the work above is that these "human subject" takes on a specific identity in the work I perform here. In my work, Foucault's human subjects are the Black men and woman as objects of the public health sector. Black Feminist Thought presents the concept of intersectionality and the matrix of domination as a framework of interrogating the creation of knowledge about the sexuality of Black folks and the science employed to reach these conclusions.

Therefore, while scholarship recognizes that our demands have been achieved, voting rights for example, similar conversations surrounding the discrimination and resulting health inequality and how to solve this prevail. For example, while Black folks have acquired the right to vote, the Black vote is still disenfranchised due to these unaddressed racist core elements at the root of the founding of this nation that DuBois and Chestnutt wrote about in 1903. For example, practices like gerrymandering dilute the value of the Black vote today. This is the present-day strategic grouping and redrawing of political and racial lines to create or destroy voting districts. This practice has mostly benefited the dominant group and continues to disadvantage or render ineffective our voting power (Morrison and Bryan 2019).

Further, though conversations within the halls of academia and in Washington on how to improve the overall socio-economic standing of marginalized populations no longer publicly contain language such as Blacks are “... a race widely dissimilar and in many respects inferior, whose present status is to us a social injury...” (Gilman 1911 78). Bonilla-Silva (2017) says that a more subtle and insidious ways of expressing the same sentiment prevails through colorblind racism. 
SISTA is an avenue that allows me to examine the trend within scholarship of rendering race irrelevant or the trend using race unfairly to make causal and correlational conclusions regarding the "culture" of Black folks and our vulnerability to infectious diseases. Schlobohm (2016) analyzes the ways critical cultural studies scholars have pushed back against circulating cultural logics as they create a pathology about those mostly impacted. Cultural logics also obscure and absolve white heteronormative patriarchy of a system responsible for disproportionately burdening Black folks with illness. Enfield (2000) describes cultural logics as those ways people within a society collectively use identical assumptions when interpreting and hypothesizing about other people's motivations and intentions. The danger with cultural logics is that the models and scenarios created used as reference in drawing conclusion about the motivations responsible for people's actions or responses to HIV/AIDS may become stained by stereotypes.

Schlobohm's (2016) analysis examines the ways public health messages or campaigns are embroiled in the racial formations that have characterized America's history. The racial categories created during the racial formations process have led to "tangled connections between racial configuration, individual subjectivity, and health.” I build on Schlobohm's work here to highlight what well-meaning programs like SISTA can reveal about the complicated, larger conversation regarding the wellbeing of all living on the American mainland is, particularly the continued struggle for Black folks' health. The birth of public health and the literature on this sector illuminate the fragmented nature of such a discussion. 


\section{Public Health}

Suffice it to say that the public health sector was formed in the milieu of slavery and continual violation of indigenous people. Before I indict the public health service for the "bigoted exclusion of black Americans from structures of governmental support” (Schlobohm's 2016), I offer that at its inception, the public health sector was tasked with providing medical care that would have otherwise been unavailable or at least deficient without government intervention.

Prior to receiving a racist, classist reputation, the public health service emerged out of the "Act for the Relief of Sick and Disabled Seamen" of July 16, 1798, established by President John Adams (Jensen 1997). Because US economy was heavily dependent on a booming domestic agriculture and manufacturing industry, a large number of merchant sailors were employed to operate on river steamboats. Therefore, government officials realized that it was necessary and important to maintain a healthy maritime labor force and provide adequate care for sick and injured mariners and sailors. This was the beginning of the US government's move towards a federally funded healthcare system. Marine hospitals emerged out of this and became the oldest organized medical services and a bedrock of a new government initiative towards an organized healthcare system (Jensen 1997).

Later, the marine hospital services became the major health providers when yellow fever and smallpox broke in the early 1900's. This $18^{\text {th }}$ and $19^{\text {th }}$ century period saw the advent of preventative medicine and subsequent institutionalization of public health as we know it today. Peter Bryce (1918) provides a detailed account of the official founding of American Public Health Association that occurred on April $18^{\text {th }}$, 
1872. Per Bryce, the American Public Association freed the whole world of “Democlean sword of death” brought by yellow fever, the plague, and smallpox and so by 1892 the first international sanitary commission was established to guard against more outbreaks. According to Bryce, present at this inaugural event of the association in Atlantic City were

Dr. Stephen Smith, Dr. E. Harris, C. F. Chandler and Doctor Bacon of New York, Dr. J. Morris, Baltimore, Dr. Henry Hartshorne of Philadelphia, Dr. Christopher Cox of Washington, Dr. John Rauch of Chicago, Dr. William Clendenin, Cincinnati, and Dr. John M. Woodworth of the Marine Hospital (1918 327)

I present this guest list as a celebration of who was present but, more importantly, to acknowledge and indict the absence of marginalized populations. It is to recognize that this is how populations remained disenfranchised because they were not embraced in these processes. These men of medicine excluded at their founding, those who were mostly impacted by infectious diseases, the poor white folks, and all people of color.

While marine hospital services claim the founding of organized health care services, the American Medical Association quickly took over this role. With their newly minted organization, they proceeded to standardize education system through US universities and also map out avenues through which this American Public Health Association could access all forms of research and other funding through institutions like the Rockefeller Institute and the Sage Foundation (1918). This is the evidence for Foucault's argument for technologies that were used to give authority to the doctor. 
Also notable in Bryce's offering of the history of public health is a celebration of the work of Dr. Charles Denison whose contribution to the public health sector was what Bryce considered as a "sociological view of the subjects" (1918). Denison (18451909), as an insider to the sick population because of his struggle with tuberculosis, became less concerned with the pathology of "consumption" which he defined as conditions, “including nearly all such lung affections as are destructive in their tendency” (1879 2). Instead, Denison gave up his medical practice, became entrepreneurial by finding and proposing alternate treatment to what was currently being offered for this condition. In his Rocky Mountain Health Resorts (1880), he maps out a detailed health-resource map of the Rockies, and painstakingly "colored elevations and isothermal lines of mean annual temperature and rainfall, plus average seasonal temperatures, relative humidity, wind speed and direction, and clouds” in an effort to attract those suffering from the same condition he did as well as to attract insurance companies (Mitman and Numbers 2003).

As highly esteemed as Denison was by Bryce, other doctors were not too pleased with his work. First, his proposal was deemed as elitist because he was proposing these health resorts as though they were available to all, but they were not. Like many of his time, Denison omitted, in his work, the discussion on how socioeconomic conditions would limit people’s ability to access clean air and spacious living quarters offered by the Rockies. Further, he was critiqued for glorifying Denver as a “Garden of Eden” and also some physicians found errors in his calculations and map presentations (Mitman and Numbers 2003). 
This brief synopsis citing $18^{\text {th }}, 19^{\text {th }}$ and $20^{\text {th }}$ century medicine and the significant involvement of doctors in the founding of the American Public Health Association is useful in my treatment of public health, medicine, and psychiatry interchangeably though they all presently have their own separate governing associations. As mentioned earlier, Talcott Parsons (1902-1979), 24 years Foucault's senior, is one scholar whose view of the relationship between the health care provider and the patient varies significantly from critical scholars such as Foucault. Parsons, much like Bryce provide a romanticized analysis for the role of the medical provider that does not critique power relations involved and sees the relations as a beneficially symbiotic one. In The Sick Role and the Role of the Physician Reconsidered Parsons 1975 encourages that doctors must provide a careful analysis of how distinct the roles of patients are as they interact with expert medical providers. He is especially interested in the ways this relationship provides insight into the "satisfactory functioning" of "a system of social relations" that must not be ignored. Parsons argues that the medical provider deserves this special responsibility because he is "institutionally certified" and must guard his fiduciary responsibility for the health of his participants in the health care system. Parsons (1975) does not regard doctors as constituting an aristocracy nor as occupying positions of superiority in relations to their patients, but rather believes instead that the “... physician has been institutionally certified to be worthy of entrusting responsibility to in the field of the care of health, the prevention of illness ...” (1975 266).

On the other hand, Foucault's analysis over the years after Parsons is critical of the "medical experience in modern times." His thinking about death and disease in quite an opposing view from that of Parsons. Whereas Parsons says practitioners 
possess scientific expert knowledge which in turn confers medical authority devoted only to the serving of patients, Foucault saw the medical field as an entity "man" needed to be freed from. He sees it as the unholy union between the hospital and university. Unfortunately, this union persists because the doctors refrain from the political task of interrogating the true source of illness, "tyranny and slavery” (1973 33). Foucault (1973) critiques the ways medical knowledge also creates a normative subject by studying the healthy man. It is this healthy man whose physical and morals are then upheld as the standard for good behavior and against which all others are judged.

It is with this background that I approach similar topics of power, knowledge, and the subject. These themes foreshadow my discussion on exploring how power, as a process is embedded even in HIV/AIDS prevention programs. This discussion involves understanding the ways power is institutionalized and experienced by those involved in these kinds of disease prevention interventions as well as understanding the ensuing complexities. Per Foucault, this kind of power is more complex because it is simultaneously oppressive and productive, productive in HIV/AIDS prevention because it allows planners to decide whether they can understand HIV infection and how it can be prevented and oppressive because of questions arising when determining the norm, or base rate to compare the current rates and current behaviors to. Other questions and problems pertain to determining who decides the standards upon which humans should be measured.

When scholars and critics write about these governmental programs, they offer that the programs have as centered on the experiences of whites. One HIV/AIDS, 
Cohen (1999) observes that "nearly all of these studies are centered around the experiences of white individuals and white communities, where whiteness is assumed to serve as the normative or "baseline experience of those affected by HIV/AIDS" (23). Writing about the "war on poverty” Katz says “...The culture of poverty is an ethnocentric idea. It takes one set of standards - usually white, middle class American and applies them to the evaluation of other groups” (Katz 2013 42). On health research in general, Ghazal J. and Gorman B.K. (2010) discuss the need for more women centered health research. They lament the fact that most available research is centered on the experiences of men and white women, that all other racial groups are seen collectively as "minority groups.” They do note that this tendency to generalize about women's health based on data from men is changing and is no longer the normative research model. They point out that an intersectional approach is needed, so is a mixed methods approach to research as they offer a clearer picture of how different social factors and relationships shape health profiles of men and women. However, as relevant as their argument is, they too, fall into the binary mode where their focus is on white women's experiences being generalized based on white men’s standards.

The cited work above comes together to knit into place the various conversation that inform this dissertation. Well-meaning HIV/AIDS professionals and activists who work whole heartedly and are dedicated to saving lives and making change do so in this contentious realm. Contentious because, in addition to applauding medical advances, scholars have also directed criticism towards US medicine. As Siegel (1989) offers, the "rationality of science" where the person in the lab coat, typically the white, male, heterosexual as the unbiased seeker of truth is slowly being dismantled. Scholars 
interested in the United States' local and global HIV/AIDS efforts continue to question the role of medical knowledge and scholarship on the marginalized and their susceptibility to infection and ways to prevent it. This kind of power, embodied in medical knowledge, is what I explore in this dissertation. It is the power that involves health care and how medical knowledge is dispersed. Through medical knowledge, Foucault says, the social system performs two duties, 1) relaying information, and 2) possessing the authority necessary to make sure this information is upheld through an "ensemble of regulated" system of instruction. Foucault says that this power is insidious because it has the ability to influence our future action and affects people's possibilities and choices (1973).

In the context of SISTA therefore, I offer in this dissertation, that medical science and the advances therein do not occur in a vacuum but within a specific social, political, historic, and cultural context. This history involves the inhumane scientific experiments used to test and evaluate drugs and devices to the denial of said treatment to some specific populations, particularly the marginalized (Washington 2006). While these tendencies have somewhat shifted, contemporary scholars and activists such as Paul Farmer, Mohan J. Dutta, Deborah Lupton have studied and written about neoliberal health policies and programming. These health scholars critique public health as taking neo-liberal standpoints in their disease prevention programming and their general health messaging. Various academic standpoints like medical sociology, have emerged to redirect health conversation away from circulating discourses effectively blaming individuals for their poor health outcomes. They argue that such messaging not 
only implicates individuals but also absolves oppressive socio political and economic structures from having to change. 


\section{CHAPTER FIVE}

\section{BACKGROUND TO METHODS}

I was a participant observer to SISTA program in 2006 as a recipient of the training. This experience led me to follow this training up and become certified as a SISTA facilitator in 2010. With these experiences, I returned to the field of HIV/AIDS prevention training again in 2013 and, this time, only to observe the full five weeks of training underway at a domestic violence shelter in New York City. Armed with both data and more questions from these experiences, I had full intentions of completely immersing myself in the dissertation as an ethnographic researcher now able to combine participant observation as a method of studying the how Black women interacted with SISTA.

The honor awarded me of participating in the SISTA training program in 2006, 2010 and 2013 led me to the hope that by 2015 when I enrolled in at PSU, I would reconnect with my contacts from previous trainings who would be sure to permit me access to yet another ethnographic study as they had in the past. Using IE and Black Feminist Thought, I had hoped to relay the stories of everyday people and how the participants would describe their experiences with the program in relation to how academia and public health spoke and wrote of these experiences. Additionally, my intent was, and still is, to better understand the real-life experiences of all the players involved in researching, creating, and disseminating HIV/AIDS prevention programing to Black women. I also had hoped, in turn, to acquire firsthand knowledge on how SISTA was institutionally organized and experienced by Black women from their multiple standpoints and the points they come to contact with the state and power in so 
far as HIV/AIDS is concerned. This is because my overall intention is to center SISTA as a conduit to better understand the historic and contemporary ways Black women and Black women's exposures are spoken of in academia and how these framings have continued to influence policy and funding decisions.

However, when I discovered that SISTA had been defunded by the CDC and removed from the Compendium of Evidence-Based Interventions and Best Practices for HIV Prevention (also known as "the compendium”) in 2015, I had to rethink my research strategy. I note here that the compendium was formed as part of the HIV/AIDS Prevention Research Synthesis (PRS) project made responsible for creating criteria for identifying evidence-based interventions (EBIs). EBIs were those practices described as best practices that "help HIV prevention planners and providers in the United States select interventions most appropriate for HIV prevention within their communities” (CDC 2020). As mentioned earlier, the decision to remove SISTA from the compendium was made, in part, as a move by the CDC away from DEBIs in preference of the move towards a "treatment as prevention" model of interventions which saw the introduction of the Pre-exposure prophylaxis (PrEP) pill. (See figures 11, 12 , and 13 for a sample of the compendium).

Well, since the adage is “everything happens for a reason,” as frustrating and temporarily disarming as these changes seemed to me at that time, I have since discovered that my dissertation stands to benefit more from a mixed methods project. Partly by design and partly by circumstances mentioned above, this dissertation thus uses mixed method primarily because of the approaches' benefits from the traditional inductive / deductive approaches of social research. Each phase is meant to add to the 
tools I needed to explicate theories on power, the concepts of the subject, and how power is exercised and experienced by individuals and institutions as well as the implications on the lives of everyday people, Black people.

The research questions that guide the project are:

1. What controlling images about Black women are present in a program like SISTA which is meant to serve them?

2. How do controlling images prevail even in the presence of alternate theories like Black Feminist Thought?

3. To what extent are the constructions of SISTA accepted or rejected by African American women?

\section{Research Philosophy: Institutional Ethnography and Black Feminist Thought}

This project is framed using methodologically and theoretically diverse yet connected work from various scholars, one of which is Dorothy Smith’s “' $\mathrm{K}$ is Mentally Ill': The Anatomy of a Factual Account,” (1978). This is an account of Smith's interviews with a group of college friends who collectively construct and believe their friend "K" to be mentally ill with no knowledge of K’s family history nor knowledge of whether $\mathrm{K}$ had ever sought help for this condition. Without the benefit of any psychiatric training, this groups of friends create among themselves a collective and normative standard. Using this standard and their own understanding of mental illness they reach conclusion that K's behaviors were consistent mental illness. Smith continues to say that form of social organization produces a slew of unintended consequences for $\mathrm{K}$ and in the large scheme of things, Smith thus demonstrates how information on the behaviors of individuals is constantly being assembled, being processed, and tested. Thereafter, this information on the behaviors is then matched against some paradigm in order to qualify individuals for entry in any predetermined group membership (Smith 1978). 
While Smith (1978) never actually says whether or not K is indeed mentally ill, her argument is that whether $\mathrm{K}$ is mentally ill is not important to the analysis. What Smith says is significant are the implications of this work to researchers in helping us understand the steps and activities that exist between the reader of a narrative such as the narrative regarding K’s health, and the original event as well as make these steps explicit. Further, what Smith seeks to reveal through this account is that the location of the researcher, or the sociologist, in the middle of constructing as factual an account of $\mathrm{K}$ as someone who is or is becoming ill also becomes significant and makes the sociologist an active participant in the construction of the events she treats as data. Smith prefers this approach as opposed to conventional frameworks partly because conventional methods do not regard the sociologist as a participant as an active participant. Smith’s approach allows her to push against Weberian value-free sociology and permits her to problematize the general caliber of work produced in mainstream academic fields that regards women merely as participants, as objects of study, and not as the valuable sources and creators of knowledge we are.

My research design is meant to bring together all these arguments, arguments involving the unfair treatment of women in research, and arguments bringing to light the complex world of research and the intricate processes and relations therein. Thus, institutional ethnography (IE) as a theoretical and methodological framework unpacks this complexity for me, particularly Smith’s concept of “ruling apparatus” as a conceptual tool that explicate these ruling relations. It is at the intersections of IE and Black Feminist Thought that this project lies. In developing IE, Smith (1987) was prompted by the fact that academia, as a ruling apparatus that operates through texts 
and documents, is organized to exclude marginalized voices such as the voices of

"women and men of color, native peoples, and of homosexual men and women” (p107).

She defines this apparatus as

that familiar complex of management, of government administration, professionals, and intelligentsia that coordinate and interpenetrate it, as well as the textually mediated discourses that coordinate and organize particular places, persons and events into generalized and abstracted modes vested in categorical systems of, rules, laws, and conceptual practices (Smith 1987 108).

Though the project is a personal political journey, I add Black Feminist Thought as the foundational theory upon which themes of power and knowledge production for this project are based. Using the SISTA training manual, peer reviewed journal articles and combining IE's concept of the problematic, Black Feminist Thought's concept of intersectionality and content analysis, I provided a broader view of the culturally available knowledge about Black sexuality and thematically expose the conventional, mainstream methodologies responsible for arriving at this knowledge.

\section{Summary of mixed methods approach}

My work joins conversations among scholars interested in improving our tools for properly contextualizing health disparities. I recognize here that over the years, research on health, particularly research on gender and health, has been largely quantitative. Making the same argument Ghazal and Gorman’s (2010) posit that health studies stand to benefit from a mix of qualitative and quantitative methods because these methods allow for a broader discussion of hidden biases sometimes obscured by a single method.

Morgan (2010) studied researchers and documented the reasons given for making research choices to use one approach over another. He concluded that scholars 
decided on the best approach to research methods based on a need to resolve some uncertainty. He therefore urges researchers to critically evaluate these motivations for embarking on an integrated research project, as this would allow us to make proper connections between reasons for pursuing a mixed methods research approach and the designs that fit the purpose for the research.

In line with this argument, I purposefully elect to use mixed methods because of the methods' deductive and inductive qualities. Using these attributes in collaboration with Black Feminist Thought and Institutional Ethnography (IE), I explore the themes of power, knowledge, and oppression in my endeavor to understand the ways a wellmeaning program such as SISTA can inadvertently oppress the women it seeks to "empower".

\section{Institutional Ethnography and Development of Personal Standpoint}

In 2009, I attended a mapping session on institutional ethnography where I was honored with access to the expertise of Dr. Susan M. Turner and Dr. Dorothy E. Smith plus 16 graduate student participants from all over the world who helped workshop my thinking process and in 2010, I signed up to train as a SISTA facilitator where I received an updated version of the manual upon graduation (Appendix B). Following Smith's (1987) argument that the personal standpoint allows us to ask questions that have yet to be formulated, questions that can explicate the latent puzzles of how the everyday is tied up in "relations of ruling,” I developed themes from my dissertation project to determine how the "problematic of the everyday" is revealed through the SISTA manual and other materials as well as the viewpoints that were excluded. 
For Smith (1987), these excluded voices of men and women of color, working class people, and native Americans. Smith’s work provides invaluable starting point to examine the exclusion of marginalized people from decisions that impact their lives. In this health work, I examine the role of "class" in the ways state agencies such as the CDC organize and regulate society. I analyze the balance of power, how it intersects with gender and race in determining the ways state agencies and institutions determine the experiences of women, Black women in the context of SISTA.

In collaboration with Institutional Ethnography (IE), my research implemented Susan Turner's mapping techniques, which are based on and integral to institutional ethnography and the sociology of Dorothy Smith. In the simplest form of this technique, I mapped my process and experiences with SISTA, with academia and with community-based organizations. 


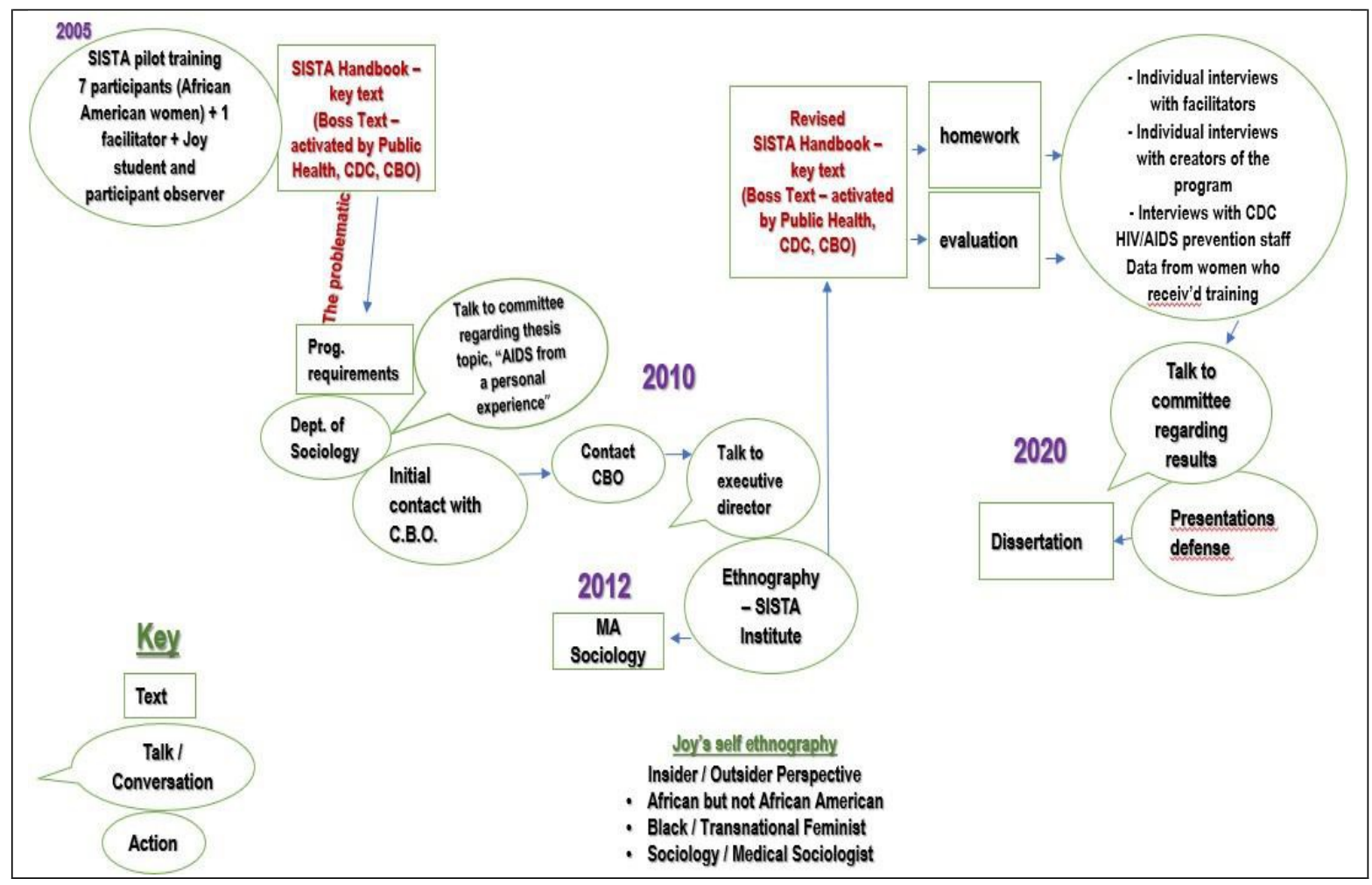

Figure 2. Joy’s Institutional Process

Mapping my process rested on the premise that mapping utilizes diagrams to illustrate how texts generate actions on the part of people who interact with them. Per Turner (2003), IE maps provide a way of viewing the connections between texts and the actions of people. Mapping is used as a way of understanding institutional practices through investigating texts responsible for governing the practices and actions carried out by people who are generated by these texts. Because actions in an institution usually lead to unanticipated, non-desired and sometimes detrimental consequences to a particular group who are interacting with that institution, IE maps serve as a visual aid to text in explaining the complex steps and show the internal organizing of how these institutional processes work. Therefore, for the researchers, IE maps clarify areas that 
may be missing in research, where problems are occurring, and can act as an aid in directing research in a more productive path for all involved and for all impacted. Turner (2003) situated her research and grounded her inquiry in her lack of knowledge of how city hall functions. I began mine by recognizing the questions and misgivings I had about the framing of the program when I participated in it. Further, Turner (2003), like other IE researchers, located her "problematic" and method of inquiry in activism which in turn became her ethnographic resource. I, too, came from AIDS activism. Starting therefore, from the premise that IE relies on data from interviewing, observation, and documents (Campbell 1998) and understanding that IE depends on finding the problematic and adopting a standpoint (Ng et al 2013), I designed the map of my intellectual process and my own standpoint to depict the relationship I entered into with academia and community-based organizations. My design was motivated by the desire to determine the extent to which the state mitigated these institutional experiences.

Participating in the training was because Toziwa had recognized my activist work and invited me. I discovered that through the program, my identities and social locations intersected to influence the ways I reacted to it. The critical lens through which I processed "what was happening” led me to seek more information on the forces behind socially organizing the events as they occurred as well as controlling our participation. My identities as a scholar, a Black woman, an African woman, activist intersected to inform the critical lens I used to question who created it, why the parameters set existed in the way they did and how / why the women on the ground such as myself were reacting to it in their various ways. 
For these reasons and because Smith discusses "the problematic of the everyday" as a conceptual tool at the disposal of researchers to inquire as to "the social relations in back of the everyday worlds in which people's experience is embedded” (1987), I thought it the best of the tools available to me to analyze the SISTA program. The problematic, as a conceptual tool, challenges standard "objective” ways of doing research by allowing us to grasp how these everyday worlds and activities are tied into and linked to dominant forms of social organizing. The "problematic," or the point of disjuncture for me, therefore, was the point where I questioned the consistency of what the CDC says about Black women and their risk and how Black women describe themselves and their actualities described in literature and also measured from the quantitative data obtained from Wisconsin. Per Smith (1987) and Turner (2003), local and visible forms of work, such as training programs at shelters, sometimes obscure extra-local relations that are rarely entirely visible to people going about routine activities.

In my interviews, I was looking for that insight into themes of ruling relations in these routine activities as well as controlling images contained in language meant to help Black women. In my first experiences with SISTA, I knew right away that I had apprehensions about the language contained in it and this realization colored my scholarly lens. Therefore, while I became more uneasy with the activities, and the theoretical framework upon which it was based, I became motivated to use more of the tools I acquired to make sense of my own discomfort. Initially, I was furious, I could not understand why Toziwa would stand behind a program such as this one that stereotypes and pathologizes the behaviors of Black folks. Like Turner (2003), I too, 
began with this as an insider standpoint rooted in political activism. Turner argues that in order for relations of ruling to change, they must first be identified and the taken for granted generally accepted knowledges critically analyzed. As I participated in SISTA, I concluded that I was participating in a text mediated extra local relationship with academia and the CDC. It is these concerted sequences or courses of action laid out in the SISTA manual and the actors involved in the creation of knowledge surround Black women's health that I explore.

In this study, facilitators are aware that SISTA activities are coordinated with their affiliated community-based organization and CDC assessments and evaluations yet may not be intimately familiar with the extent to which ideas about 'culturally relevant' programs are mediated by Public Health Services and rooted in complex and intricate historical understandings of risky behavior among African Americans. Because these differing understandings can lead to frustration, and sometimes resistance, I entered the study with Smith's argument that relations of ruling, usually embedded in boss texts, may be responsible for this. Smith and Turner (2014) discuss “boss texts” as those governing texts and documents that become understood as “institutional mandate.” In the context of SISTA, a program meant to prevent HIV/AIDS among Black women, I problematize the framing of Black men and women in these texts as well as the defunding of SISTA and subsequent removal of the program for the CDCs Compendium of Evidence-Based Interventions and Best Practices for HIV Prevention.

Besides my overall research question, I examined the handbook and how it served as standardized regulation for the HIV prevention. Other questions were, how 
was the subject of research constructed? How was the training content decided upon? How was it vetted and what aspects of it were taken up elsewhere? Who gets trained? What is in the training handbook? What are the key points the handbook seeks to address? What are the priorities expressed in the handbook? What and who is missing from the handbook? Where is it from? Whose concerns are represented? Who decides on the information? The content? How is it vetted?

Rankin (2017) says for an IE researcher the collection of data, analysis, and “writing up" are not distinct phases of an IE project. However, for purposes of simplifying and organizing my work, I add Elo and Kyngäs' (2008) data analysis process. Elo and Kyngäs argue that regardless of whether the researcher is utilizing content analysis deductively or inductively, these three stages can be useful for a researcher and it is these that I implemented in order to make sense of my inductive content analysis. 


\begin{tabular}{|c|c|c|}
\hline Stage & Description & Materials \\
\hline Preparation & $\begin{array}{l}\text { Collection of Data } \\
\text { implemented in four stages: } \\
\text { Stage I- } \\
\text { Participant Observation } \\
\text { 2006SISTA participant } \\
\text { training - } \\
2010 \text { - SISTA } \\
\text { participant observation } \\
2013 \text { - SISTA facilitator } \\
\text { training } \\
\text { Stage II - } \\
\text { Content Analysis } \\
\text { Continuous since } 2006 \\
\text { Stage II - } \\
\text { 2018 - Quantitative Data } \\
\text { Acquisition } \\
\text { Stage IV - } \\
\text { 2019, } 2020 \text { - interviews }\end{array}$ & $\begin{array}{l}\text { Data collected from: } \\
\text { a) SISTA training implementation manual } \\
\text { b) journal articles and supplemental training } \\
\text { materials on SISTA } \\
\text { c) } 2017 \text { participants from a } 2016 \text { study by } \\
\text { the } \\
\text { Medical college of Wisconsin's department } \\
\text { of Psychiatry and Behavioral Medicine. } \\
\text { d) Interviews with } \\
\text { (i) Creators of SISTA } \\
\text { (ii) CDC Researchers and Scholars } \\
\text { (iii) Community Based Program } \\
\text { (iv) Capacity Builder } \\
\text { (v) Community Based Facilitators }\end{array}$ \\
\hline Key I & \multicolumn{2}{|c|}{$\begin{array}{l}\text { Interviews - Unacknowledged class privilege acts as a mechanism though } \\
\text { which controlling images prevail, even in the face of opposing discourse such } \\
\text { as Black Feminist Thought. } \\
\text { Black women reported feeling abandoned the defunding of SISTA because } \\
\text { they have been left without the extra resource for protection they have had. } \\
\text { Content Analysis - The multi dimensionality of Black Folks' sexual behavior } \\
\text { is ignored by Theory of Gender and Power as well as by Public Health } \\
\text { modules that rely on oversimplified theoretical approaches to sexual behavior }\end{array}$} \\
\hline Org & \multicolumn{2}{|c|}{$\begin{array}{l}\text { Project was organized as an IE project with Black Feminist Thought as a } \\
\text { guiding conceptual framework. Further, though I did not design the project as } \\
\text { an } \\
\text { auto ethnography, the "personal is political” tone of the work makes the } \\
\text { organization of it more fluid than traditional mixed methods projects. }\end{array}$} \\
\hline Reporting & \multicolumn{2}{|c|}{$\begin{array}{l}\text { While work has been devoted to studying overt forms of racist practices that } \\
\text { have oppressed and violated Black folks, current Public Health initiatives } \\
\text { present opportunity to examine the subtle racist practices responsible for } \\
\text { unequal health outcomes. } \\
\text { Ignoring the complexities of the lives of Black folks, ignoring colonialism } \\
\text { racism, and genocide makes scholars complicit in reproducing the-ism we see } \\
\text { to dismantle. }\end{array}$} \\
\hline
\end{tabular}

Table 1. Summary of mixed methods approach 
a.) Preparation - this stage constitutes the bulk of my data collection phase. To begin, I did not recognize it then, but do so now that the preparation stage was initiated by the fact that I had participated in the SISTA training three times. It was in the first training where I became interested in examining the ongoing complex relationship between Black folks and Public Health. Black Feminist Thought became the obvious theoretical framework for me to ground my work in. Because I had been taught to be objective as a researcher, the next stage of preparation was to identify a framework that would account for and treat my experiences as data.

For this, I elected to ground my work in IE as a feminist methodology that respects my standpoint as data. With my standpoint established, I identified the SISTA implementation manual as a conduit through which controlling images were transmitted. In the manual were theoretical frameworks responsible for SISTA, thus, I prepared to analyze literature on the history of the origins of SISTA through journal articles and CDC website.

Schlobohm (2016) conducted a similar critical analysis of SISTA. Following this work, I prepared a categorization matrix similar to Schlobohm's (2016) presented in table 2. below to help me account for the ways controlling images are transmitted through the SISTA implementation manual. When Schlobohm (2016) conducted a close reading of the SISTA facilitators implementation manual, she identified what she terms as “Black tropes”. I prepared data collected via analysis of manual similarly. 


\begin{tabular}{|c|c|c|}
\hline \multirow{2}{*}{$\begin{array}{l}\text { Tropes - } \\
\text { Schlobohm (2016) }\end{array}$} & African culture & Problem \\
\hline & $\begin{array}{l}\text { If Black women can connect } \\
\text { with their African roots, they } \\
\text { will increase their pride and } \\
\text { sense of self efficacy }\end{array}$ & $\begin{array}{l}\text { Homogenization of the African } \\
\text { continent } \\
\text { Assumed connection of African } \\
\text { American women to Africa. }\end{array}$ \\
\hline & Black men as threatening & Legitimates oppression \\
\hline & $\begin{array}{l}\text { Poetry - Nikki Giovanni and } \\
\text { Maya Angelou }\end{array}$ & $\begin{array}{l}\text {-African narrators finds strength in } \\
\text { Africa but references Africa of } 2000 \\
\text { years ago }\end{array}$ \\
\hline & “Strong Black woman" & $\begin{array}{l}\text { While Black women are seen as being } \\
\text { in crisis, they need knowledge to return } \\
\text { to their strong status. This promotes a } \\
\text { neoliberal agenda of self-management" }\end{array}$ \\
\hline & Concepts of Black pathology & $\begin{array}{l}\text { "Status of Black Folks caused by the } \\
\text { disintegration of Black communities } \\
\text { and family structure.” }\end{array}$ \\
\hline
\end{tabular}

Table 2. Schlobohm examples of "Black tropes” (2016)

In preparing my data, I planned to use a close reading method as well, as opposed to other techniques such as first reading because the close reading goes beyond figuring out what the text says (Shanahan 2012). A close reading is concerned with challenging the text to give up its hidden meanings and allows me, the researcher, to make broad connections and assertions in an attempt to interpret the "written artifacts of society” by using particular evidence from text (Beach et al 2009). Per Schur 1998, conducting content analysis in this microscopic and macrocosmic way helps the user of 
this method to avoid linear readings to seek for more beyond what meets the eye. This literature review allowed me to prepare the themes to conceptualize and discuss IE's central concern: "the problematic."

b) Organization - this stage was a challenging stage as it involved organizing data from my three contacts with SISTA in 2005, 2010 and 2013. Organization was, however, simplified by keeping in mind that IE examines the ways work processes are coordinated through texts and documents, and also by keeping in mind that IE begins with the embodied and lived experience of the teller, I organized my data by beginning with my point of rapture with the SISTA training texts and documents. As mentioned earlier, Smith discusses rapture or disjuncture as that point where a scholar starts to question the dominant discourse and recognize the extralocal modes of ruling that organize our daily lives.

I regarded the SISTA implementation manual as representing that extralocal mode of ruling. Therefore, at the end of the SISTA training, I asked Toziwa if I could keep the training manual. Though I realized at that point that I wanted to spend more time analyzing the manual for content, I was not consciously aware that I had in fact entered an IE world, nor was I aware that I had entered an institutional world governed by academia, by the SISTA Institute, the CDC, and the state. However, the ways the manual controlled our interactions caught my attention and motivated me to receive the same training Toziwa had in order to get closer to the beginning of how knowledge about Black women's vulnerability to HIV/AIDS was constructed, distributed, and maintained. Further, I was attracted to the manual because, though Toziwa was willing 
to give me the manual at the end of the training, her protectiveness of it made it clear that we were not allowed access to it during the training.

Retrospectively identifying my point of entry, therefore, became central to organizing my data. Like all IE projects, I built this study on the premise and recognition that my first contact with the SISTA project had presented an entry point and opportunity to explicate the role of academia in creating scholarships surrounding HIV/AIDS and the implications of such research on the lives of Black folks. Due to attending three training, collecting journal articles and other supplemental materials from the CDC, I found myself inundated with text and documents and weeding through these to code for the most relevant data to my research has been challenging, overwhelming, and even emotional; challenging because of the sheer difference in volume between the 2005 manual and its 2008 revised version (Appendix B), overwhelming because it is hard to decide what to use and what to omit and emotional because, though I do not identify as African American, I identify with the politics of oppression, with the experience of Blackness and with the experiences of colonial violence. As a critical scholar armed with the lens of Black Feminist Thought, my antennae detected the racist undertones of public health, yet my sociological training was telling me to remain objective, hence my appreciation of an IE lens.

Further, scholars such as G.W. Smith (1990) helped me organize this project as a political ethnography. Also doing AIDS work, G.W. Smith is credited for reframing the ways in which AIDS was problematized and confronted the stigmatization by electing to talk and write about AIDS from the standpoint of the people living with AIDS (PLWAs). This work pioneered the ways scholars can start to rethink their work 
as more than just academic work but work that seriously confronted the social, biomedical, and institutional barriers to living with HIV/AIDS. This work, in addition to work coming out of counselling psychology encouraging practitioners to embrace a social justice-oriented framework, helped in organizing my thoughts and giving me permission to be well invested in centering my critique.

It is liberating and encouraging to engage with G.W. Smith’s work and to see fields like counselling psychology emerge as a push against traditional psychology which has been described as historically ethnocentric. Counseling psychology argues that psychologists can no longer ignore that disadvantaged or marginalized groups need a change in social structures and also need an increased access to resources and tools for self-determination to attain better health outcomes. Further, counseling psychology stands a field that identifies itself and its practitioners as social justice-oriented (Goodman, Liang, Helms, Latta, Sparks, Weintraub 2004).

Organizing this work also involved acknowledging Goodman et al’s (2004) argument that while scholarship is increasingly becoming social justice oriented, there has not been a clear concept of what a "social justice” project looks like. Goodman et al's (2004) posit that one strategy used by critical scholars in pursuing social justiceoriented work is to revisit academic work that reproduces stereotypes. My work follows this recommendation and is organized around exploring what stereotypes and controlling images exist in a well-meaning program like SISTA. Therefore, in addition to examining the SISTA training manual for content, I conducted interviews with 15 individuals; all scholar scholars and community-based organizations in order to 
contextualize the theme of controlling images. The hope is to uncover how these images are maintained and passed on throughout time.

Because SISTA had been defunded by the time I began data collection, I could not interview the SISTA participants in order to get their views on how SISTA, as an extralocal program, controlled and managed the lives of Black folks. As mentioned earlier, in the absence of contact information and firsthand interviews from women whom I undertook the program with, I was privy to have as a valuable resource, access to the quantitative data set provided by the Medical College of Wisconsin Department of Psychiatry and Behavioral Medicine. They collected survey data from 2071 women acquiring services at four agencies AIDS Service Organizations or Community Based Organizations that provided both SISTA and other referral services in Tennessee, Texas, Missouri, and New Jersey. These agencies provided participants for the study and I use the descriptive data to add the voices of the women who received the SISTA training regarding their attitudes towards condom use. Though I had collected this data set before the interviews, I did not analyze the data until after I conducted my interviews. My goal was to hear from those involved in the institutional process before I heard from the women who participated in the training. In retrospect, had I analyzed the data base before the interviews, the data collected may have been useful in the design of the interviews. However, I did have perspective of the participants I had encountered during my own training. It is through their voices that I designed the interviews. In that regard, the dataset was the last to be analyzed. My approach was inductive as my goal was to identify themes I may have missed along my research journey. With this data set, I hope to answer the research question addressing the extent 
to which the constructions of Black women presented by SISTA were accepted or rejected by African American women themselves.

c.) Reporting - this stage comprised data analysis and discussion. One of the biggest attractions of IE is the fact that it releases the researcher from the trappings of traditional social research studies which require objectivity and allows IE researcher is to report "what happened” from their standpoint (Rankin 2017). Though Rankin points to other work that does not use standpoint, such as that of G.W. Smith (1990), to say it is not necessary for every IE project to have standpoint, she contends that IE gives permission to those us who want to center our particular empirical locations as tools for critical scholarship and activism. For Ranking (2017) the IE researcher acts as an activist when their analytic stance is motivated by a desire for social change. This is to say, when IE researchers collect evidence it is mostly to build an account of how resources are distributed, how things in the world are continually being socially organized for particular people, especially the oppressed. My purpose is to add to an understudied area of how well-meaning programs like SISTA represent the disjuncture between helping underserved folk and inadvertently advancing a colorblind racist ideology. Ignoring the reality of this leads to continued unequal health outcomes for historically marginalized populations.

It is from this standpoint therefore, that I present and report my experiences with SISTA. I noted my initial response to the glowing ways Toziwa talked about her role as a facilitator, the role of SISTA in changing the lives of Black women, the role of the Black women who had created the program, and the role of the CDC gave me pause to imagine how her work was both useful on the one hand and presenting a problematic to 
be analyzed. I noted that each day she came to the presentation, each time she delivered the presentation, and in turn, each time she managed our day she revealed the ways we were all linked and connected to an institutional process which I reveal in this paper. I am using an IE lens in this mixed methods project with the analytic goal of finding and describing the ruling relations and how these extend beyond me and the study informants.

Content Analysis: Smith (1987) argues that data is often in a state of perpetual decay for a social scientist and that sometimes we ought to rely on historical records for the constructions of meaning. In light of this argument, I offer that the SISTA training manual and other accompanying documents served as valuable forms of historical data to study those processes and mechanisms deemed as responsible for the creation and perpetuation of particular knowledges surrounding Black women’s susceptibility to HIV/AIDS. What SISTA means to me as a student, a Black woman and a researcher is embroiled in the politics of race, gender, class, and sexuality in the United States and I hope SISTA as a program and its accompanying documents help me explicate this.

I conducted a thematic analysis of 2 SISTA training manuals I acquired in 2006 and 2010. The title of the 2006 manual was The SISTA Project: A Peer-Led Program to Prevent HIV Infection Among African American Young Adult Women and the title for the second manual was SISTA Implementation Manual (See Appendix). I proceed to conduct analysis on these two version of the manual to obtain a general overview of the significant changes to the content as well as the language employed in these manuals as it relates to Black women's sexual behaviour. 
Interviews: Inductively, therefore, I conducted interviews to gain more insight to the aspects of SISTA I may have missed from the creators, the CDC and the CBOs who disseminated the program. I conducted 15 interviews with CDC Researchers, and SISTA Facilitators and SISTA creators.

\section{Detailed research method}

Consistent with Nader (1972) this study is characteristic of research labeled as "studying up.” This is the concept where researchers seek to understand of processes where power and responsibility are exercised in the United States. Recognizing this phenomenon of studying up (Nader 1972) led me to a better understanding of why I collected interview data last. For example, Emerson et al (2011) say, a "white, middle class researcher” concerned with intersecting inequality is better equipped to study up and go "behind the scenes" and gain understanding from the elite. While it stands to reason that I would collect the interview data last to allow the content analysis and data analysis to inform the questions I asked, I also took time to schedule interviews because of a sheer sense of intimidation and lack of confidence in whether I was indeed qualified to ask the questions I had formulated during my experiences with the SISTA training.

Fear of rejection was one of those driving factors and Gusterson H. (1997) describes the instances he and his team had to deal with this rejection from their elite subjects. Quite on the contrary, only one community-based organization refused to participate in this study. On the whole, therefore, I did not have difficulty gaining access to the elite nor did I find my participants insular. The positive response I received proved instrumental in my overcoming the "impostor syndrome." This is a 
term coined by Clance and Imes based findings from a study on high achieving women. Clance and Imes discovered and reported that regardless how successful these women became in life, their backgrounds contributed to their sense of intellectual phoniness.

I felt as though I was way out of my depth doing this work because I was collecting qualitative data from scholars and researchers directly responsible for the creation of SISTA from its inception to its dissemination and removal from the compendium. Additionally, I was collecting data from scholars who have studied SISTA, written about the program and have helped implement and evaluate it as well as from community-based organizations (CBOs). The community-based organizations were located mostly on the east coast. I eventually overcame my feelings of inferiority and was pleasantly surprised by how accessible respondents were to me. I had a tougher time gaining access to facilitators and I attribute that to the hands-on nature of the work they do as they work closely with their clients and are less likely to be in the office or less likely to be administrative.

Questions asked in the in-depth interviews I conducted were concerned with understanding the process that led to the creation and dissemination of SISTA. These interviews were designed in a mixed methods approach within an institutional ethnography frame to explain "what happened". IE is an accessible mode of inquiry I used to conceptualize questions regarding the ways colorblind racism becomes transmitted through texts and documents such as the manual and journal articles outlining the theoretical framework upon which SISTA was based (Smith 1987). My questions included lessons learnt from the SISTA creation and dissemination and what the scholars and facilitators think could have been done differently. By asking this 
question, I intended to investigate whether those involved in creating SISTA could indeed retrospectively critic the unfortunate, unintended, and dangerous stereotyping of Black folks that resulted from the ways some of the role-playing vignettes were framed. Additional questions also sought to understand why Black Feminist Thought as a theoretic framework was excluded from a program aimed at addressing the needs of Black women in preference of an imported theory of gender and power.

The sample was a sample of CDC staffers who both worked on the early stages of dissemination of the program as well as the evaluation of it. These staffers were identified through the training manual and from published SISTA program evaluation peer reviewed journal articles. Snowball sampling was utilized to recruit the participants shown in Table 4. Having met Chenzira, my Hispanic respondent in 2013, I had remained in contact with her throughout the years. When time came for me to conduct interviews, I asked her to introduce me to other women whom she knew as facilitators. Through her contact, I was able to interview her supervisor, Mlambo, a white female identifying respondent who relocated to New York from California. Though this study is a convenience sample of CDC staff members, creators of the program and facilitators, they were all instrumental in providing data for this project. Of the 15 respondents interviewed, four were not particularly concerned with confidentiality but the rest filled out the necessary confidentiality agreements. For this reason, and with the exception of Dr. Wingood, to the best of my ability, I will treat every interview with confidentiality by using pseudonyms so as to protect those of my respondents who wanted to maintain confidentiality. 


\section{Content Analysis - SISTA Training Manual}

Content analysis has been used in a variety of studies to reveal and examine a myriad of social phenomena. Initially, content analysis was used quantitatively when researchers counted the presence of any phenomena under study (Beach et al. 2009). Whether the researcher is using content analysis qualitatively or quantitatively, or whether they are using one of the subfields such as discourse analysis, thematic analysis or narrative analysis, Beach et al (2009) say what makes content analysis a critical process is the framework used. Here, they mean that scholars are more interested using this method to "think within, through, and beyond the text" (Beach et al 2009). To this end, newspaper articles have been analyzed for their ability to reveal gender bias in sports reporting (Pendeson 2002), television news has been analyzed for content that demonstrates controlling images of welfare mother in mainstream news media (Kelly 2020) and children's book reviews have been analyzed for content by librarians to determine the suitability of particular books for various library collections (Bishop and Van Orden 1998).

I use Black Feminist Thought and Institutional Ethnography frameworks to conduct a content analysis examination of the training manual, that is, 1.) the 2006 training manual and 2.) the revised and updated 2008 version, as entry point to answer the questions regarding the presence of controlling images about Black women in a program like SISTA which is meant to serve us. Follow up research question considered by this analysis is how the concept of intersectionality can help determine the ways programs such as this oversimplify the complex experiences of Black women. 
McCoy (2006) says that institutional ethnography is meant to keep the institution in focus and is interested in bringing attention towards embodied individuals and institutional relations with the SISTA training manuals, I intend to examine the women embodied as facilitators and the participants determine whether I can pick up traces of controlling images inherent in the ways the state has conducted itself when referencing the behaviors of the Black population. McCoy (2006) suggests that the ways people participate in the discourse differs but because language is universal, it is the key constituent in how institutional discourse is transmitted. Institutional discourse is defined as those authoritative ways of knowing (measuring, naming, and describing) phenomena that become actionable (McCoy 2006).

Historically, Black women have bemoaned abundance of work that speaks about them. Through Black Feminist Thought, Black women have articulated the need to be spoken with and not about. My project builds on that of Schlobohm (2016) to examine the continuing denial of Black women's subjectivity through a program like SISTA. Schlobohm thoroughly examines 2008 manual from cover to cover to "trace SISTA's redeployment of some already-existing tropes of blackness and neo-liberal subjectivity” (2016 iii). She argues that the “intervention’s attempts to help black women avoid contracting HIV/AIDS are unfortunately complicit in regimes of antiblack oppression”.

Though Schlobohm does not call her method "content analysis," she does indeed perform a cover to cover micro and macro level content analysis of the SISTA 2008 training manuals to show how these texts circulate already existing "tropes of Blackness.” Schlobohm problematizes SISTA for attempting to "help black women 
become strong, empowered subjects of neo-liberalism.” She adds that in so doing, SISTA

reinvigorates centuries-old logics in the United States whereby the racist expulsion of black Americans from structures of state support is authorized by narratives of black irresponsibility and inadequate self-management (2016 iii-iv)

My work is performing several different tasks. First, it employs Black Feminist Thought as a theoretical framework to code for and center what Patricia Hill Collins calls “controlling images”. Schlobohm (2016) uses the term "black tropes” to explore the same concepts and her analysis is wider ranging than my use of Hill Collins here (see Table 9).

Secondly, using IE, my work thus explores what Smith (1987) terms "ruling relations" to reveal how women become subject to these relations as well as how these ruling relations translate to "controlling images.” Though controlling images have indeed evolved over the years, the content analysis presented here will explicate the ways the images persist still and have significant influence over the lives of everyday Black women.

\section{The Insider Standpoint: Experiencing and Embodied Subject}

While I am using mixed data, I still want to underscore IE, the "sociology for women,” as a lens that is useful in giving me permission to depart from conventional research methods. By calling IE a “sociology for women,” Smith’s work on ruling relations and the social organization of knowledge focuses on what she calls gender subtext of social relations. Therefore, when Smith says that IE is a "sociology for women," she is not claiming that it is a sociology exclusively for women. She is saying, instead, that IE is a form of inquiry into society from the standpoint of women situated 
outside of, rather than inside, relations of ruling (1987 46). Further, by using this method, Smith claims its superiority over conventional and popular Marxian and Foucauldian sociological theories of power as these were not robust in their analysis of how power is experienced along gender lines.

My work incorporates both the gender and racial subtext to this analysis, first by acknowledging my dual privileged / oppressed Black woman standpoint, privileged only by being a part of an institution of higher learning. From this vantage point, I got a bird's eye view into how SISTA was socially and institutionally organized through the women participating in it with me in 2005, 2010 and 2013. Therefore, while there is merit to acknowledging the micro/macro level forces responsible for the proliferation of HIV/AIDS such as volatile gender related situations, this phenomenon is not unique to Black women and is hardly directly causal to HIV/AIDS though it indeed is correlational factor.

\section{Point of entry}

Though I did not design this as an auto ethnography, my project certainly fits the model of one. Raymaker (2017) would peg my experiences as an “insiderresearcher' and I use this position to bring into view my experiential data and its implications to the study ruling relations. As previously mentioned, I entered the SISTA training in February of 2006 when a friend, Toziwa, a Prevention Specialist at a local HIV/AIDS agency whose work focused on serving historically marginalized populations, invited me to be a part of the first training. When I agreed to participate in the training and offered for the women to meet and train at my residence, I did not 
realize it then but do so now, that I also had entered into the world of the CDC which controlled every aspect of the training taking place in my living room.

Toziwa arrived at my house bearing paperwork, training materials such as condom demonstration items, charts, pens, paper to write on and movies. These would be my units of analysis for part of my observations, particularly the plain white instructional manual (Appendix B). This is manual is significant because though we were all excited to share this moment to learn how to make significant changes to our daily lives and make healthy choices, it became more obvious that we were institutionally bounded to follow the manual. My scholarship interest was piqued as we began to follow the manual stipulations and as I began to notice the moments of departures from these stipulations. For example, though the program was supposed to authoritatively run for two hours over five weeks per CDC specification, all the women in my 2006 training agreed to take one Saturday out of the month, and train for ten straight hours from $8 \mathrm{am}-6 \mathrm{pm}$, and as mentioned earlier, the training was conducted in the living room of my one-bedroom apartment.

While I have some notes from these meetings, I note here that because parts of this analysis are retrospective, they may suffer from the fallibility of memory (Brodsky 1993 238). Nonetheless, the training, the manual, and peer reviewed journal articles are useful in explicating the ways the machine that is the healthcare system works and the impact it has on the women who participate in it. The manual and peer reviewed journals are also vital in revealing the role of academia in creating and sustaining the discourse in charge of controlling the work of women. I provide this entry point because it is most relevant to the analysis of the ways the SISTA training manual 
managed to merge my identities together and launched me from a student to a critical scholar of power and how it functions through these state initiatives.

At this her first training, Toziwa expressed that she was interested in both providing us with this new tool she believed every African American woman must possess and practicing the training before she rolled it out to the community. Toziwa reiterated and emphasized that a program such as this was vital for the community because it empowered Black women. Further, Toziwa expressed that the training had to be run exactly as specified by this text she brought with her (Appendix B). When I asked her to explain, she replied that this was because if any problems did indeed arise during the training, she could be sure she had been adequately trained to attend to them.

When I finally got into the text myself, I did not see this specific stipulation. However, a further search of the internet brought me to the SISTA Institute, where the training of facilitators was coordinated by the CDC. The instructions from the SISTA Institute indeed discouraged deviation from the program's core elements. These core elements were not printed in the original manual but were in the materials known as the “technical assistance materials” from the SISTA training institute and were indeed changed by the time the 2008 manual was printed:

SISTA has several core elements. As defined, core elements are the fundamental features of an intervention's intent and design that are thought to be responsible for the intervention's effectiveness.

\section{SISTA core elements}

These components should be maintained and implemented to ensure program effectiveness and fidelity to the intervention.

Suffices to say, therefore, that I paid close attention to the manual, what it stipulated and how Toziwa deviated when she needed to and how she adhered it when necessary. When Toziwa began by emphasizing that this was a program for African 
American women, by African American women, she was saying so partly because she was unquestionably proud of the progress African American women had made in entering positions where they could help other African American women. However, she was also saying this because the manual told her to, see excerpt below

To encourage participation, SISTA should be publicized as a program for African American women developed by African American women. SISTA marketing

The SISTA training manual became the guiding document for our contact that day. A large portion of what Toziwa said, from the above-mentioned involvement of African American women in the creation of SISTA to the facts and figures about HIV prevalence in the African American community, were prescribed by the manual and connected to what was known as the SISTA training institute. While I was uneasy about my presence among "my sisters” most of my initial experience at this introductory phase were positive. I had respect for Toziwa in her position, I was happy to be in a room with other Black women and I was proud to be a part of this process of informing one another on ways to strengthen our communities.

Given the power I perceived the manual to have, I chose to extend my knowledge of how the SISTA manual worked. I learnt that for one to enter the institute and be trained as a facilitator, one had to be affiliated with a CBO. Through my activism and yearly participation in the CBO's annual AIDS walk fundraiser, I was able to obtain sponsorship to attend through them. I was therefore accepted into the training which occurred in New York City in 2010. During this training I came to understand Toziwa's standpoint and how “core elements” guided the ways the training manual was to be disseminated. 
CHAPTER SIX

ANALYSIS

\section{Relations of Ruling}

The work of this dissertation was to place my experiences, the experiences of

African American women and the experiences of all who were involved with any aspect of SISTA within an IE framing. IE makes specific arguments highlighted earlier and repeated here to connect them to the data collected. To begin, a I identified my "problematic”, that is, those narrative I discussed earlier that revealed the ways I processed conflicts arising from the authorized knowledge of and my experiential knowledge as a Black woman. Per IE, as I engaged with the social world, I was in effect caught up in and was participating in relations put coordinated by invisible institutions.

I was now engaged in the social relations with other Black women and with the economy of ruling institutions in ways begged inquiry (Rankin 2017). Per Rankin (2017) the inquiry is guided by the need to know "what is happening?” The activities or what was happening was/is coordinated by and occurred through texts such as books, forms, computer fields, and many other "textual artifacts" (films, audio recordings, tickets, etc.). My job was to reveal how the activities are then replicated and circulated across time and location and the implications for Black folks (Rankin 2017 2).

Thus, through IE I sought to empirically study these ruling relations, this authorized knowledge and use its methodological and theoretical framing here to investigate 1) the ways our lives were coordinated, and 2) the mechanism through which stereotypical ideas about Black lives are circulated across time and the reactions 
of everyday people who come into contact with the program, including myself. My experience of participating in SISTA were part of the story and part of the data.

The other significant part was my observation of Toziwa as she interacted and engaged with the facilitator's manual, a document she did not create. This helps in my use of IE to understand the extent to which women are active participants in creating the discourse that guides SISTA. The fact that she did not help create SISTA but had to engage with it, makes SISTA and the creation of it a representation of what Smith (1987) calls an extralocal, impersonal, universalized form of action that is knitted together institutionally without the participation of the women for which it was intended. Thus, the work Toziwa was doing, educating women to use condoms, was that sexual division of labour that entered her and I into relations we were not fully present in creating. Using the gender, racial and class subtext, I am interested in untangling how academia, as a ruling apparatus, rules the work produced by women and how academia participates in the perpetuation of the tradition of keeping women as outsiders in creating discourses that impacts their daily lives as well as understand how active women are as participants and as subject of creating that discourse.

The impact of relations of ruling on Toziwa was also evident in the ways Toziwa was invested in strictly adhering to the manual. I concluded that this was because the manual stipulated that the success of the program would be determined by the facilitator.

-Facilitator savvy: The successful implementation of the SISTA Project intervention weighs heavily on the skills of the facilitator.

\section{Relations of ruling on facilitator}


I also concluded that this lofty expectation added pressure on the part of the facilitator to be successful in addition to the astronomical cost of $\$ 72000$ to run a training for 10-12 women. It stands to reason therefore that having the program's success dependent on her must have posed tremendous pressure on the shoulders of Toziwa. Also, as mentioned earlier, Tendai, Toziwa's boss attended the training in her capacity as a Black woman interested in gaining and benefitting from the attributes the program offered Black women. Be that as it may, the power dynamic implied by her presence is unmistakable and may have contributed to Toziwa feeling the need to make it known to all of us that she was indeed following the manual as ordered.

These facts inspired a two-fold response from me that contradicted some of what I had learned through my understanding of Black Feminist Thought. First, Black women have historically been aware of our oppression, have been fighting inequality since we arrived on the shores of this country despite facing persistent intersecting forces impeding their progress. This meant for me, that the desire for Black women has been more for self-determination than empowerment. This colored my view of SISTA to some extent. I needed to hear that the program would enhance what we have, rather than teach us something new. Secondly, I also became mindful of the control the manual had over our daily lives and in some small measure, Toziwa exhibited acts of resistance, for example the deviation of allowing us to do this training in one day rather than five weeks and by inviting me, an African woman, to a program meant only for African American women.

Before she began the training, Toziwa asked the women to make community agreements. She added that this meeting was to be conducted as a "kitchen table." She 
referenced the "kitchen table" as an African American tradition to talk about all important issues in the kitchen. She proceeded to ask all of us to create community agreements which we would refer to in order to conduct the meeting in an amicable manner. I believe I offered my home to be gracious but in retrospect, I believe I did this also to belong and to ingratiate myself to the women. This was because I felt as though I was reaping the rewards of a resource that was not meant for me and continued to wonder about my being invited into this program when Toziwa knew I am not an African American. The idea of the "kitchen table" as an African American tradition was a tradition I could not relate to. Also, I believed that in the US, the kitchen is the room most families like to talk. Therefore, I began to question the essentialist ideas surrounding culture and the notions of sisterhood.

Further, from my vantage point, I noticed that the general outlook of the women did not exhibit much of an open critique SISTA in the same way I did and did not question the role of the state in creating these problematic generalizations about culture and about sisterhood.

\section{Assumptions of Sisterhood}

Once we began engaging with the content my observations extended to the ways the manual guided Toziwa's facilitation as well as how she managed the conflicts that arose. One conflict was that the title of the manual was The SISTA Project: A Peer-Led Program to Prevent HIV Infection Among African American Young Adult Women. For a moment, I indeed felt like a peer, given that the other women in the room undergoing the training with me on the day I took the study were same age as I was and that they also were activists and community leaders. The Black women present, including 
Toziwa, were Tendai, Toziwa's supervisor who, in addition to being an HIV/AIDS prevention specialist and SISTA facilitator, also worked as a contract manager and project monitor for the CBO. Her job was to acquire grants and she had acquired the grant for this CBO to implement SISTA. She was not at the SISTA training in her capacity as monitor though. She said it was for her own development as a Black woman. Tapiwa was a street outreach coordinator for the CBO, Tadiwa as a domestic violence case worker for a local domestic violence shelter, Chido was a trained teacher and health educator, Tafara an associate director for a local religious sect and health educator and finally me, graduate student and activist involved with volunteer work at the CBO.

I engaged with the conceptual tool of the problematic to analyze the disjuncture I felt an African woman. The politics of identity raged in me because I thought I was an imposter reaping the benefits of a program not meant for me. Further, as much as Toziwa was indeed a peer, the fact that she had control of the manual and that there were parts of it we were not allowed to have access to form what I saw as a hierarchy. This was evident in the fact that she was following instructions from the CDC and was made custodian for information we were not empowered or privy to have. Further, the notion of "peer education" also appears to fall away when I looked at the introduction to the manual and the instructions to be followed. Example of "them" and "us" dichotomy contained in the "peer program" The language contained in the introduction and indeed echoed throughout the manual, which was exclusively in the hands of the facilitator, speaks of African American women participants as "they." This indicates to 
me that the facilitator was not considered a part of this group, thus contradicting the concept of peer, creating instead them and us ideology and dichotomy (hooks 1984).

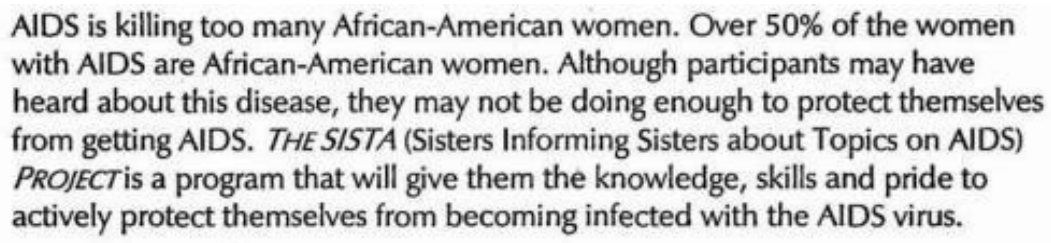

This notion of sisterhood and the notion of peer training was challenged and the process of ruling became evident in the ways Toziwa was protective of some of the texts and documents in her possession and would not allow us to have access to the training materials. Granted it is a "peer-led" initiative, meaning there had to be one sister transferring skills from one sister to another sister.

bell hooks points to the ways class bias remains obscured in feminist work. While bell hooks is speaking mostly about white feminists, her work is relevant because the ideology of “common oppression” and sisterhood is used in SISTA. bell hooks speaks to a revolutionary feminism where participants envision radical work that recognizes and critiques and exclusionary practices within the work we perform.

\section{Controlling images}

The above section is meant to lay the groundwork for answering the research questions. One of the main research questions under review is, what controlling images about Black women are present in a program like SISTA which is meant to serve them? We have discussed how these images have evolved over time yet are still present. This section takes a deeper look into the manual, interviews, and journal articles to explore this question. The section is also guided by Hunzaker and Valentino (2019) whose work has been devoted to understanding cultural schemas and how they help scholars to 
better understand the ways culture influences "individual beliefs, preference and actions” (2019 976). Hunzaker and Valentino’s (2019) groundbreaking study looks at the beliefs of US liberal and conservative people with the aim of empirically investigating schemas or beliefs on poverty. This work is discussed later in this section, but I introduce it here to highlight my finding that controlling images rely on class privilege and colorblind racism to perpetuate incomplete and harmful beliefs and understandings about Black women’s susceptibility to HIV/AIDS.

The questions arose after my entree into the program. When I attended the training for the first time, I became interested in health behavior theories upon which SISTA was based and why these theories were chosen above all others to explain the proliferation of HIV/AIDS in our communities. I have discussed some of my findings in the literature review section. To reiterate here, I identified a few controlling images contained in the initial study regarding the sexual lives of Black women. I did not call them "controlling images" then but even without much sociological training, my initial point of rapture with this study was to question the assumptions at the base of creating such variables, particularly the focus on sexual behaviors of African American women. My critique of such an approach was its oversimplification of the sexual lives of Black folks. I have since concluded that, SISTA is essentially a good program caught in the center of a problematic history the US has with Black folks as highlighted earlier. However, I am not the alone in this critique of the contradictions contained in the program. Schlobohm expresses this dilemma well:

While SISTA deployed the tropes of pathological blackness, Afrocentric blackness, and strong black women in response to contemporary cultural 
understandings of black femininity, their specific forms were shaped by the other public health trends (Schlobohm 2016 77)

I decided to fully immerse myself in the genealogical work regarding the ways controlling images are transmitted and upheld through public health theoretical models. I learnt that when Wingood and DiClemente sought to identify the correlates of noncondom use among African American women they selected "condom use" in the Black community as the dependent variable with "frequency of vaginal sex," "age of sexual debut” and "number of sex partners", "substance use”, "partner abuse,” and "history of abuse as a result of asking for condom use from a partner" and "beliefs regarding promiscuity” as independent variable items (Wingood \& DiClemente 1998). Following the cultural schema analysis, I seek to trace how science surrounding the sexual lives of Black women is legitimated through theory and methods such as randomized control trials.

Further, because I am using the "what happened" framework of IE, I discuss how I experienced the training materials through role playing vignettes provided. At the initial contact with the SISTA training, I was not sure what this feeling of apprehension was but through IE I came to know this experience as lines of fault, points of rapture or disjuncture (Smith 1987). Initially, I thought my unease was due to the fact that the program was not created for me, but through Black Feminist Thought, combined with an IE lens I recognized that these vignettes were not created by the low-income women for whom this program was intended.

Historically, controlling images were used in slave times as a contrast to what Hill Collins calls the cult of true womanhood (1991). In the SISTA manual, controlling 
images exhibited themselves in the language used to speak about Black men and women. True and elite women, in other words, white women, were expected to possess “piety, purity, submissiveness, and domesticity” (Hill Collins 1991). In order to justify complete subjugation of the slave woman, four criteria emerged as presented in Table 9. From then, through the women's suffrage till now, Black women's voices are met with persistent and blatant racism. Black women's lives continue to languish in obscurity and in one-sided, oversimplified, and incomplete representations of our lives, particularly our sexual lives. These unfair and dangerous representations of African American womanhood have indeed evolved since the slave era, but Black feminists argue that these images still persist, and their effects have remained the same.

\section{1.) The Welfare Queen}

The trope of the welfare queen is ubiquitous and has been analyzed thoroughly (e.g., Gilkes 1983, Kelly 2010, Givens and Monahan 2009). Literature is clear that SISTA was intended for low-income Black women. Appendix H. entitled "Conceptual model for the Theory of Gender and Power" demonstrates the ways data collected from Black women on government assistance was used as the foundation for the SISTA project as does appendix K. Hill Collins argues that controlling images have taken in an ideological presence and still function to subjugate the knowledges of Black women, thereby denying them agency and self-determination.

I created table 3 to show examples of SISTA role playing scenarios created with the aim of helping Black women navigate situations that may put them at risk but unfortunately simultaneously stimulate and perpetuate longstanding stereotypes. This table also shows how Hill Collins conceptualizes the controlling images and how they 
represent themselves in the SISTA program. Appendix C. shows that some of the activities for the first session were innocuous and useful to introduce us to HIV/AIDS facts and the toll it was having on Black women. The deeper we got into the training, however, the deeper my discomfort was and as mentioned earlier, I did not quite have the words to connect the woman, the intellectual and the activist. What was unequivocal was that felt ill-equipped to critique the work of such accomplished researchers of such a well-funded program, global program.

Therefore, I show a few of the instances where the role-playing vignettes resonate with the controlling images theme. One such example is the "how do you handle this" role play activities aimed at teaching women to be "more assertive" rather than “aggressive.” While this activity may be useful to describe real life situations confronting Black women, it unfortunately activated existing controlling images and prevailing stereotypes regarding Black lives. I coded the welfare queen as a consistent controlling image that resonate throughout the various "how do you handle yourself scenarios” contained in the manual. The welfare queen image exhibits itself through a number of vignettes, the most notable being the "Just my Baby Daddy" vignette. I say this image is consistent with Hill Collins' controlling image of the welfare queen because as per Hill Collins, the welfare queen is that Black women who is dependent on this welfare state. She is not only poor but highly reproductive, hence having a "baby daddy” rather than a spouse as expected in a heteronormative society like the US.

\section{2.) The matriarch}

The matriarch is an image of a Black woman who emasculates Black men and is aggressive. In the scenario below, Lovita's irresponsible man damages her car and in an 
aggressive manner she wiggles her finger and him and yells, “I don’t care how you get to work....” After presenting a few such scenarios, the Black woman is given an alternate way to talk and get her needs met. In this scenario, she is taught how to "be less aggressive” and “more assertive.”

The movie "It's Like This" also activates the matriarch image. Because this is the one item that is no longer in my possession, see Schlobohm (2016) for a detailed synopsis of the movie. The story is also summarized in the manual and in Appendix J. Again, the story of "Gladys” represents a matriarch who is the head of the household. She is the one taking care of two children, her mother, and a boyfriend who has, and has infected her, with HIV. When the boyfriend commits suicide, Gladys’ house is once again a female headed household. There is no desire on my part, and it would be irresponsible of me as a scholar, to downplay or ignore the truths and realities in our communities that leave us vulnerable to infectious diseases. However, historically and in contemporary times, Black folks have insisted on a proper and balanced representation of their lives. Misrepresenting or over representing one aspect of our lives continues to miss the deep-seated causes of inequity experienced by Black folks in the United States and indeed globally.

\section{3.) The “angry Black woman”}

This image also weaves the scenarios together. Whether the woman is a welfare queen or a matriarch, she is seen and described as “angry.” The trope of the "angry Black woman” has been activated numerous times to dehumanize us each time we attempt to address the harsh reality of our everyday. When Black women express outrage at the injustice we face, we are seen as "angry” without being given the credit 
for the inhumanity that has left us angry in the first place. Black women suffer from the violence that also puts all "Black women" women in one category. One might argue that me saying that Black women's anger must be acknowledged is in itself reductionist as not all Black women share similar experiences. The legitimacy of Black women’s anger may be an aspect missing from my life as a Shona woman, who has been identified as Black but lack the lived experience of being an African American woman.

Having said this, however, historically, Black women have waged wars against slavery, colonialism and neo colonialism. This fact remains understated when speaking of the lives of the historic and contemporary experiences of Black women as a constructed racial category. Instead, programs such as SISTA seek to 1.) acknowledge that the angry Black woman is not desirable and 2.) that the "angry Black woman” needs to be retrained to be assertive because being aggressive is an inappropriate emotion (Jones \& Norwood 2017, Spring, Cameron \& Cicara 2018). In addition, the theory of gender and power is sold as a feminist theory. According to Hirsh (1981) feminists must use the categories of class, race, sex, nation, age, and sex orientation to explain the complexities and power relationships at the root of all institutionalized inequality. She argues that feminism should be concerned more about this than "spending a weekend in an expensive workshop that guarantees to teach you how to become assertive (but not aggressive)” (Ehrlich 1981).

\begin{tabular}{|l|l|}
\hline $\begin{array}{l}\text { Controlling } \\
\text { Images }\end{array}$ & SISTA manual \\
\hline
\end{tabular}




\begin{tabular}{|l|l|l|}
\hline welfare & \multicolumn{1}{|l|}{$\begin{array}{l}\text { Situation B: Creative Nail Salon } \\
\text { queen }\end{array}$} & $\begin{array}{l}\text { A. } \\
\text { You have finally decided to get acrylic nails at the local salon. }\end{array}$ \\
\hline Matriarch & Situation C: He's Just My Baby Daddy! \\
A. Video Characters: \\
1. Gladys - Main character in the video living with HIV. \\
2. James - Boyfriend of Gladys \\
3. Cynthia - Sister of Gladys \\
4. Shana Pearl - Mother of Gladys \\
5. Darrel - Oldest son of Gladys \\
6. Robert - Youngest son of Gladys \\
7. Shana Pearl - Daughter of Gladys (named after the grandmother) \\
B. Situation A: Credit Card Debt \\
C. $\begin{array}{l}\text { You and your partner have been together for two years. During this time, } \\
\text { your credit has been spotless and his less than perfect. During your } \\
\text { relationship, you have seen "Final Notices" regarding several bills lying }\end{array}$ \\
\hline
\end{tabular}

Table 3. Examples of vignettes containing “controlling images”

\section{Interviews}

I designed interview questions with the intent of placing the findings in my content analysis section into the context of understanding Black women's relationship with the ruling class has direct and immediate effects on our participants, be it positive or negative. By interviewing CDC staffers, the community-based organizations, researchers I sought to determine where the lines of fault lay in the social relations organizing our experiences (Smith 1987 50). I was specifically interested in understanding the extent to which scholars and researchers consciously interrogate the implications of their privileged positions with regards to how these contributed to the production of work that fits into the controlling images framework. I sought knowledge on how concerned scholars are with this argument. Thus, as knowers responsible for producing work that subordinates the worlds of Black women, I investigated the levels of awareness by CDC scholars, researchers, staffers, creators of SISTA and facilitators 
and also their willingness to discuss the ways their methods and theories generate accounts about people’s lives that override the localized perspectives of “other" knowers.

Just as I was critical of SISTA for generalizing the lives of Black women from 128 BayView area women, I also did not want to shortchange the program by making any conclusion based solely on the impressions I got from the content of the manual and my experiences in the program. Thus, I interviewed those involved with creating and disseminating it and also interviewed the women who participated in the 2013 training. Because I did not have Portland State IRB for these 2013 New York interviews, I shall not use their views here. However, as they were part of my experiences, some of their views were instrumental in helping me the questions I asked in my current dissertation.

My interviews were intended to mimic Hunzaker and Valentino whose work on cultural schemas of poverty which provides insight into some long-standing beliefs and attitudes towards poverty and insight into whether these beliefs and attitudes vary across social groups in the US over time (2019 976). This work is important because Hunzaker and Valentino empirically explored the association between one’s affiliation to liberal and conservative politic in the US influences commonly held beliefs about U.S. poverty and its relation to chronic unemployment. According to Hunzaker and Valentino (2019), these two groups conceptualize the solutions to poverty differently also based on their political beliefs. The conservatives see being chronically unemployed as attributable to "having parents on welfare." Their proposal to solve this is to reduce government spending on cash transfers to the poor as this may lead to 
promoting employment and ultimately alleviating poverty. For liberals, they see the concept of being chronically unemployed as most similar to "living in a bad neighborhood.” For this group, government investment into "infrastructure improvements and small business grants in local communities to increase employment will probably provide better solutions for resolving poverty.”

In the same line of thought, I conducted in depth interviews with a purposive sample and snowball sample of SISTA CDC Division of HIV/AIDS Prevention staff members, creators, disseminators, researchers of SISTA and community-based organizations. My sampling strategy was purposive and may not be representative of all the CDC employees or community-based organizations. However, my purpose for choosing this sample was to because I retrieved some of the names of the respondents from the SISTA training manual acknowledgement page. The facilitator respondents came from the list acquired from the 2010 SISTA facilitator training where we had shared our information in order to stay in close contact after the training. After I made the initial contact, my respondents snowballed to contacting other facilitators, researchers, scholars from the CDC, academia, and community-based organizations to participate in my study.

Two interviews were conducted at the CDC in Atlanta, GA, one interview was conducted in the respondent's office, one was conducted in my office at Portland State University. The rest of the interviews were conducted over the telephone. The cultural schema I intended to reveal is shown below. I discuss controlling images as a theme and also reveal the ways social class is complicit in the perpetuation of such a lens. 


\begin{tabular}{|c|c|c|}
\hline \multicolumn{3}{|c|}{ Scholars - Researchers - CDC } \\
\hline Panganai (W/M) & PHD & Researcher/Scholar/College Prof. \\
\hline Jabulani (W/M) & PHD & Researcher/Scholar/CDC \\
\hline Tonderai (W/F) & PHD & Researcher/Scholar/College Prof. \\
\hline Chemheni (W/F) & PHD & $\begin{array}{l}\text { Retired College Professor Clinica } \\
\text { Psychologist / Former CDC }\end{array}$ \\
\hline Chirandu (W/F) & (MA, PHD in progress) & Researcher/Scholar/CDC \\
\hline Chido(B/F) & PHD & Researcher/Scholar/College Prof. \\
\hline Tauranai (B/F) & PHD & Researcher/Scholar/CDC \\
\hline \multicolumn{3}{|c|}{ Trainers / capacity building } \\
\hline Chenai (W/F) & MA & Trainer /Capacity Builder \\
\hline \multicolumn{3}{|c|}{ Facilitators - Program Directors } \\
\hline Mlambo (W/F) & MA & CBO, Supervisor \\
\hline Chenzira(H/F) & BA & $\begin{array}{l}\text { CBO facilitator, program } \\
\text { manager }\end{array}$ \\
\hline Dairai $(\mathrm{B} / \mathrm{F})$ & BA & CBO writer \\
\hline Pilani(B/M) & MA & Entrepreneur /Self Employed \\
\hline \multicolumn{3}{|c|}{ Community-based Facilitators } \\
\hline Thandiwe (B/F) & GED & CBO Facilitator \\
\hline Zanele (B/F) & GED & CBO Facilitator \\
\hline Sikhombiso (B/F) & $\begin{array}{l}\text { CASAC (ordained } \\
\text { minister) }\end{array}$ & CBO Facilitator \\
\hline
\end{tabular}

Table 4. Pseudonyms, self-reported gender, and occupation of respondents 
Table 4 shows the gender, racial, and educational background of the respondents. The respondents were layered according to occupation and proximity to the CDC. At the community-based level, Mlambo was a program director and never personally disseminated SISTA or any DEBI, Pilani was a disseminator of a similar program, run by the CDC but through funding by the Racial and Ethnic Approaches to Health (R.E.A.C.H.) to Substance Abuse and Mental Health Services Administration (SAMSA). He is the only African American identifying male facilitator and has since changed occupations. The PHD’s were all scholars and researchers and were also closely associated with CDC. Including Mlambo, three of my respondents were not directly involved with SISTA though they disseminated similar programs and are familiar with the process of grant writing, program development, pilot testing and dissemination. One is retired, one, Chenai, is known as a capacity builder. Capacity builders' job is to train facilitators on behalf of CDC and evaluate the level at which CBO’s are equipped to disseminate DEBIs.

Ten of my respondents were trained in behavioral health. The overwhelming response to SISTA was/is positive and all were impressed by SISTA albeit for different reasons and respondents were proud of the milestone this program achieved for Black women. All but one did not have much to add in terms of critically exploring the question "if there was one thing you could change about SISTA what would it be?" Though the framing of this question changed depending on how the interview progressed, the aim was the same. I was interested in unpacking how the cultural schema of how controlling images are transmitted. 
When the country, the world, and the Black community were hit by the AIDS epidemic, Public Health Services was desperate for a solution for Black women. According to Panganai, there was little literature speaking of Black women’s vulnerability or how to address it. Chemheni echoes this sentiment and as someone who was working with gay men on the onset of the epidemic, she remembers and recounts the various programs available for gay men. Community popular opinion leaders' interventions (CPOL) was one of these and Programs that Work is another one. While these were rigorous interventions, they were focused on changing risky sexual norms and behaviors in the gay community but when Black women's statistics began to surge, the desperation for a program for Black women increased.

Per Chemheni when the HIV/AIDS epidemic hit

people were desperate to be able to do something ... people were desperate ... people were dying at an incredibly rapid rate ... there were no cures, there were no medications... CHEMHENI / W / F Scholar, researcher, writer.

\section{Academia as a ruling apparatus}

While the program creators were indeed responding to the need to prevent HIV/AIDS proliferation in the African American community, they did not escape the trappings highlighted by Smith (1987); one, that while SISTA is applauded for being created for Black women by Black women, the Dr. Wingood, the program’s creator says she was not taken seriously in academia when she proposed that she would be creating a program for African American women and two, that though I argue that the most appropriate theory to use in the design of a program for Black women would be Black Feminist Thought, the program creators decided on the theory of gender and power as it could be operationalized better than Black Feminist Thought would be. 
Smith (1987) argues that institutionalized structures such as universities function to stifle the creativity of women to the extent that SISTA became the product that functioned to generalize the experiences of women and hence objectified them.

This observation was validated by Panganai when about the consequences of prioritizing psychosocial factors over structural ones

ME: "how do you navigate the balance of, of looking at HIV/AIDS as, as a psychosocial epidemic without necessarily sounding like blaming the people that are mostly impacted?” Panganai responded by saying it is indeed a fine balance:

“... but I mean so ...I am gonna go there with you because I think it's worth talking about. I think it's a fine balance but unfortunately, you know, if you want to attract funding if you want to attract attention, you gotta highlight where the epidemic is...”

It goes without saying that everyone involved with the program had the best intentions. Unfortunately, at the cross section of helping Black women stay healthy, finding the money to do so and coming up with the studies to substantiate and justify the funding, resides a history of the state control of Black folks' sexuality and the scholarship produced to support this monolithic understanding of Black folks sexual live.

I asked all the respondents, "What would you say were the shortcomings of SISTA, if you can think of any?" or "if you could do something differently what would it be?” It was my hope that expected some retrospective conscious awareness of how SISTA inadvertently fed into longstanding controlling images of Black women 


\section{1) The Jezebel}

Though the creators, writers, and disseminator of SISTA were not intentionally seeking to present African American girls as promiscuous jezebels, the schema driving this line of work fits into a stereotypical Black woman whose sexuality needs to be controlled. As mentioned earlier, years after SISTA, I expected a more critically analytical review of SISTA, particularly from scholars speaking to the stereotyping of Black men and women in this way.

In my interviews, I listened for my respondents to speak to what I considered as controlling images. The jezebel described as a hypersexualized Black woman emerged from anecdotes provided by my respondents.

Frequently the young Black women had male sex partners in many cases, that were six years older and if you had a young Black woman who was like 15 her boyfriend frequently would be like 21....If SISTA teaches assertion skills and you've got four boyfriends and you use your assertion skills to say no, we gonna use condoms, no, we r gonna use condoms, you know, etcetera. JABULANI / W / M

These interviews excerpts are not meant to gloss over the realities in our communities that make us more susceptible to illness and other violences. They are also significant because they bring into view the power relations, we are subject to and the prevailing cultural schemas regarding the behaviors of Black women and how this behavior is seen as needing to be normalized through the assertiveness training model.

The jezebel image is linked to the welfare queen because of the fact that the hypersexualized Black woman ends up having too many children, has a "baby daddy" or uses abortion as birth control. This woman has conflicting values with African American womanhood and hence the SISTA training was at hand to instill these values. 
Values can be affirming for a group of people but can, in retrospect, also work to implay that a lack of values is also a lack of morality and a form of deviance.

Now, how come I had a baby with him, and I got an abortion with him, period, or why do I use abortion as a means of birth control? Why is it that I can't be consistent on taking the pill? Why is it that I wanna use a condom with him but not with him what is it that's happening? What happened in my background that causes me to make these decisions? DAIRAI - Writer / Facilitator / AA / F.

This respondent presents a hypersexual young Black woman who does not use condoms, does not take the pill, gets pregnant frequently, and uses abortion as birth control. She explains that this trend is attributable to the psyche of the young women and how SISTA is helpful in correcting this way of thinking. In my interview with Panganai I ask, "These things take place among white populations also, no?” exactly, exactly, 'cause yeah, you're right.... it was just another threat another threat to the communities, another, another burden they had to confront. Because clearly HIV exists within social networks and some communities have higher prevalence of HIV than others, we can't deny that, so women in those high-risk communities, all things being equal, for women in a high-risk community has unprotected sex and a woman in a low-risk community has sex who do you thinks at greater risk of exposure. They are both engaging in the same behavior.

In these questions, I intend to allow respondents the space to expand the idea that these behaviors are present in every community and not just the African American community. The respondent proceeds to say that it is the African American community that needs support and as scholars, it is our job to present the need. Panganai also says that during the time they were writing the SISTA program with AIDS statistics among Black women on the rise, there was no work addressing HIV/AIDs in the Black community. With no cure or vaccine in sight and the African American community being underserved and understudied, they needed to find funding for Black women. 
What resulted was work highly acclaimed by the community as long overdue, but simultaneously objectified Black women by relying on longstanding stereotypes. Using Foucault's lens, SISTA allows us to study the oppressive and controlling effects of governance and objectification of human subjects - Black women in this instance.

Therefore, as groundbreaking as SISTA was in its mandate to reduce Black women's vulnerability to AIDS, it spearheaded a plethora of work using different angles to explore the psyche of Black women, our value systems and condom use.

Our values will determine your behaviors, so if you value a relationship with your male partner and you are not going to umm, you are not going to use protection against HIV that will threaten that value ... TAURANAI AA / F / CDC, disseminator, scholar, researcher

Dairai is also a respondent who believes that SISTA allows each participant to "look at your own personal habits, you own values and how they play in your everyday decisionmaking.”

\section{2) The Matriarch}

Pilani:

"the key issue, for women in general but certainly for African American women family is very integral to their lives so the SISTA motto was... be safe for your family, your community and yourself. So, we wanted to engage the women in prevention knowing that if they prevent HIV among themselves there reducing the risk of community transmission and you know they helping their families 'cause you know, they're gonna be there to be the mom for their children.” PILANI W / M / -Scholar, researcher

Pilani suggested that the message to African American women was for them to get healthy for their children and for their community. While this is a noble intention, it places burden and the fate of the health outcomes for African American women on the shoulders of African American women. This expectation once again places us in the 
position of the caretaker, hence absolving the patriarchal state that left us in these compromised health outcomes to begin with. 


\section{CHAPTER SEVEN}

FINDINGS

\section{Class and reproduction of controlling images}

I determined that class and colorblind ideology were the two main mechanisms through which controlling images prevail even in the presence of alternate theories like Black Feminist Thought. This is because none of the four facilitators interviewed expressed this ideology in their answers. Panganai, one of the $\mathrm{PhD}$ scholars and researchers in my sample indicated that they were responsible for creating the language that would be passed along from woman to woman.

For example, with the value system of Black women under review, the hope of SISTA was to normalize Black women to reevaluate our value systems, retrain us to be assertive and not aggressive and conform to a white, heterosexual norm, “ We had our language which was run over and over and over it, so it resonated with our African American women.” PANGANAI, W / M / Scholar, researcher.

This language left its traces along the public health services hierarchy all the way to the community-based organizer. I encountered it during my training, and traced it to Atlanta, the home of CDC where Tauranai, CDC staffer and former disseminator echoes, “The SISTA intervention helps people differentiate between assertion and aggressions, cause there is a real difference...”

Zanele uses the same language when I asked her what she liked about

\section{SISTA:}

Women out here doesn't really know how to speak up for their selves. Some is too timid, and some is just too aggressive so and when you do the training and you facilitate it tell you how to communicate... ZANELE, B/W - facilitator. 
Zanele, Thandiwe, and Sikhombiso are three of the facilitators who came into the program first as a client and now as facilitators. Zanele left her home when she was 13, became pregnant at age 15 and was HIV positive by the time she was 20 . She is in her 50s now and from the above quote, she too was sold to the idea of the "angry black woman.”

When I asked her what the attributes of SISTA were and she responded by telling me that she learned communication skills, that some women "is too aggressive," she did not reiterate how this aspect was connected to HIV/AIDS susceptibility.

SISTA is a site to study and reveal the fact that “...people were scrambling to get something done...” as expressed by Chenai and also a site to answer questions regarding the meaning of 'science" as well as what get to count as a "scientifically proven" affective program. When I asked why theory of gender and power were preferred theories over Black Feminist Thought, Dr. Wingood answered, "I needed a theory that I could operationalize.” My other question was why individual behavior took center stage over structural level causes in the discussion of the proliferation of HIV/AIDs in the Black community. Another of my respondents from the CDC said yeah, yeah but you gotta remember they are very challenging because structural interventions are more difficult to study ... JABULANI.

Jabulani contends that Black men also need support, that structural interventions are possible such as increasing employment services for formally incarcerated men.

"This is where well-intentioned programs fall short. The people who it's for are not leading it. People support what they, key word help create. If they are not involved at the genesis of anything, you can expect an 
apocalypse. It can't be about me without me. If it's about me, I have to be involved.” Pilani AA / Male / Former Facilitator

I posit that controlling images, prevail through unacknowledged class privilege. Smith (1987) offers that IE is rooted in a Marxist feminist framework that interrogates class. Over the years, various scholars have discussed the concept of class and debated on who and how class is to be defined and discussed. What is undeniable is that class is indeed a fundamental topic in sociology, and it reveals itself in a program like SISTA though it is highly regarded as a peer education program. Marx is used by other scholars too though Foucault says he quotes Marx without necessarily saying so and without using quotations. Foucault (1980) says because of this practice of not quoting Marx or using quotations, other scholars have begun to believe that Foucault does not use any of Marx’s works. However, Foucault scoffs at this because he sees these as arguments of people who do not know Marx’s text. If they did, he says, they would instantly recognize Marxist influence in Foucault's writing. Foucault's point is just as physicists write about physics and not do not feel the need to quote Einstein or Newton, he, too, does not feel the need to offer "eulogist comments" to demonstrate that he expressly credits Marx. Afterall, he says, he does not really need to because it is impossible for critical scholars to write within a whole range of topics without finding links to Marx (1980 52-53).

It is in this same line of argument where I derive my work. I have been pondering on ways to address class as well as how to or whether to define my use of class here. While Marx's works on class is the most cited, scholars after him have engage with other dimensions of class distinction apart from economics. Weber is one 
of these. Olin (2000) offers that “comparisons between Weber's class analysis and Marx’s pose a particular exegetical challenge.” In short, Weber distinctly wrote about social class by expanding Marx’s view of economic criteria used to determine class by adding "status" to the discussion of class. Per Weber, class could also be defined by “values, attitudes and beliefs” (Jones 1975). Bourdieu though focused mostly on French culture is another scholar influenced by Marx and also by Weber.

His view expands on Weber's by tracing how the concept of "habitus” can be used to explain the ways social structures are reproduced through cultural capital. He sees habitus as these trained capacities or unifying principles that structure certain propensities to think, feel, and act in specific determinate ways (Navarro 2006). Though he focuses on France, Bourdieu's argument is relevant to the US context and particularly to my discussion on HIV prevention. For example, Bourdieu believes that habitus is an embodiment of a form of cultural capital which can shape current practices and consumption pattern. These practices are then transmitted from one generation to the next by distinctive means, just like with economic capital. Depending on what form of culture is passed down this cycle allows for the accumulation of power to continue (Bourdieu 1984).

This proves that discussing class has been interesting and complex, but each theorist has been able to build on the next though sometimes they disagree. For example, on Nietzsche Foucault said

For myself, I prefer to utilize the writers I like. The only valid tribute to thought such as Nietzsche's is precisely to use it, to deform it, to make it 
groan and protest. And if commentators then say that I am being faithful or unfaithful to Nietzsche that is of absolutely no interest. (1980 53)

I introduce this discussion on class to highlight the disagreements, the complexities, and even some of the collaborations devoted to rigorously studying class in the hopes of understandings how class can be used as a conceptual frame. I give this extensive introduction to the study of class to offer that I recognize the scholars differing and converging definition of class as well as understandings of factors leading to class formations and the consequences thereof, be it economic or cultural. I enter the conversation with a recognition that regardless of how scholars have used the concepts of class, knowledge creation and power, the consequences of the concepts are real for those of us who have been ignored, misrepresented, or objectified. It is not in the scope of the dissertation to critique or analyze which scholar's use of class, knowledge and power is most accurate or useful. It is, however, useful to recognize that class analysis is ubiquitous and all the work we do to analyze institutions using a social justice lens borrows from some form of a recognition of class. This dissertation is focused more on how race, class, gender, form the matrix of domination complicit in furthering stereotypes that serve to complicate the lives of Black folks.

In Smith’s (1987) discussion of class struggle, she argues that the subject, the knower whose life story we are telling, is located, and experiencing a world that is determined and shaped by a set of complex extended relations that include class. Smith also says that seeing the world in this way opens up possibilities of exploring these complex relations, especially the ways they work in organizing this capitalist society we live in. The interviews with scholars, researchers, and community base organization, 
reveal the complex relations that have factored into the politicization of Black men and women's health.

I hope I have conducted what Foucault calls an analysis of "historical knowledge of struggle” (1980 82). What Foucault (1980) argues is that institutions of power systematically and continually and create subjugated knowledges by censuring the ideas and expressions of the marginalized. As scholars we are called not to conform to these hegemonic narratives but create spaces for these knowledges to break through. This has not been easy and will not be easy because, in order for us to advance, we must conform and produce work that fits into the white hegemonic frame. I place my analysis of SISTA in a conversation the historical violation of Black bodies.

...for Black people in America, their everyday lives and their political struggle are defined by specific techniques of repression associated with racism in a given period (Gilkes 1981 289).

I am writing in the historical period where racism exists now in neo liberalism and well-funded, even well-intentioned government initiatives and the struggle for the health outcomes for people of African descent are still in peril. The people who are responsible for decisions can no longer afford to turn a blind eye because to quote Delaney, “This isn't an argument about how many angels can dance on the head of a pin. People's lives hang in the balance of this decision” (Treichler 2004 4).

As I considered the theme of controlling images in the training manual, some of which are presented in vignettes cited in this dissertation, my finding was that class privilege is at the center of how these images prevailed and continue to prevail even in the face of opposing viewpoints like Black Feminist Thought. The struggle for selfdetermination has been a part of the fabric of Black folks' lives since we stepped on the 
shores of the land now called the United States. While the women's suffrage was a significant moment where Black women actively sought to shake oppression by pursuing alliances with white women in the movement, in contemporary times, however, class privilege is now the avenue through which Black elites have become the conduit through which Black women’s subordination persists and the health of Black, Indigenous and People of Color still remain in jeopardy.

The first clue of SISTA being a classed program is in the core elements. This program was supposed to be facilitated by "skilled" facilitators. In the original version, there was a preference for the facilitator to have a master's degree. In the interviews, this idea of SISTA being a peer led education was also contradicted by Dairai. As one of the most prolific and prominent writers of the SISTA curriculum, when asked about the biggest shortcomings of the program was, her answer related to the inadequacies of women who served as facilitators. She explained that the biggest shortcoming of the program was the fact that other facilitators where ill equipped to train.

If they don't have the facilitation skills to read the curriculum and follow the curriculum with fidelity then you just have a trainer with no skills. DAIRAI AA/F

Community-based facilitators did not use buzz words such as "efficacy" and "fidelity" in their interviews, but they were pleased with SISTA because it was a vehicle for Black women to share experiences and create bonds. It is also these women facilitators who were devastated when SISTA was defunded. 
Scholars - Researchers - CDC

ME - What would you say was the biggest success for SISTA and how would you measure success?

Oh, that's easy well you measure success in a lot of ways. From a research standpoint did you get really good effects? Did you did you publish it's a peer review, did your colleagues have to review your article etc., etc. That is one level of success. But a more important leve is what kind of downstream impact does that article have on African American women and their ability to protect themselves and as a consequence of SISTA the CDC adopted it made it of Tier 1 evidence-based intervention. - PANGANAI, W/M

What was the biggest strength of SISTA?

JABULANI - SISTA deals with assertion skills, part of that had to be with a social determinant in our culture ... is that if a, a woman tells a man she won't have sex with him unless he uses a condom a woman, women fear they will be seen as aggressive, JABULANI, W/M

I think another something else that really helps SISTA is not only was it a successful intervention, however, there was enormous adoption of this intervention. Part of it was how it was framed and package. It was not packaged per se as an HIV intervention, though it was. (CHIDO, AA/F)

Trainers / capacity building

“...it met the requirements for an evidence-based program...minimum sample size of 100, sometimes 125 ...they had to be based in behavioral theory, they had to have demonstrated behavioral change one of (at that time) nine different criteria, so delaying sexual intercourse using a condom, using contraception... if they demonstrated behavior change ... and replication. Chenai W/F Trainers / capacity building

“... because all of them are grounded in science and theory and good practice and learning strategies...”

Chenai W/F Trainers / capacity building

Facilitator - Program Directors 
"For me it wasn't about the content at all. For me it was about the fact that you were able to get women together to talk about the risk of HIV and be able to have women learn how to negotiate with their sexual partners around that risk. That was the biggest strength in the intervention. There is strength in numbers. DAIRAI AA/F.

The real strength of the program is the sisterhood that gets created as a result of the camaraderie the women feel as they get together around this kind of intervention. DAIRAI $\mathrm{AA} / \mathrm{F}$.

“... coming together around the kitchen table and the encouraging dialogue and conversation around topics that were beyond just didactic skills building ... I thought that, that really was a

draw for SISTA, and I felt you know it made me proud to be part of working with that intervention ... Mlambo W / F

Community-based Facilitators

NO, I liked everything about SISTA, the graduation, the individuals it's a beautiful thing. ZANELE - AA/F

\section{What component of SISTA did you like the most?}

“...SISTA deals with how we communicate, you know. People say I, I wanna tell my partner but I don't know how, you know, so one of the components of SISTA is the communication style you know how to disclose if you feel that you need to...” Sikhombiso / B / F

Table 5. Responses to SISTA success

I color coded the table above to above shows the responses to the question,

“what is the biggest benefit of SISTA?” Scholars, researchers, the CDC, and CBOs had different markers to measure success of SISTA. Scholars, researchers, and the CDC staffers measured the success in terms of peer reviewed journal articles published on SISTA, subsequent programs, and in terms of how widely distributed it was globally. College educated Program Directors and facilitators with a public health training spoke in terms how the program was successful because it fits the criteria set in the compendium. 
Those who had direct contact with the participants and whose experience were like my own were both trained as participants first and then received training as facilitators. The difference between some of their experience and mine is that they actually worked as facilitators and changed people's lives whereas my training did not translate into me training others. Further, three were introduced to SISTA first as clients. They are living positively with HIV, received SISTA training as part of the services offered to them and decided they too wanted to make a difference, give back to their community and become facilitators themselves. They were the most impacted by the defunding of SISTA by the CDC and its removal from the compendium.

The removal of SISTA from the compendium did not have the same effect on researchers and CDC staffers. When I asked what respondents thought about the move by CDC from a health behavior model to a medical model by introducing the preexposure prophylaxis tablet, they saw the move as a "natural" course of research. 
Scholars - Researchers - CDC

ME - "Yeah um what do you think about the bio, the biomedical model since the CDC seems to have shifted from intervention to biomedical with pro with pro with PrEP

“Well, you know that yes, I think that again part of the progress of science. - PANGANAI, W/M

ME: “...how do you envision PrEP to be a better model than the behavioral model?”

“...I think what we have with behavioral interventions is we have deterioration of effect over time, you know, and you don't have deterioration of effect over time with the biomedical interventions .... JABULANI, W/M

Trainers / capacity building

ME: “...you feel free to say this is not an area that you want to cover but in terms of interventions I since they moved from this behavior model to a treatment model where they are now focusing more on PrEP as opposed DEBIs. Do you have any opinions on what that has impacted organizations?

“... you know I'm not I'm not saying that I think it's a good idea to shift funds away from African American women especially with their high, but I think dash actually a broader statement about all the evidence-based interventions they have to become more innovative this whole idea of like sitting in a classroom for 12 hours straight or 12 hours you know once a week or two or three times a week that's just clearly how young people function these days. Chenai W/F Trainers / capacity building

Facilitator - Program Directors

“... yeah, they defunded it because they're (African American women) not a high-risk population and so as a result their (CDC) primary focus is biomedical which is getting people onto prep which is which I am against ... Black women's lives don't matter that's how I feel about that ...” - DAIRAI $\mathrm{AA} / \mathrm{F}$.

Community-based Facilitators

What do you think about not having funding?

“... why would you put money into WILLOW and not into SISTA. They should have kept SISTA cause you know how to meet you people. I see that, you know, I see women out there struggling, cause there is no funding for those people. For those sisters. We got to the shelters every single day and there is nothing we can do for them but give them VOICES.

ZANELE - AA/F

Table 6. Responses to CDC shift in funding priorities 


\section{Colorblind racism and reproduction of controlling images}

Colorblind racism is another conduit through which the controlling images

prevail even in the face of social justice and emancipatory frameworks like Black Feminist Thought. Carr (1997) says that colorblind racism was the dominant liberal ideology that emerged out of a need by integrationist elites to envision a future of racial equality. This ideal fell to pieces rather quickly, according to Bonilla Silva, partly because we all are "racialized subjects" living is a racialized society. What we are faced with now is "racism lite," a contemporary form of racism that is institutional, seemingly nonracial, and subtle. This form of racism also exhibits itself in single research methods where there is no cross examination of results (Bonilla-Silva 2018 3).

The randomized control trials were the only method used to understand Black women's vulnerability to HIV/AIDS as well as their attitudes towards condoms. The trainer in my sample was also hesitant to endorse this method.

I think we could think a little bit about more about what is the element of a behavior change intervention that would actually yield a, a, I mean an individual can self-report positive behavior changes and I think you know some of that may be related to intervention effect. Chirandu W/F CDC scholar, researcher

Randomized controlled trials have their benefits. In the context of perpetuating controlling images, SISTA emerges as problematic in the sense that studying "age of sexual debut” in isolation leaves out stories such as Zanele's story. She became HIV positive after leaving the home at 13 . While "age of sexual debut” is in her story as a measure of vulnerability, she also came into contact with crack cocaine, poverty, and domestic violence against her mother. Her mode of transmission could have been intravenous drug use and, additionally, her story does not contain narrative of the fear 
of men leading to her not using condoms. She says she knew nothing of AIDS and how it enters the body or how to fight it. She does wish she had had a program like SISTA where she could learn life skills from other women. This is confirmed by Mlambo, the Program Director who has seen this story replicated numerous times.

...I think, I think the group interaction was beneficial and, yeah, definitely that women had space where they were encouraged to, you know, be proud of their gender and their ethnic identity. Probably there's not a lot of spaces for people to do that all the time so yeah. Mlambo (W/F/Program Director).

In my study, I wanted to understand how my respondents understood the concept of a

“culturally relevant" program, as SISTA is laid out to be. Of note is:

When you are working on an intervention or when you are working with education, it is imperative that you customize it, it is imperative that you tailor it so that it is received by those who would benefit from it the most in a way that they are accustomed to receiving information. So, you have to take into account trust you have to take into account habits, patterns, communication styles, you gotta take into account history, cultural background...so all of these things go into the design and the implementation of all of these programs ...so let's say you go in for grant, let's say you go in for training in the community you have to make sure that you know you speak the language. You, you connect with people and meet them where they are that's it, that's what I mean by culturally specific... Pilani ... (B/M)

This respondent took a view of cultural relevance that was consistent with expectations of CDC funding. In order to prove that the program would be eligible for funding, it had to meet the grant requirements highlighted in my interview with Deborah above. My follow up question was intended to push the respondents towards understanding that the program walked a very thin line between creating a culturally relevant program and oversimplifying the lives of Black folks and also perpetuating and relying on longstanding controlling images. When I phrased the question in this way, 
the scholars were forthcoming in their answers. They acknowledged that I was asking good questions:

...you see you're raising good questions. I don't think we've really taken those challenges on, uh because, as I said these are big challenges, yeah, so we need a social movement to address those challenges, yeah, we need a movement ..."

Though my respondent was willing to admit that I was asking good questions regarding the role of structural issues and the need to consider these a lot more, and that the current models stereotyped Black folks, they were still unwilling to move away from the individual model:

You have hit it right on the head, Joy. You know, it's funny, 30 years ago, this was novel, no one thought about this 30 years ago. Now everyone recognizes its individual behavior, relational behavior, community influences but they're all influence that they all coexist under societal influences.

\section{Quantitative Data Analysis}

My approach to the quantitative data section was purely descriptive. Using the IE lens to discuss questions asked of women who participated in the study, the ways data was used, as well as the results reached, I explore the links between method and theory (McGibbons, Griffin, Peter, \& Gallop 2010). Methods used to reach conclusions about Black women’s vulnerability to AIDS have been dominated by randomized controlled trials and surveys. One such study is "Partnership-Level Analysis of African American Women’s Risky Sexual Behavior in Main and Non-Main Partnerships” published by Broaddus, Owczarzak, Pacella, Pinkerton \& Wright in 2016. It is this study whose findings and methods I discuss here. Their study used the theory of gender and power to reveal associations between perceptions of a partner's risks for HIV and 
women's risky sexual behavior. This work concluded that there is a continued need to emphasize skills training in "condom attitudes, condom negotiation behaviors, and overcoming partner resistance to condoms within both main and non-main partnerships” (Broaddus et al 2016 2893).

While their study added another layer to understand ways to assist Black women to effectively negotiate condom use and while they also focused on older women and not adolescence as previous studies did, I interpreted this study as yet another one relying on controlling images about Black women’s sexuality. As highlighted earlier in the paper, Black folks have been historically and systematically left out of studies. Unfortunately, when we are and when we have been included, it has predominantly been through the oppressive lens that showcases us as a monolith. Washington (2016) makes an argument similar to Smith (1987) that scholars', particularly women’s intellectual work and in Washington's case, Black women’s work, is sometimes dwarfed or silenced in academia. If scholars, scholars of color, are to be heard, they must publish work that speaks to whites.

In the case of this quantitative study by Broaddus et al (2016), the methods employed, and conclusions reached may benefit literature any body of work regarding Black women’s sexual lives. A quick look at other studies similar to Broaddus et al (2016) generated by a search for their article reveals a myriad of other studies focusing on the sexual lives of Black women (Appendix K.). From the Black feminist perspective, from IE perspective, and from table 9., however, it is evident that Broaddus et al (2016), conflate the experiences of Black women who are in different cities, and 
do not have much in common except one significant aspect ignored by this analysis; the shared history of structural violence affecting Black women.

\begin{tabular}{lcc} 
& \multicolumn{1}{c}{ Number, Frequeney of partmerships } \\
\cline { 2 - 3 } Abusive partner & $93(12 \%)$ & $38(12 \%)$ \\
Partner resistance to condoms & $283(36 \%)$ & $141(43 \%)$ \\
Partner had sex with other women & $123(15 \%)$ & $120(36 \%)$ \\
Partner had sex with men & $278(35 \%)$ & $110(33 \%)$ \\
Partner injected drugs & $38(5 \%)$ & $22(7 \%)$ \\
Partner incarcerated & $124(16 \%)$ & $54(16 \%)$ \\
\hline
\end{tabular}

Note: $\mathrm{N}=718$

Table 7: Parameters of women under study in Broaddus et al (2016) study

The entire dataset consists of 2071 women and only 718 women were selected for the purposes of the study. The fact that the 718 Black women who participated in the study also reported having a partner who injected drugs and had a partner who had been incarcerated indicate structural considerations needed for optimal Black women’s health that were ignored in these studies. Further, studies focusing on HIV/AIDS in the Black community ignore significant missed opportunities to speak to a lack of HIV/AIDS prevention in prisons as well as the delayed action on the part of the Reagan administration to offer clean needles.

This erasure of structural racism from an analysis of the lives of Black women points to another significant question related to the study. Washington (2016 6) notes that most university studies focused on the lives of inner-city Black women also recruit women who live close to these universities and cites of study. While blatant abuses of human subjects have been officially outlawed, the subtle forms of racism still exist, known as racism lite. Bonilla- Silva argues that racism lite is a form of institutionalized 
racism that maintains the racial order and keeps whites from appearing "racist" (BonillaSilva 2006). The concept of racism lite or colorblind racism will be discussed later in the paper.

In this section, however, I examine the questions asked and how these questions perpetuate a racist cultural schema discussed earlier (Hunzaker and Valentino 2019). These questions may not have been deliberately designed to be racist, but they indicate some publicly shared cultural understanding of Black folks' sexual activity. For example, Table 8. indicates that 164 women answered a question on who has more say in their relationship regarding condom use. Though this is only $8 \%$ of the respondents, 83 of these women said they had more say in their relationships regarding condom use and $92 \%$ of the women did not answer the question at all. According to their article, however, when this question was placed in a multivariate mixed regression model along with other variables, some of the reported findings were "fewer instances of condomless vaginal sex," "more condom negotiation behaviors," "fewer instances of condomless vaginal sex with non-main partners.” (2006 2901)

There is no denying the volatile gender relations and gender violence that are characteristic of patriarchies like the US. However, HIV/AIDS is not merely a Black woman's burden and the efforts to control it should also have considered men. Regardless, study after study focuses of some configuration of how powerless Black women are in their sexual lives even when other studies speak to the complex ways we negotiate sex (Gentry 2007). 
Overall, who has more say about whether you use condoms, you, or this partner?

\begin{tabular}{|l|l|}
\hline He has more say & 27 \\
\hline I have more say & 83 \\
\hline We have equal say & 54 \\
\hline Total & \\
\hline Missing Values & 164 \\
\hline
\end{tabular}

Table 8. Responses to "who has more say over condom use in your relationship?” 


\begin{tabular}{|l|r|}
\hline Missouri & 576 \\
\hline New Jersey & 344 \\
\hline Texas & 620 \\
\hline Tennessee & 530 \\
\hline Total & 2070 \\
\hline
\end{tabular}

Table 9. Sites quantitative data was collected from

My purpose in analyzing the data was to determine which questions were asked, how the women answered these questions, how they were analyzed, and the implications of such an analysis to those who use a different lens, like IE for example and Black Feminist Thought. In my interview with Pilani, he expressed that in the face of HIV/AIDS, public health was faced with limited to no research on African American women. They, therefore, needed an expedient program that would satisfy the funders. Quantitative methods, therefore, with all their attributes, fall short when they produce parameters that are one sided and damaging to Black women's health. These studies are also dangerous because they refuse to acknowledge the true effects of racism on the lives of Black folks.

\section{The problematic - Black women as objects}

The next concept under review is that of the objectification of Black women. As mentioned earlier Cohen challenges scholars to ask research questions aligned with the questions the people we are studying are asking about their own integrity. Smith (1987) devised IE to counter oppressive research by beginning to ask questions that begin from the standpoint of women. Cathy Cohen told Jafari Allen to ask research questions aligned with the questions the people we are studying are asking about themselves. The 
problematic, as a conceptual framework, has allowed me to look into the questions being asked of Black women, how they answer, as well as present literature relating to some of the questions the women are asking about their own lives.

To date, the research field is inundated with different iterations of how Black women have sex when the concept of intersectionality dictates that Black women who are served by this program live in circumstances complicated by police violence, crack cocaine, mass incarceration, houselessness and underemployment. This colorblind view, the view that ignores racism completely, makes scholars complicit in the continued oppression of the historically marginalized. Also, it encourages recommendations for interventions that only partially serve those mostly impacted.

Broaddus et al (2016) makes the conclusion that it is important to center partnerby-partner data in research because this relationship aspect potentially shapes sexual risk. What makes this research significant is how it adds another dimension to the story of sexuality in the Black community.

\section{Implications of study}

I contend that as scholars, we may have evolved to become more critical in our treatment of research subject and in our respect for their dignity. We have come to value their knowledge as well as the ways they experience power in the United States. Our willingness to empirically engage with the causal and correlational impact of the interplay of race, class, gender, and health outcomes is increasing. More work is needed still as evidence by President Trump’s dismay and disbelief that Black folks were/are disproportionately impacted by CO-Vid 19. More importantly, the question "why?” is still on the population's lips (Williams 2020). While racist language such as that by 
Gilman Perkins can only be found in white supremacist literature and has been deemed harmful and unacceptable, ideological oppression is still consciously or unconsciously being exercised and experienced.

This section further utilizes Smith's use of the gender subtext to discuss how power is reproduced through methods and theory. Her IE replaces traditional discourses on power as she finds them insufficient to discuss its authoritative impact on women. In discussing how women have either been ignored and objectified in research and professionally excluded from the educational setting, she adds that when women have been in. When they were included, through this gender division of labour, they were concentrated in the non-ladder positions of lecturer or instructor. For those who do advance to the tenure track position they found they must produce work that is publishable, and this work does not ordinarily represent the women's perspectives. Thus, Smith regards academia as a "text mediated structure," as a machine that possesses some predetermined modes and methods of deciding who advances to prestigious positions. Some women have resisted academia, but most must function in this system and in order for us to advance must produce work that satisfies those in authority: white, heterosexual males (Smith 1987 111).

In another example as women, white women in the context of Dorothy Smith's analysis, attempted to enter the health care field, their participation in the emerging field of gynecology remained limited to midwifery. Smith (1987) offers, therefore, that by establishing Women's Studies departments, feminist scholars proved that their standpoint is a valuable methodological device which deserved a platform in academia. In the meantime, women's work still remains entangled and colored by the white, 
heterosexual, male gaze because the social world is still governed by men who remain in control and representative of the power and authority of institutionalized structures governing society.

In this gendered division of labor, the racial subtext is missing, and Smith says that this aspect is also missing from her work as she has not fully incorporated the ways racial oppression intersections with gender in organizing these relations of ruling. This is the gap my work addresses. Using part of my story as data, I highlight this racial and gender subtext in women's participation in my work because the role of teaching women to use condoms fell primarily on women, women of color. Following Smith’s process, I began by discovering my own point of rapture, or discomfort, as I engaged with the condom conversation as a woman, as a Black woman, and as an immigrant woman. I located these activities within a specific Black Feminist frame to understand how my encounters were embedded in a specific history in the lives of women of African descent and our relationship with institutions of power that continually seek to subjugate our work and our knowledge.

Smith urges those of us who become part of the intelligentsia to own our privilege as we conduct research. Smith implicates members of the dominant class, particularly in academia in creating and recreating the ruling apparatus. As inquirers, she argues that it is our job to recognize that we have been brought into determinate and specific relations with those whose experiences we seek to express. Foucault (1980) echoes this, that knowledge perpetuates power, and that power is perpetuated through knowledge. He adds that one place where this phenomenon is mostly visible is within universities. With knowledge being produced at the universities, it behooves scholars to 
state our positionalities as Smith here does. She respects her privileged position with regards to the subjects she interacts with and offers,

I am white, English-speaking, a paid member of the Canadian intelligentsia. I have my place in this same organization of relations that generate the experiences of the world of those I observed. (1987 113)

When we create or gather knowledge, our participants do not tell us what questions to ask. This means our "subjects" are not really participant in the text mediated world we create for them. According to the 2008 SISTA training manual, the theory of gender and power and the social cognitive theory were instrumental in the birth of the SISTA intervention.

It was only two of my 15 respondents who critiqued SISTA. One of those critiques came from one respondent, Mlambo, a self-identifying white woman who offered that splayed a different way of thinking about and tackling social problems. Because she describes herself as a "systems-based thinker", she provided a critical lens through which she viewed SISTA came as no surprise. She discusses how SISTA's core elements limited her work as a service provider based in a metropolitan city. In her view, Black women come with complicated identities, all of which must be taken into consideration if she is to provide sufficient service. Because of her experience with serving Muslim immigrant women, Hispanic women, Black women from the Caribbean, Mlambo was one of the first to critique SISTA's generalizability and depart from the "African-American women only" model of SISTA. Though the core elements specified that they ought not to be changed, Mlambo saw the need to change some of the activities and poems to make them more relatable to all the women served by her organization. 
My other respondents, Pilani, summed up the study well. When I asked him what could be done changed about culturally relevant programs he concluded that “people will support what they help create.” He added that any program that is created without us cannot be for us. His argument is that well intended organizations fall short because they do not follow this argument as first concept for success. He gives this as the reason many programs are remain unsustainable, why in ten years or twenty these programs die. He suggests that the people who benefit from it should be the ones leading it.

From figure 3. below, we see from my study that the majority of Black women who are supposed to benefit from this program, are not at the helm of its creation. In my study, the majority of positions where decisions about Black women’s sexual health are concerned are occupied by people who are considered as white and the people for whom it is meant for are not leading it. He added the quote "No imported solutions for local problems.” It is evident in the graph that the Black women with the least amount for formal education were the ones implementing a program they did not help create and were also the ones left suffering when program was defunded. Pilani also asked us to consider the African saying, "when elephants fight, it is the grass that suffers and the CDC is a big ass elephant and there are other large organization to Substance Abuse and Mental Health Services Administration (SAMSA), World Health Organizations, National Institute of health, they are all out there and as they go around discussing the latest and greatest, as they wait for another cycle of funding and more grants to prove what we already know are doing so while people are dying. 

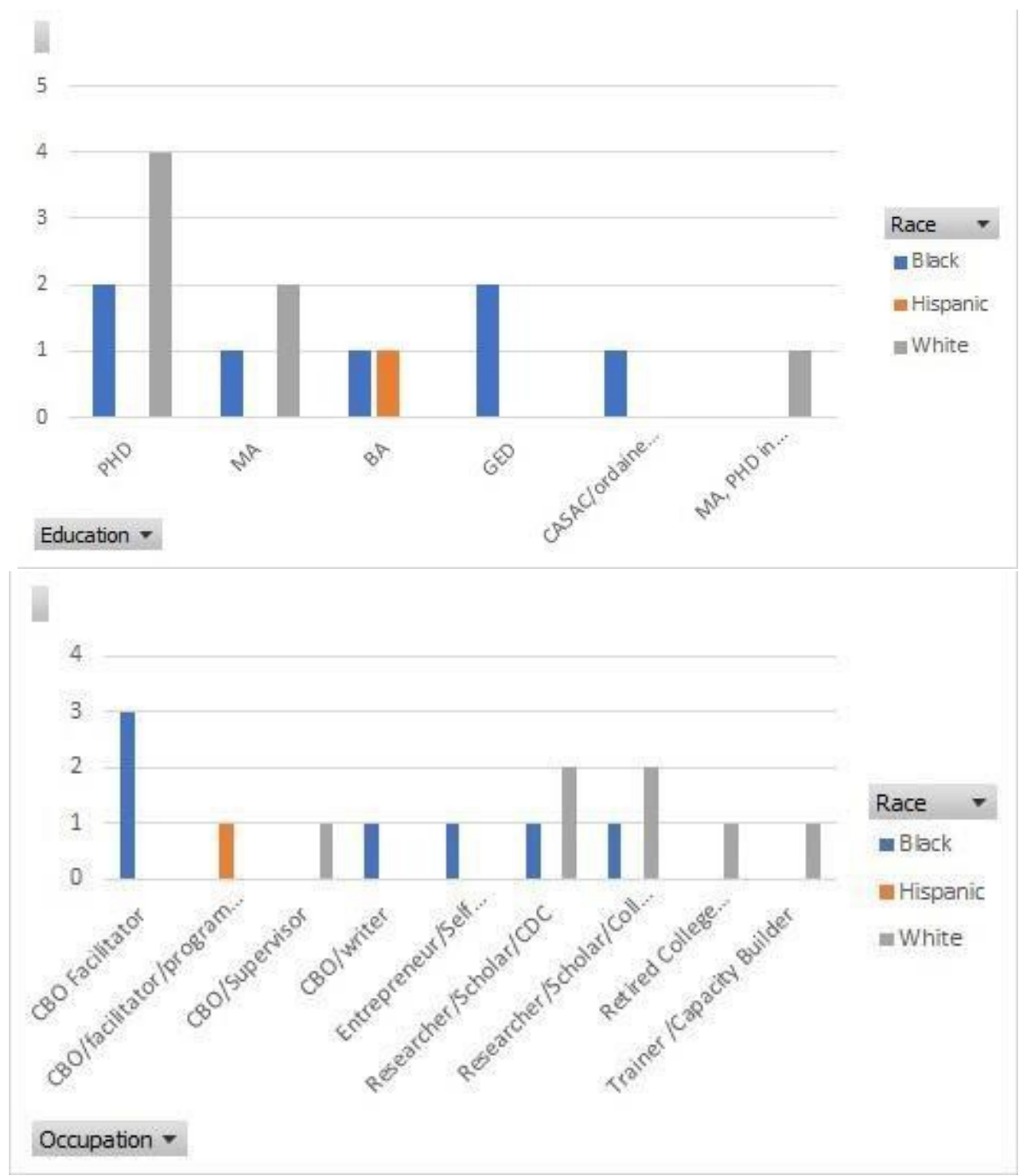

Figure 3. Race, gender, educational and occupation make-up of respondents 
Why "Decolonization?"

\section{CONCLUSION}

In African American and HIV/AIDS, Wingood and DiClemente said, "Prior to

creating a new agenda first requires an assessment of the lessons learned from our current prevention efforts conducted among women” (2010). My work here has been informed by this agenda - prioritizing the health of Black folks and continuing to grow by learning from present and past programs. Creating a dissertation in the era of COVID-19, the murder of George Floyd and others means that we can no longer downplay the violence under which Black, Indigenous, and other people of color (BIPOC) have existed for generations in the US.

To begin, I use the term “decolonization” acknowledging Eve \& Tuck’s (2012) argument that the concept of decolonization has been employed superficially and also as a metaphor. I must acknowledge that my work cannot do the term justice from an Indigenous perspective as any premature attempt to doing so will only add to complicity in harming Indigenous folks and undermining their struggles for sovereignty. They say that scholars must distinguish between decolonizing work and social justice work. My future, as a scholar, is to find a balance between both. Per Eve and Tuck (2012), what decolonization wants is different from what social justice wants. I contend that gaining depth in this form of work this is going to be a long-term project for me. I considered changing the topic but thought to remain true to what I originally set to do with this project.

I align with Eve and Tuck (2012) as they argue that decolonization is a project that seeks to change the world order, that it is a project of complete disorder and cannot come out of friendly understanding. I do not depart completely from Eve and Tuck 
here but use the term from my own perspective. I acknowledge that as a citizen of the Third World who straddles many worlds, I found Fanon's understanding of "decolonizing the mind" useful as a scholar. Eve and Tuck warn that decolonizing the mind alone is not sufficient as a decolonizing project. I take it here as an important step while simultaneously acknowledging that I am a settler on stolen land. I am not intentionally "waylaying” what a more complete decolonization process should look like but am taking the first step of acknowledging settler epistemology, advocating for and conscientizing myself and others to a pedagogy that ignores settler colonialism.

I am hoping to lay some ground for myself in this process, by acknowledging that I do not focus on Indigenous struggles for sovereignty in this work. I focus here on the fact that the colonial process continues and as Eve \& Tuck (2012) acknowledge, the work of "decolonizing the mind is not unimportant" as it allows us to see the ways we, as scholars, continually remain complicit in producing work that maintains the status quo. Dorothy Smith acknowledges her privilege when she writes as mentioned earlier. This reflexivity is an aspect missing from SISTA. The creators and writers, though Black women, possess class privilege and enjoy a proximity to power. From this vantage point, they are well able to speak the language of the settler that blames Black folks for their unequal health outcomes and hence seek to redress their "abnormal" behavior (Foucault 1980), the creators do not acknowledge that it is a classed program and that under another lens it, in fact, disempowers women while simultaneously trying to empower them.

Another dimension to consider is presented by an ethnographical study which uncovers and discusses the intricacies accompanying seemingly commonplace decision 
[not] to use condoms conducted in Atlanta by Gentry Quinn. Though hers is a more of a microlevel analysis of the ways in which African American women in her study negotiate their daily romantic lives, she centers the fact that the women made these decisions in the context of volatile structural conditions. Therefore, while the women in this study may exhibit what is termed as "high-level risky behavior”-particularly a lack of condom use - they reveal other intricate details that usually remain ignored as relevant when sexual decision making is discussed in health behavior literature. Quinn (2007) identifies what she terms five stages of relationships. These stages detail the ways in which women negotiate sexual encounters and also the remarkable implications on the spread of HIV in the Atlanta neighborhood. These five stages are courtship, commitment, conflict, compromise, and conclusion (2007 99).

She recognizes the nuances present at each stage and how these delicate situations guide decisions for condom [non]use. At the courtship stage, for example, where the women are interested in building trust Quinn uncovers the challenges associated with convincing the women to insist on condom use primarily because their priority is on establishing trust. It is similarly as challenging at the commitment stage to introduce condoms since trust has already been established. However, in cases where trust continually gets violated within the relationship, the nature of this relationship automatically transforms to the conflict stage. Here condom use is still largely nonexistent. Quinn attributes this to a willingness by the women to compromise despite the women's feelings of betrayal by their partners. At this conflict stage, the women experience a desire to renew trust and feel that insisting on condom use will jeopardize this effort. This trend usually leads to the conclusion stage where women may decide to 
abandon the old relationship and begin a new one hence creating a brand-new romantic cycle (Quinn 2007 99).

This is not the only work that discusses the complex ways women's priorities factor into their decisions. Black Feminist Thought argues for an intersectional lens and asks that scholars distance our work from Eurocentric, masculinist ways of understanding the lives of Black women. When I asked Dr. Wingood why theory of gender and power was more preferable to Black Feminist Thought, her response was that it was due to the fact that Theory of gender and power can be operationalized. Theory of gender and power produces this conceptual model upon which the CDC can hang its funds.

Leslie McCall (2005) discusses ways that we ought to study intersectionality as a method to critically analyze the complex social forces that have been ignored or neglected in the study the multiple locations women occupy. Therefore, the argument that "structural level causes are tough to study" as mentioned by one respondent, is challenged by McCall's work on operationalizing intersectionality in order to fully account for the lived experiences of women.

The preliminary study of 128 Bayview area Black women responsible for birthing SISTA focused solely on the sexual behaviors, measuring variables such as "age of sexual debut" and ignore the significance of Bayview Hunters Point as a site for community action against environmental injustice. In 1995 the same year the HIV/AIDS study was taking place, Bayview Hunters Point residents were up in arms against environmental racism because there was a plan to build yet another power plant in this area (Clifford 1996). Further, in addition to fighting HIV/AIDS and 
environmental racism, residents were feeling the effects of high drug use and heavy police presence (Lynch, Omori, Roussell and Valasik 2013). SISTA literature says little to nothing about this environment the women being studied found themselves in. SISTA fails to acknowledge that in the face of high drug use, the community felt let down by the state when the state refused to engage in a meaningful clean needle exchange as a preventative measure against intravenous HIV/AIDS transmission. The state was also indicted by and other communities of color for failing to also engage in meaningful prevention efforts for incarcerated men.

In speaking of themes surrounding “recognition” and “identity,” (Taylor 1992) points to the ways scholars essentialize these ideas of community and ignore the fact that as scholars, we usually engage with research from the vantage point of the dominant groups. SISTA is an example of a missed opportunity to speak, the creators who are indeed African American and the idea of community. As he explores the meaning of identity, he urges scholars to continually explore the ways our works are entrenched in positions of power and the ways we comply with discourse of power in order for our work to be recognized. This argument continues to come into view during my interviews with scholars, researchers and community-based organizations working on SISTA. I found that while the program is hailed as a program for "Black women by Black women,” those involved in creating the program essentially speak for Black women ignoring that HIV/AIDS prevention was also not a priority for all Black women even those regarded as at risk. Some women who lost social services would see the HIV+ status as a pathway to resources. This fact was revealed in my interviews, but also by Quinn Gentry (1997) who uncovered a trend among Black women to 
deliberately seek to get HIV infection because, for them, being poor with no access to healthcare, housing and the like was worse than being HIV+.

Further, the idea of "sisterhood" has been challenged by Mohanty whose work warned upper class sisters against reproducing work that further oppresses their otherwise “lower” class country sisters (1991). Marketed as a "peer-led” intervention means as class privilege and reflexivity go unacknowledged resulting, once again the reproduction of harmful stereotypes. Speaking from their position of class privilege, my respondents were not forthcoming in recognizing SISTA as presenting a onedimensional scenario to sexual behaviors of Black folks. It was with probing that we broached this topic plus the pathologizing nature of SISTA when viewed from other lenses. Dr. Wingood was taken aback when I asked the question of whether she had come across literature advancing the argument of SISTA’s demonizing Black men. Though she did say she had not, she did acknowledge, however, that program developers sometimes lose control of the programs they create once these programs are in the hands to larger institutions such as the CDC.

Having said this, it bears recognizing that Clatts’ (1995) suggests that sustainable and effective prevention is largely dependent on interdisciplinary cooperation. He critiques and is skeptical of projects that he accuses of making false and problematic claims of being “scientifically based.” Much like Taylor (1992) who critiques “eurocentered intellectuals" whose work on culture is not only homogenizing but also condescending, Clatts bases his skepticism of the literature focusing on changing "sexually risky behavior" as methodologically challenged. He argues that these generalized studies are flawed when they fail to consider the complexities 
presented by the complex identity categories that people occupy. For Clatts (1995), in some instances, say when it comes to trans folks who did not see themselves as gay, refused to accept they could be at risk for HIV since HIV/AIDS was a "gay thing." Clatts (1995) argues therefore, that these identity categories impact the ways people respond to programs that can be helpful. In my training, some Black women rejected the idea that SISTA was a program for African American women and did not embrace it because they did not identify as African American. They were there simply because they were forced to and were there for the 5 weeks to pass.

To this day SISTA has been generalized to fit the habits of an entire population of African Americans without consideration for the multiple positionalities and complexities of women's everyday lives. In this regard therefore, Clatts argues that in order to even begin to conceive of the idea of what constitutes risky behavior, social scientists should consider the complexities of place and time, and he adds,

To continue to pretend that a two-hour session with an AIDS educator can measurably increase 'self-esteem' in a person who has lived in a context of violence, discrimination, and abject poverty ... is completely to miss the mark (1995 250).

I would concur and advocate for more community-based initiatives that do not disenfranchise the community but those that consider that teaching women to use condoms in relationships where they have limited choices is less effective than inviting communities to become custodians of their own health by increasing inclusive programs that involve Black Men. Studies such as the one Newman, Williams \& Massaquoi (2008) conducted in Canadian came at a time when Black women in Canada are disproportionately impacted by HIV/AIDS as well. A lesson from this study is that 
about putting women at the forefront of planning, involving the Black community

institutions as well as starting sex education early as part of what can be done to reduce HIV/AIDS in the African American community (Newman et al 2008). This is going to take political will in a climate where sex education in the United States is mired in abstinence only political agendas.

As medical sociologists, we continually advocate for increased interdisciplinary strategy to addresses core causes of what drives so called "risky behavior.” We advocate for a distancing from problematic theoretic frameworks that label and pathologize populations experiencing less than optimal health conditions. HIV/AIDS work has some alternate models such as comprehensive harm reduction protocols (CHRP) highlighted by Callahan, Flynn, Kuenneth, \& Enders (2007). These are considered as transtheoretical models noted for using non-dominant, non-hegemonic concepts to understanding health behavior. The models acknowledge and incorporate individual constraints in making healthy choices.

This strategy increases efficiency of the programs already in place and starts to address the discontent surrounding the biased resource allocation to HIV/AIDS.

Evidence was found of three distinct sources of inefficiency in the allocation of HIV/AIDS prevention resources: inefficiency in the mix of interventions selected; inefficient targeting of key populations; and technical inefficiency in the production of HIV prevention services (Bautista-Arredondo 2002 s67).

As Wingood and DiClemente suggest, a "new vision and forward foresight” is needed because HIV/AIDS still continues to devastate the Black community.

From this standpoint, effective resource allocation should involve governmental initiatives and policies to reduce exposure of marginalized populations to fundamental 
causes. Activities such as after school programs can significantly lower youth exposure to risky behavior but those are usually the first items to be cut from state budgets. Further, inner city schools are disproportionately impacted by these cuts. Therefore, using medical sociology frameworks multiple stakeholders can advocate for a conversation that allows the African American community to define their own concept of risk and how to organize around it. For example, among the issues plaguing the African American community is a lack of healthcare. Medical sociology can make political recommendations based on sociological studied critiquing the rise of thirdparty payers such as insurance companies and how this has impacted how African Americans access health and healthcare.

\section{Study Limitations}

This study is mixed methods but more so, it is auto ethnographic. This means that it relies on standpoint as far as my experiences were with this state sponsored programming. I, therefore, welcome suggestions on how to make this project better as I may have blind spots because I am personally and politically invested in it.

For starters, however, I do wish I had more time to interview more people regarding the SISTA program. Were it not for the fact that this study uses Institutional Ethnography which gives me permission to start from my standpoint, I would say that the study is not objective. However, I do acknowledge that I am not an objective observer of the program. I also acknowledge its merits and contributions to the lives of Black women. I also wish I had more time to study the impact of drug use in the lives of Black women and its implications to the susceptibility of women to HIV/AIDs as 
well as present work that speaks to women's subjectivities other than that of Gentry alone.

In conclusion and in light of Hill Collins' (2000) discussion on how Black women have struggled over the years to respectfully critique the work or other Black women, I acknowledge the groundbreaking work that SISTA is. Though, SISTA did not significantly enfold Black men in the efforts to curb HIV/AIDS, it was a welcome tool for some Black women. For example, one respondent, Zanele says she may have not gone through what she went through had she had a program like SISTA in her youth. Dairai said it was not about the content, it was about the comradery the program fostered, the space it created for Black women to sow into each other's lives. However, the way forward is to also acknowledge the way it disempowers women while endeavoring to empower women by ignoring their subjectivities and elevating controlling images. As mentioned earlier, reflexivity is missing in the SISTA program and it is sold as a peer-led initiative yet, once again it ignored the class dynamic. In order to make lasting changes in the outcomes of BIPOC, we must start with work that seeks to transform unjust social institutions. My respondents all agreed that this is an uphill task, acknowledge me to doing the work, and confirmed that the work that critiques domains of power is where true transformation begins. This includes acknowledging the ways dominant discourse on HIV/AIDS contains essentialist understandings of a Black woman’s standpoint. 


\section{REFERENCES}

Al-Saleh, Danya and Rosenfeld, Heather D. 2016. "From White Privilege to White Supremacy: An Illustrated Interview with Laura Pulido." Commentary on environmental racism. Retrieved on June 15, 2020.

(https://edgeeffects.net/white-supremacy-environmental-racism/).

Baciu, Alina, Negussie, Yamrot, Geller, Amy, Weinstein, James N., 2017. “The State of Health Disparities in the United States." pp 57-97 in "Communities in Action: Pathways to Health Equity.” National Academies Press, Washington (DC). Available from:https://www.ncbi.nlm.nih.gov/books/NBK425844/.

Bazin, Hervé. 2001. "The ethics of vaccine usage in society: lessons from the past." In “Current opinion in immunology.” 13. 505-10. 10.1016/S09527915(00)00248-X.

Beach, Richard, Encisco, Patricia, Harste, Jerome, Jenkins, Christine, Raina, Seemi Aziz, Rogers, Rebecca, Short, Kathy G., Sung, Yoo Kyung, Wilson, Melissa, \& Yenika-Agbaw, Vivian. 2009. "Exploring the "Critical” in Critical Content Analysis of Children's Literature.” pp. 129-143in 58th Yearbook of the National Reading. Oak Creek, WI: NRC.

bell hooks, 1984. "Black Women: Shaping Feminist Theory.” pp 544-550 in Let Nobody Turn Us Around: Voices of Resistance, Reform, and Renewal; An African American Anthology, edited by Manning Marable and Leith Mullings. New York: Bowman \& Littlefield Publishers, Inc.

Blauner Bob, 2001. Still the Big news: Racial Oppression in America. Philadelphia Temple University Press.

Bonilla-Silva, Eduardo. 1997. "Rethinking racism: Toward a structural interpretation.” American Sociological Review 62(3): 465-480.

Bourdieu, Pierre. 1984. Distinction: A Social Critique of the Judgement of Taste. London, Routledge.

Brown Givens, Sonja, M. and Monahan, Jennifer, 2005. "Priming Mammies, Jezebels, and Other Controlling Images: An Examination of the Influence of Mediated Stereotypes on Perceptions of an African American Woman.” Media Psychology 7(1): 87-106. 
Browning, Christopher and Cagney, Kathleen. 2003. "Moving beyond Poverty:

Neighborhood Structure, Social Processes, and Health.” Journal of Health and Social Behavior 44(4): 552-571.

Bryce Peter, H. 1918. "History of the American Public Health Association.” American Journal of Public Health 8: 327-335.

Burawoy, Michael and Wright, Erik Olin, 2002. “Sociological Marxism.” pp 459-486 in Handbook of Sociological Theory, edited by J. Turner. New York: Plenum Books.

Byrd, W. Michael. and Clayton, Linda A., 2003. Unequal Treatment: Confronting Racial and Ethnic Disparities in Health Care. Washington, DC: Institute of Medicine of the National Academies.

Combahee River Collective. 1981. "The Combahee River Collective A Black Feminist Statement.” Women's Studies Quarterly 42: 210-218.

Cohen, Cathy J. 1997. "Punks, Bulldaggers, and Welfare Queens: The Radical Potential of Queer Politics?” Lesbian and Gay Quarterly 3(4): 437-465.

Centers for Disease Control. 2018. "Diagnoses of HIV infection in the United States and Dependent areas.” In HIV Surveillance Report 30 Retrieved on June $18^{\text {th }}$, 2019.

https://www.cdc.gov/hiv/group/racialethnic/africanamericans/index.html

Centers for Disease Control. 2016. "Effective Interventions. HIV Prevention That Works." Retrieved on June $18^{\text {th }}, 2019$.

(https://effectiveinterventions.cdc.gov/en/HighImpactPrevention/Interventions/S IS TA.aspx).

Denison, Charles, 1900. “The Failure of the Consensus Judgment with Reference to Tuberculosis.” Medical News, 77(26): 1001.

Bird, Chloe E., Conrad, Peter C., and Allen M. Fremont, 2000. The Handbook of Medical Sociology. Englewood Cliffs, NJ: Prentice Hall.

Clance, Pauline. R., and Imes, Suzanne. A. 1978. "The imposter phenomenon in high achieving women Dynamics and therapeutic intervention.” Psychotherapy: Theory, Research \& Practice 15(3): 241-247. 
Clatts, M. 1995. "Disembodied acts: On the Perverse use of Sexual Categories in the Study of High-risk Behavior.” pp. 241-256 in Culture and sexual risk:

Anthropological perspectives on AIDS edited by $\mathrm{H}$. ten Brummelhuis and G. Herdt, New York: Gordon and Breach.

Cockerham, William C. 2017. Medical Sociology. New York: Routledge. doi.org/10.4324/9781315618692

Cohen, Cathy J. 1999. Boundaries of Blackness: AIDS and the Breakdown of Black Politics. Chicago, IL: University of Chicago Press.

Collins, Patricia. 2002. Black Feminist Thought: Knowledge, Consciousness, and the Politics of Empowerment, London and New York, Routledge, Taylor, and Francis.

Connell, Ronnell W. 1987. Gender and Power. Stanford, CA, Stanford University Press.

Crenshaw Kimberlee. 1991. "Mapping the Margins: Intersectionality, Identity Politics, and Violence against Women of Color". Stanford Law Review 43(6): 12411299.

Crenshaw, Kimberle. 1989. "Demarginalizing the Intersection of Race and Sex: A Black Feminist Critique of Antidiscrimination Doctrine, Feminist Theory and Antiracist Politics." Pp 139-167. University of Chicago Legal Forum. Retrieved on January $18^{\text {th }}$, 2020. https://chicagounbound.uchicago.edu/uclf/vol1989/iss 1/8

Davies H. 2007. "Ethical Reflections on Edward Jenner's Experimental Treatment." Journal of Medical Ethics 33(3): 174-176.

Denison Charles. 1880. Rocky Mountain Health Resorts: An Analytical Study of High Altitudes in Relation to the Arrest of Chronic Pulmonary Disease, Boston: Houghton

Depadilla, Lara, Windle, Michael, Wingood, Gina, Cooper, Hannah and DiClemente, Ralph. 2011. "Condom Use Among Young Women: Modeling the Theory of Gender and Power.” Health Psychology 30(3): 310-319.

Deveau, Jean L. 2009. “Examining the Institutional Ethnographer’s Toolkit.” Socialist Studies 4(2): 1-20. 
DiClemente Ralph, Crosby, Richard A., Kegler, Michelle. 2002. "Understanding and Applying Theory in Health Promotion Practice and Research.” pp 1-15 in Emerging Theories in Health Promotion Practice and Research: Strategies for Improving Public Health. San Francisco, CA: Jossey-Bass.

DiClemente Ralph J and Wingood Gina.1995. “A Randomized Controlled Trial of an HIV Sexual Risk-reduction Intervention for Young African-American women.” JAMA 274 (16):1271-1276.

Smith, Dorothy E. 1996. "The Relations of Ruling: A Feminist Inquiry Studies.” Cultures, Organizations and Societies 2:(2): 171-190.

DOI: $10.1080 / 10245289608523475$

Ehrlich, Carol. 1981. 'The Unhappy Marriage of Marxism and Feminism: Can It Be Saved' in Women and Revolution: A Discussion of the Unhappy Marriage of Marxism and Feminism, Quebec, Canada: Black Rose

Emerson, Robert. M., and Fretz Rachel I., and Shaw Linda. 1997. Writing Ethnographic Fieldnotes. Chicago: University of Chicago Press.

Enfield, Nick J. 2000. “The Theory of Cultural Logic: How Individuals Combine Social Intelligence with Semiotics to Create and Maintain Cultural Meaning." Cultural Dynamics 12(1): 3564. https://doi.org/10.1177/092137400001200102

Farmer, Paul. 1999. Infections and Inequalities: The Modern Plagues. Berkeley, CA: University of California Press.

Foucault Michel. 1977. Discipline and Punish: The Birth of the Prison. New York: Pantheon.

Foucault, Michel. 1972. The Archaeology of Knowledge. London: Routledge.

Foucault, Michel. 1982. “The Subject and Power.” Critical Inquiry 8(4): 777-795.

Foucault, Michel and Gordon, Colin. 1980. Power/knowledge: Selected interviews and other writings, 1972-1977. New York: Pantheon Books.

Foucault, Michel 1973. The Birth of the Clinic. New York: Pantheon Books.

Foucault, Michel. 1979. Discipline and Punish: The Birth of the Prison. New York: Vintage Books. 
Fryer, Roland. G. Jr., and Holden Richard. 2011. "Measuring the Compactness of Political Districting Plans.” The Journal of Law and Economics 54(3):493535. doi:10.1086/661511

Gao, Chungchan, 2000. African Americans in the Reconstruction Era. New York, NY: Garland Publishing.

Garofalo, Robert., Hotton Anna. L., Kuhns, Lisa. M., Gratzer, Beau., and Mustanski, Brian. 2016. "Incidence of HIV Infection and Sexually Transmitted Infections and Related Risk Factors Among Very Young Men Who Have Sex with Men." Journal of Acquired Immune Deficiency Syndromes 72(1): 79-86.

George W. Smith. 1990. “Political Activist as Ethnographer.” Social Problems 37(4): 629-648, https://doi.org/10.2307/800586.

George Petros, Collins O. Airhihenbuwa, Leickness Simbayi, Shandir Ramlagan, \& Brandon Brown. 2006. "HIV/AIDS and 'Othering' in South Africa: The Blame Goes On.” Culture, Health \& Sexuality, 8(1): 67-77.

Gilman, Charlotte P. 1908. “A Suggestion on the Negro Problem.” American Journal of Sociology 14:78-85.

Glanz, Karen., Rimer, Barbara. and Lewis, F. 2002. Health behavior and health education. Theory, research, and practice. Wiley \& Sons, San Francisco.

Glanz, Karen. 1997. “Theory at a Glance: A Guide for Health Promotion Practice.” Bethesda, MD: U.S. Dept. of Health and Human Services, Public Health Service, National Institutes of Health, National Cancer Institute. Retrieved February 25th, 2020. https://cancercontrol.cancer.gov/brp/research/theories_project/theory.pdf

Goodman, Lisa. A., Liang Belle, Helms Janet E., Latta Rachel E., Sparks Elizabeth, and Weintraub Sarah R. 2004. 'Training Counseling Psychologists as Social Justice Agents: Feminist and Multicultural Principles in Action.” The Counseling Psychologist 32(6): 793836. https://doi.org/10.1177/0011000004268802.

Gusterson, Hugh. 1997. “Studying up Revisited.” PoLAR: Political and Legal Anthropology Review 20(1): 114-119.

Hartmann, Heidi. I. 1979. “The Unhappy Marriage of Marxism and Feminism: Towards a more Progressive Union.” Capital \& Class 3(2): 1-33. 
Hollingshead, August. 1941. “The Concept of Social Control.” American Sociological Review 6(2): 217-224.

Homan, Patricia. 2019. "Structural Sexism and Health in the United States: A New Perspective on Health Inequality and the Gender System.” American Sociological Review 84(3):486- 516.

Hunzaker, Mary. B. and Valentino Lauren. 2019. "Mapping Cultural Schemas: From Theory to Method.’ American Sociological Review 84(5): 950-981.

Jen'nan Ghazal and Bridget K. Gorman. 2010. "Gender and Health Inequality." Annual Review of Sociology 36:371-386.

Jensen John.1997. "Before the Surgeon General: marine hospitals in mid-19th-century America.” Public Health Rep. 1997;112(6):525-527.

Johnson Burke R. \& Onwuegbuzie Anthony J. 2004. "Mixed Methods Research: A Research Paradigm Whose Time Has Come Author(s).” Educational Researcher 33(7): 14-26.

Jones, Byn. 1975. "Max Weber and the Concept of Social Class.” The Sociological Review 23(4), 729-757. https://doi.org/10.1111/j.1467-954X.1975.tb00538.x

Jones, Trina, and Norwood Kimberly J. 2017. “Aggressive Encounters \& White Fragility: Deconstructing the Trope of the Angry Black Woman.” Iowa Law Review 102(5): 2016-2069.

Katz, Michael. 2013. The Undeserving Poor: America’s Enduring Confrontation with Poverty. New York: Oxford University Press.

Krieger, Nancy. 2000. “Discrimination and Health.” In Social Epidemiology, edited by LF Berkman, I Kawachi. London: Oxford University. Press

Lee, Salome. 2011. "Until We Are All Abolitionists: Marx on Slavery, Race, and Class." U.S. Marxist- Humanists Retrieved May 14th, 2020. https://imhojournal.org/articles/abolitionists-marx-slavery-race-classsalome-lee/

Link, Bruce G. And Phelan Jo C. 1995. "Social Conditions as Fundamental Causes of disease.” pp 80-94 In Journal of Health and Social Behavior. Retrieved August 14th, 2019. 
https://www.jstor.org/stable/2626958?seq=1\#metadata_info_tab_contents

London, Andrew. S., \& Myers, Nancy. A. 2006. "Race, Incarceration, and Health: A Life-Course Approach.” Research on Aging, 28(3): 409-422. https://doi.org/10.1177/0164027505285849

McGlynn Karen., Griffin Mary.Q., Donahue Moreen. and Fitzpatrick Joyce J. 2012. "Registered Nurse Job Satisfaction and Satisfaction with the Professional Practice Model.” Journal of Nursing Management 20(2): 260-265.

McCall, Leslie. 2005. “The Complexity of Intersectionality.” Signs, 30(3): 1771-1800. https://doi:10.1086/426800

Meier, August. 1963. "Negro Thought in America 1880-1915: Racial Ideologies in the Age of Booker T. Washington.” Ann Arbor, Michigan. University of Michigan Press.

Minh-ha, T. 1990. "Not you/like you: Post-colonial women and the interlocking questions of identity and difference.” pp 371-375 in Making Face, Making Soul: Haciendo caras: Creative and Critical Perspectives by Feminists of Color edited by Anzaldúa, G. San Francisco: CA. Aunt Lute Foundation Books.

Mirowsky, John, Catherine E. Ross, and John Reynolds. 2000. "Links Between Social Status and Health." pp 47-67 in The Handbook of Medical Sociology, edited by Chloe E. Bird, Peter Conrad, and Allen M. Fremont. Upper Saddle River, NJ: Prentice Hall.

Mitman, Gregg and Numbers, Ronald. 2003. "From Miasma to Asthma: The changing Fortunes of Medical Geography.” History and Philosophy of the Life Sciences 25(3): 319-412.

Morgan, David. 1993. "Qualitative Content Analysis: A Guide to Paths Not Taken.” Qualitative Health Research 3(1): 112-21.

Morrison Peter A., Bryan Thomas M. 2019. “Unmasking 'Packing' and 'Cracking' for Racial or Partisan Purposes.” pp. 75-85 in "Redistricting: A Manual for Analysts, Practitioners, and Citizens." Switzerland, Springer.

Mykhalovskiy, Erik. 2010. "Integrating HIV Treatment and Prevention: Shifts in Community-based organizing and Biopolitics in the Canadian Context" pp 6186 in HIV, Technology and Subjectivity: International Cases Studies of HIV 
Treatment and Prevention edited by Davis M., Squire C. London: Palgrave MacMillan.

Navarro, Zander. 2006. "In Search of Cultural Interpretation of Power: The Contribution of Pierre Bourdieu” in IDS Bulletin 37(6): 11-22. https://doi.org/10.1111/j.1759-5436.2006.tb00319.x

Ng, Stella., Stooke, Rosamund, Regan, Sandra, Hibbert, Kathryn, Schryer, Catherine, Phelan, Shanon, and Lingard, Lorelei. 2013. “An Institutional Ethnography Inquiry of Health Care Work in Special Education: A Research Protocol. ” International Journal of Integrated Care Retrieved September 18th, 2020. https://doi.org/10.5334/ijic. 1052

Niemi, Richard G., Grofman, Bernard, Carlucci, Carl, and Hofeller, Thomas. 1990. "Measuring Compactness and the Role of a Compactness Standard in a Test for Partisan and Racial Gerrymandering.” The Journal of Politics 52(4):11551181. https://doi:10.2307/2131686.

Orser, W. Edward. 1994. Blockbusting in Baltimore: The Edmondson Village Story. Knoxville: University Press of Kentucky.

Pager, Devah. 2003. "The Mark of a Criminal Record.” American Journal of Sociology 108(5): 937-975.

Parsons, Talcott. 1975. "The Sick Role and the Role of the Physician Reconsidered.” The Milbank Memorial Fund Quarterly. Health and Society, 53(3): 257-278. https://doi:10.2307/3349493

Patricia Homan, Lauren Valentino, Emi Weed. 2017. "Being and Becoming Poor: How Cultural Schemas Shape Beliefs About Poverty” Social Forces 95(3) 10231048, https://doi.org/10.1093/sf/sox007.

Prasad, Monica. 2018. "Problem-Solving Sociology.” Contemporary Sociology 47(4), 393-398. https://doi.org/10.1177/0094306118779810

Pulido, L. 2000. "Rethinking Environmental Racism: White Privilege and Urban Development in Southern California.” Annals of the Association of American Geographers, 90(1), 12-40. 
Quadagno, Jill. S. 1994. The Color of Welfare: How Racism Undermined the war on Poverty. New York, NY. Oxford University Press.

Rankin, Janet. 2017. "Conducting Analysis in Institutional Ethnography: Guidance and Cautions.” International Journal of Qualitative Methods. Retrieved April 19, 2020. https://doi.org/10.1177/1609406917734472

Reiland Rabaka. 2018. "W.E.B. Du Bois, the Death of the Talented Tenth and the Birth of the Guiding Hundredth: Black Conservatism, Black Radicalism and Critical Social Theory.” pp. 399-449 in “W.E.B. Du Bois and the Africana Rhetoric of Dealienation" Monique Leslie Akassi, Newcastle upon Tyne, UK: Cambridge Scholars Publishing.

Reilly, K. 2016. “Hillary Clinton Transcript: 'Basket of deplorables' comment.” Time Magazine. Retrieved September 10, 2019 http://time.com/4486502/hillaryclinton-basket-ofdeplorables-transcript )

Robert, Nola. 1998. Knowledge, Discourse, Power and Genealogy.” In Foucault, Critical Review of International Social and Political Philosophy 1(2): 109-154. DOI: $10.1080 / 13698239808403240$

Rosenstock, Irwin. M., Strecher, Victory J., \& Becker, Marshall H. 1994. "The health Belief Model and HIV Risk Behavior Change.” pp. 5-24 in Preventing AIDS: Theories and methods of behavioral interventions. AIDS prevention and mental health edited by DiClemente R. J. and J. L. Peterson. New York, NY: Plenum Press.

Sampson Robert J, Raudenbush and Stephen W, Earls Felton. 1997. 'Neighborhoods and Violent crime: A Multilevel study of Collective Efficacy." Science 277(5328):918-924.

Sawyer, S.W. 2015. “Foucault and the state.” The Tocqueville Review/La revue Tocqueville 36(1), 135-164. https://www.muse.jhu.edu/article/584858.

Schur, David. 1998. “An Introduction to Close Reading.”

Retrieved May 18th, 2020. http://sites.fas.harvard.edu/ lac14/texts-resources/SchurCloseReading99.pdf

Siegel, H. 1989. "The Rationality of Science, Critical Thinking, and Science Education.” Syntheses, 80(1): 9-41. Retrieved February 5, 2020.jstor.org/stable/20116665 
Simon, Jonathan. 2013 "Punishment and the Political Technologies of the Body" pp 6089 in The SAGE Handbook of Punishment and Society edited by Simon J and Sparks R. London: SAGE Publication.

Smith, Dorothy. E. 1978. 'K is Mentally Ill’ the Anatomy of a Factual Account.” Sociology, 12(1), 23-53.

Spring, Victoria, Cameron Daryl, C., and Cikara Mina. 2018. “The Upside of Outrage.” Trends Cognitive Sciences 22(12): 1067-1069.

Washington, Harriet. 2006. Medical Apartheid. New York: Doubleday.

Weinstein, Neil. D. 1993. "Testing Four Competing Theories of HealthProtective Behavior.” Health Psychology 12(4): 324-333.

Wiegman, Robyn. 1993. "The Anatomy of Lynching.” Journal of the History of Sexuality 3(3): 445-467.

Williams, Joseph P. 2020. "Rumor, Disparity and Distrust: Why Black Americans Face an Uphill Battle Against COVID-19.” US News. Retrieved August 15 2020. https://www.usnews.com/news/healthiestcommunities/articles/2020-0325/whyblack-americans-face-an-uphill-battle-against-the-coronavirus.

Wilton, James. 2012. "Putting a Number on It: The Risk from an Exposure to HIV." Prevention in Focus. https://www.catie.ca/en/pif/summer-2012/putting-number-it-risk-exposure-hiv.

Wingood Gina M., DiClemente Ralph J. 1996. "HIV Sexual Risk Reduction Interventions for Women: A Review.” American Journal of Preventative Medicine 12(3): 209-217.

Wingood Gina M., DiClemente Ralph J. 2000. “Application of the Theory of Gender and Power to Examine HIV Related Exposures, Risk Factors and Effective Interventions for Women.” Health Education Behavior 27(5): 539-565.

Zola, Irving K. 1972. "Medicine as an Institution of Social Control.” The Sociological Review 20(4): 487-50. https://doi.org/10.1016/0277-9536(95)00313-4 
APPENDIX A."Wake up Mommy!"

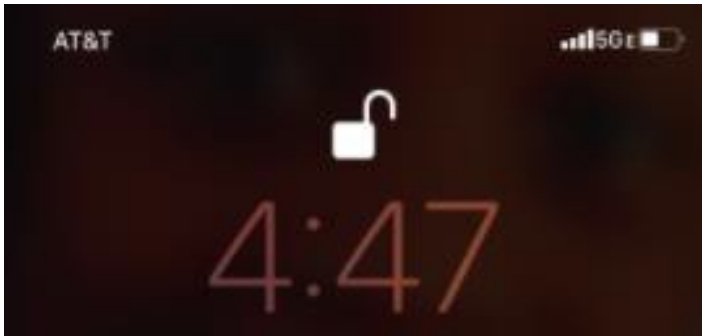

Monday, April 20

Wake up mommy!! I love you $" \mathrm{C}$

Snooze

Stop 
APPENDIX B. - SISTA Training Manual Front Page and page 2, 2005

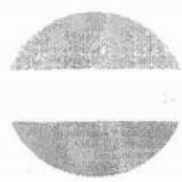

THE SISTA PROJECT FACILITATOR'S MANUAL

\section{TABLE OF CONTENTS}

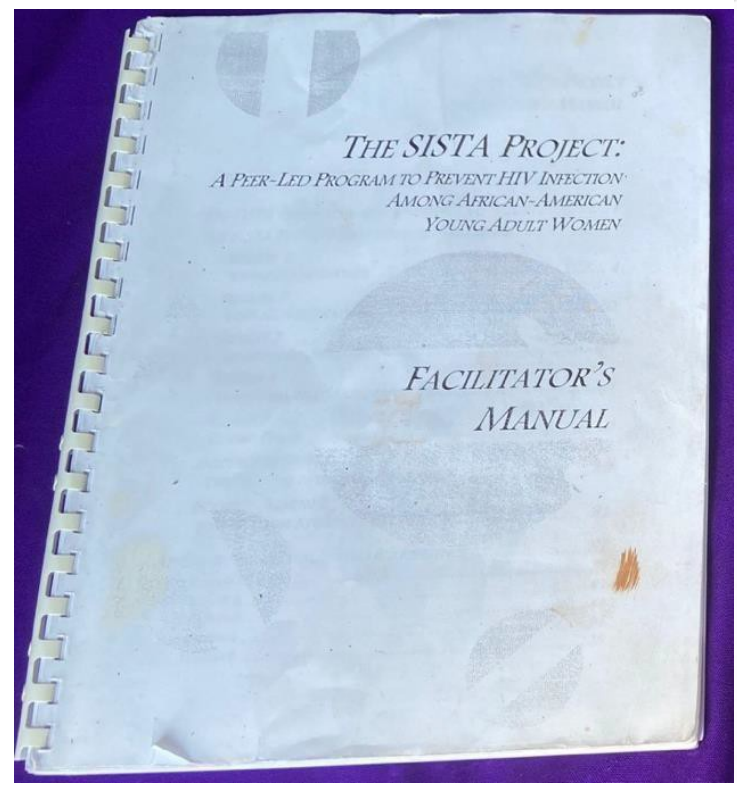

THE SISTA PROJECT: AN INTRODUCTION.

THE SISTA PROJECT: IMPLEMENTATION GUIDELINES

SESSION 1

ETHNIC/GENDER PRIDE.......................................... 4

SESSION 2

HIV/AIDS EDUCATION............................................ 10

SESSION 3

ASSERTIVENESS SKILLS TRAINING..............................21

SESSION 4

BEHAVIORAL SELF-MANAGEMENT TRAINING .....................29

SESSION 5

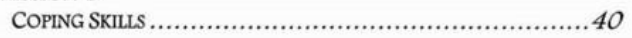

BOOSTER SESSION 1

TWO MONTHS AFTER THE INTERVENTION ...........................49

BOOSTER SESSION 2

FOUR MONTHS AFTER THE INTERVENTION .........................51

APPENDIX: PROGRAMMATERIALS FOR REFERENCE ....................52

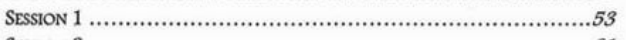

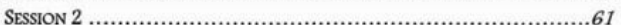

SEsSION 3 …................................................................ 84

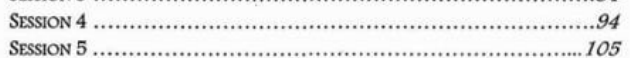

SISTA Update manual - 2008

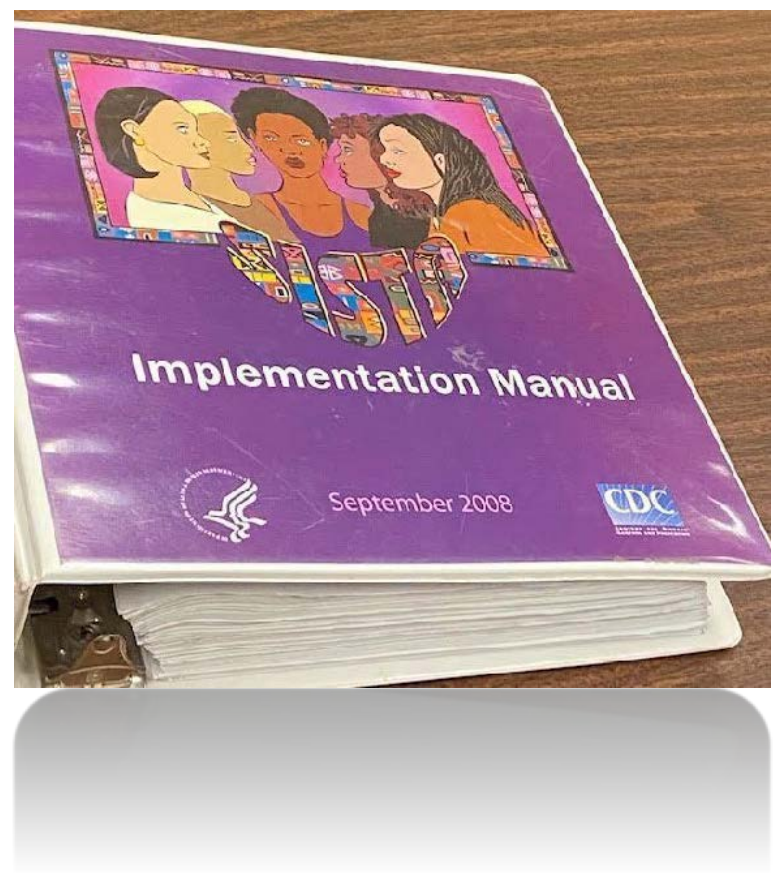


APPENDIX C. Some activities

\section{Session 1: Ethnic and Gender Pride}

\section{Purposes:}

1) To introduce the intervention and set cultural climate.

2) To discuss ethnic and gender pride and what it means to be an African American woman.

3) To identify and discuss strong and positive role models.

4) To discuss the importance of having personal values, prioritizing them, and knowing how they affect decision making.

\section{Activities:}

1.1 Introductions and SISTA Intervention Overview

1.2 Ground Rules: SISTA Agreements

\subsection{Parking Lot: At the Kitchen Table}

1.4 Opening Poem

1.5 Ethnic and Gender Pride

1.6 Personal Values Rankings

1.7 Take-Home Activity

1.8 Session 1 Evaluation

1.9 Closing Poem

1.10 SISTA Motto

\section{Session 2: HIVIAIDS Education}

\section{Purposes:}

1) To provide accurate and up-to-date information on HIVIAIDS and other sexually transmitted diseases.

2) To correct myths and misconceptions about HIVIAIDS and prevention.

3) To discuss the importance of sexual self-protection.

\section{Activities:}

\subsection{Opening Poem}

2.2 Review - SISTA Agreements and At the Kitchen Table

2.3 Review - Session 1 Key Learning Points and Take-Home Activity

2.4 Local and Up-to-Date HIVIAIDS Statistics

2.5 HIVIAIDS 101

2.6 Card Game

2.7 Video: "It's Like This...."

2.8 Take-Home Activity

2.9 Session 2 Evaluation

2.10 Closing Poem

2.11 SISTA Motto 


\section{Session 3: Assertiveness Skills Training}

Purposes:

1) To teach the participants to recognize and understand assertive, aggressive, and non-assertive behaviors.

2) To teach how assertive communication skills can be used to negotiate safer sexual behavior.

\section{Activities:}

3.1 Opening Poem

3.2 Review - SISTA Agreements and At the Kitchen Table

3.3 Review - Session 2 Key Learning Points and Take-Home Activity

3.4 Assertiveness Skills Training

3.5 How Do I Handle This?

3.6 SISTAS Assertiveness Model

3.7 Take-Home Activity

3.8 Session 3 Evaluation

3.9 Closing Poem

\subsection{SISTA Motto}

\section{Session 4: Behavioral Self-Management Training}

Purposes:

1) To facilitate a discussion about the reasons women do not insist their partners use condoms.

2) To increase women's confidence in their skill and ability to use condoms.

3) To reduce anxiety about condom use.

\section{Activities:}

4.1 Opening Poem

4.2 Review - SISTA Agreements and At the Kitchen Table

4.3 Review - Session 3 Key Learning Points and Take-Home Activity

4.4 Reasons Why People DON'T Use Condoms

4.5 Condom Basics

4.6 Condom Line-Up Game

4.7 Condom Use Demonstration and Practice

4.8 Negotiating Safer Sex

4.9 Peer Norms

4.10 Take-Home Activity

4.11 Session 4 Evaluation

4.12 Closing Poem

4.13 SISTA Motto 


\section{Session 5: Coping Skills}

\section{Purposes:}

1) To discuss coping strategies.

2) To discuss how alcohol and substance use affects sexual risk behaviors for STDs and HIV.

3) To discuss negative responses to safer sexual behavior.

4) To review sessions 1-4.

\section{Activities:}

5.1 Opening Poem

5.2 Review - SISTA Agreements and At the Kitchen Table

5.3 Review - Sessions 1-4 Key Learning Points and Take-Home Activity

5.4 Coping is...

5.5 Coping with Drugs and Alcohol in Sexual Situations

5.6 Coping with Rejection and Negative Responses

5.7 Session 5 Evaluation

5.8 Closing Poem

5.9 SISTA Motto 
APPENDIX D. - SISTA Core elements

\section{Core Elements}

The core elements of the SISTA intervention are thought to be responsible for the intervention's effectiveness. The core elements come from the behavioral theory upon which the intervention is based. Core elements are those parts of an intervention that must be implemented. Core elements are essential and cannot be ignored, added to, or changed. ${ }^{1}$

\section{The core elements of SISTA are:}

1. Convene small-group sessions to discuss the session objectives; model skills development; role-play women's skills acquisition; and address the challenges and joys of being an African American woman.

2. Use skilled African American female facilitators to implement SISTA group sessions.

3. Use culturally and gender appropriate materials to acknowledge pride, and enhance self-worth with regard to being an African American woman (e.g., use poetry by African American women).

4. Teach women to communicate both verbally and non-verbally to show they care for their partner and need to protect themselves (e.g., negotiation skills, assertive communication skills).

5. Instruct women on how to use condoms effectively and consistently (e.g., negotiation skills, assertive communication skills).

6. Discuss culture and gender-related barriers and facilitators to using condoms (e.g., provide information on African American women's risk of HIV infection).

7. Emphasize the importance of a partner's involvement in safer sex (e.g., enhance partner norms supportive of condom use). 
APPENDIX E. SISTA definition

THE SISTA PROJECT consists of five once-a-week two-hour sessions. These sessions build on one another and have been developed to encourage group participation in an open and stimulating environment. The sessions (in the order that they will be taught) include:

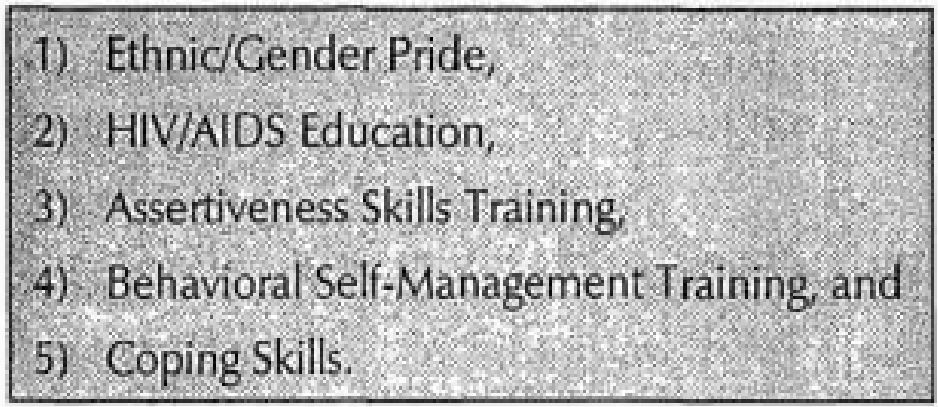


APPENDIX F. - Description of Theory of Gender and power

The Theory of Gender and Power is integrated into the activities of the intervention in the following ways. SISTA activities aim to empower African American women through discussions and shared experiences about ethnic and gender pride designed to praise the strengths of African American women and to identify African American female role models. SISTA activities include HIV risk reduction skills-building (e.g., assertive communication, condom use, etc.) within the context of gender-based power inequalities, norms and values, such as enhancing assertive communication skills, sexual risk reduction negotiation, and condom use skills. SISTA activities aim to enhance coping with emotions that interfere with safer sex decisions. Take-home assignments foster partner norms that support risk reduction strategies. 
APPENDIX G. - SISTA Logic Model
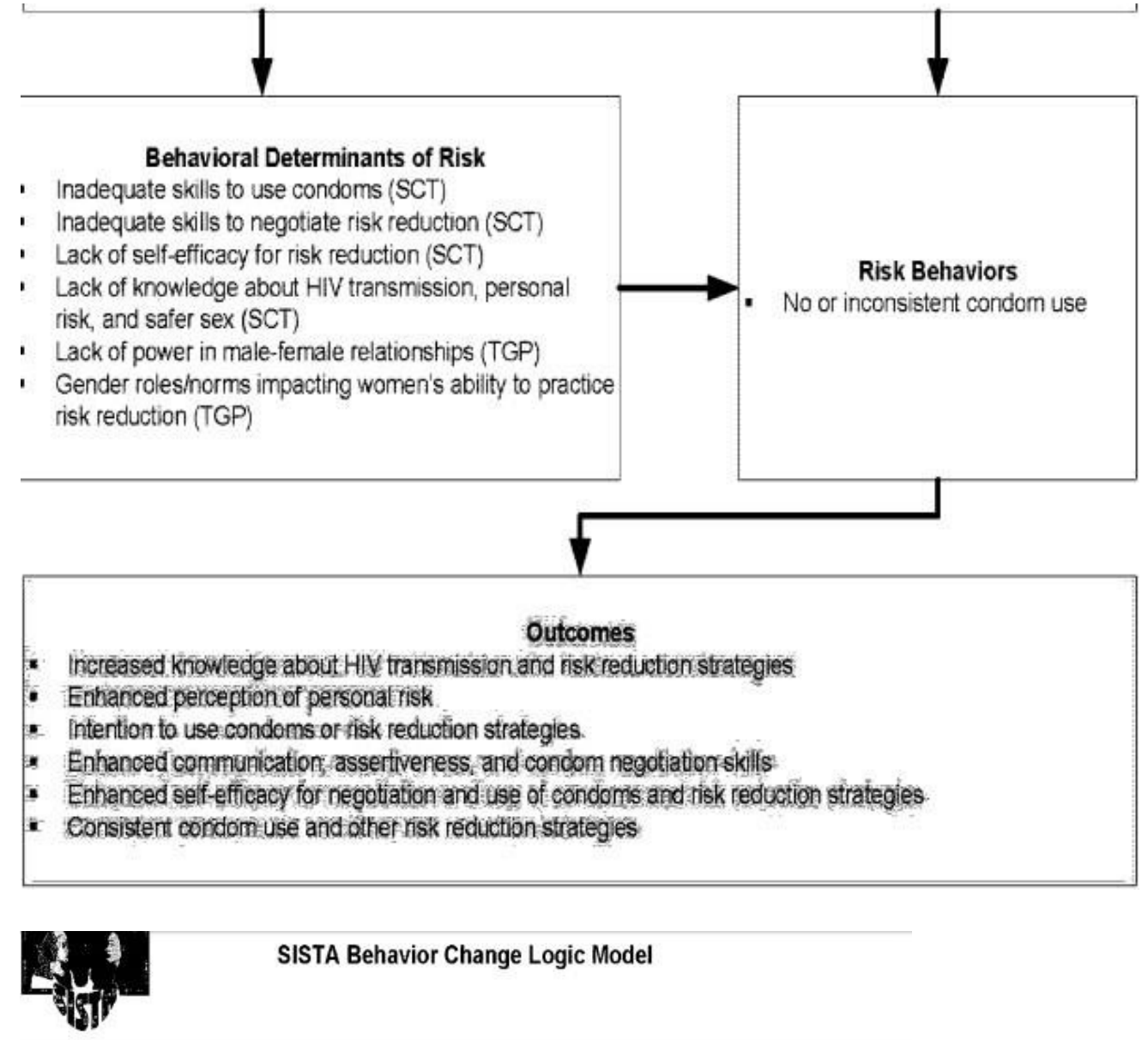

SISTA Behavior Change Logic Model

Theoretical Foundation

Social Cognitive Theory (SCT) and Theory of Gender and Power (TGP)

- Peer support and influence (SCT)

- Knowledgefinformation (HIV transmission, condoms) (SCT)

- Model condom use and negotiation (SCT)

- Skills building (condom use and negotiation, sexual risk reduction, sexual communication skills) (SCT)

- Skills building in emotionally arousing situations (TGP)

- Self-efficacy for sexual risk reduction (SCT)

- Skill building within the cultural context of gender-based power inequalities, norms, and values (TGP)

- Empowerment (TGP)

- Explore gender and cultural factors that increase vunnerability to HIV (TGP)

।

Intervention Activities

Small group discussion of African American women (peers) which include:

- Information on HIVIAIDS among African American women, HIV transmission, risk reduction behaviors, and condoms

- Modeling, role play, and practice of assertive communication, condom negotiation and use

- Discussion of gender norms and power in heterosexual relationships and impact on womeris ability to negotiate risk reduction

- Foster gender and ethnic pride via culturally relevant poems, exercises, and room decorations

- Culturally specific exercises designed to praise the strengths of African American women and to identify African American female role models

- Foster partner norms that support risk reduction strategies via home work activities

- Use skilled African American female facilitators to implement group sessions

- Enhance coping with emotions that interfere with safer sex 


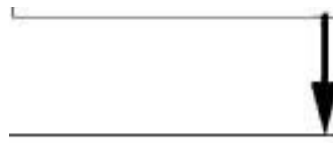

Behavioral Determinants of Risk

1. Inadequate skills to use condoms (SCT)

1. Inadequate skills to negotiate risk reduction (SCT)

1 Lack of self-efficacy for risk reduction (SCT)

1 Lack of knowledge about HIV transmission, personal risk, and safer sex (SCT)

1. Lack of power in male-female relationships (TGP)

1 Gender roleshorms impacting women's ability to practice risk reduction (TGP)

\section{Outcomes}

* Increased knowledge about HIV transmiss ion and nisk reduction strategies

- Enhanced perception of personalifisk

- intention to use condoms or risk reduction strategies.

* Enhanced communication, assertiveness, and condom negotiations skills

- Enhanced self-efficacy for negotation and use of condomis and visk reduction strategies

- Consistent condom use and other risk reduction strateges 
APPENDIX H. Conceptual model for the Theory of Gender and Power

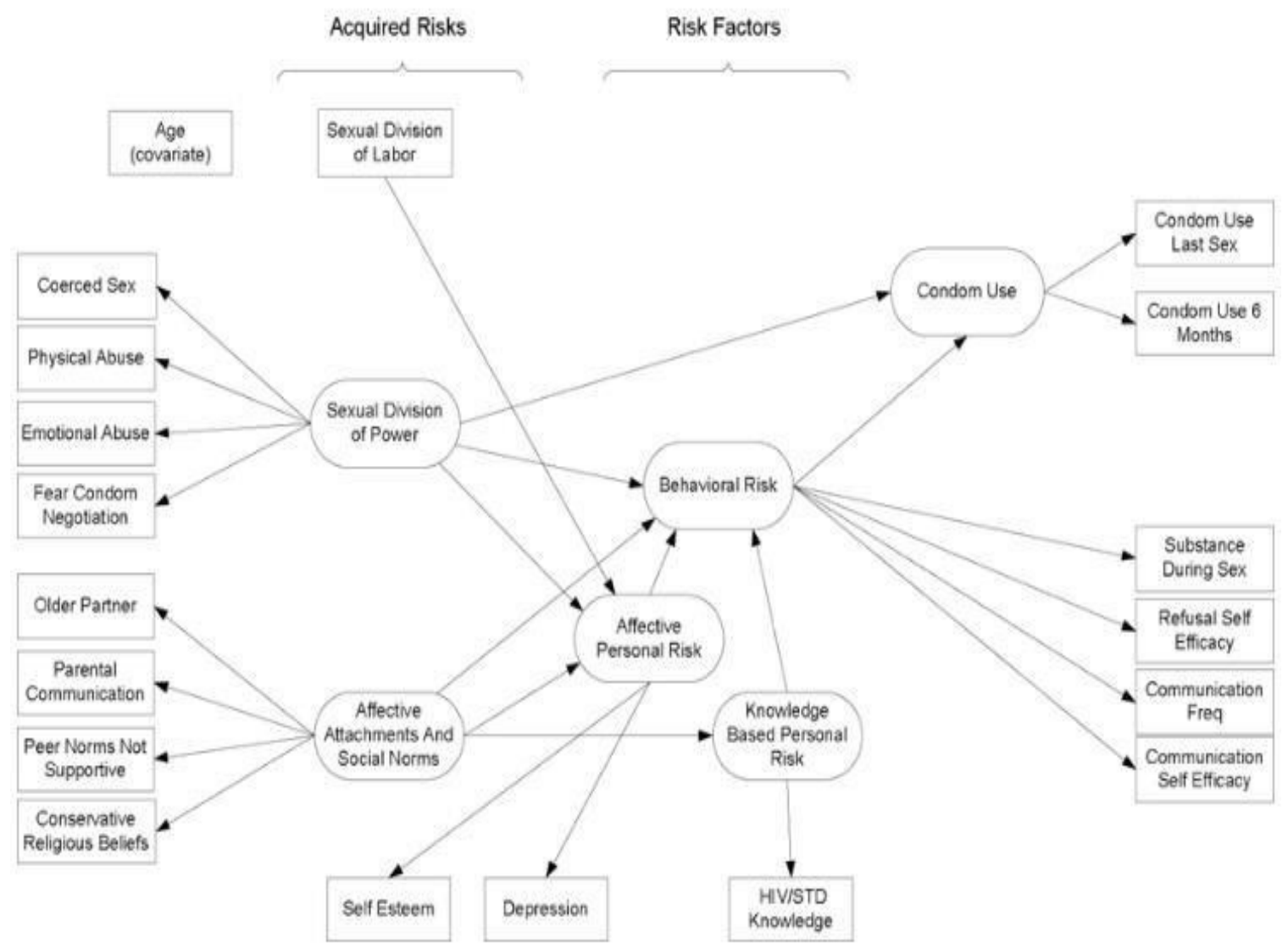

- Conceptual model for the Theory of Gender and Power Note: The Sexual Division of Labor is a composite scale describing SES that includes the variables any receipt of government aid, lack of employment, and less than a high school education. Age was tested as a potential control variable between predictors and the outcome. Ovals represent latent constructs and rectangles represent directly observed variables. DePadilla et al (2012) 


\section{APPENDIX I. Rationalization for Theory of Gender and power}

TABLE 3. Adapting the Theory of Gender and Power to the Suite of HIV Interventions for African American Women

\begin{tabular}{|c|c|c|c|}
\hline Division & SiSTA & SiHLE & WILLOW \\
\hline Labor & $\begin{array}{l}\text { Being economically dependent on } \\
\text { males }\end{array}$ & Having older male sex partners & Having limited practical support \\
\hline \multirow[t]{2}{*}{ Power } & $\begin{array}{l}\text { Being in a power imbalanced rela- } \\
\text { tionship }\end{array}$ & Having violent dating partners & Having violent domestic partners \\
\hline & $\begin{array}{l}\text { Perceiving limited partner avatl- } \\
\text { ability }\end{array}$ & Being stereotyped by the media & $\begin{array}{l}\text { Being stigmatized as an HIV } \\
\text { vector }\end{array}$ \\
\hline \multirow[t]{4}{*}{ Cathexis } & $\begin{array}{l}\text { Perceiving limited regard by soci- } \\
\text { efy of African American women }\end{array}$ & $\begin{array}{l}\text { Perceiving limited regard by soci- } \\
\text { ety of African American teens }\end{array}$ & $\begin{array}{l}\text { Perceiving limited regard by } \\
\text { societyof HIV + women }\end{array}$ \\
\hline & Having long-term relationships & Engaging in serial monogamy & Having limited emotional support \\
\hline & Desiring pregnancy & Experiencing peer pressure & Having limited appraisal support ${ }^{2}$ \\
\hline & Communicating nonassertively & Communicating nonassertively & Communicating nonassertively \\
\hline
\end{tabular}

Appraisal support involves the provision of information that is useful for self-evaluative purposes. Examples of appraisal support include constructive feedback, affirmation, and social comparison. 
APPENDIX J. Excerpt from the movie "Its Like This"

ta

- Pearl, Gladys' mom, was supportive of her daughter after she told her she was HIV positive. She was willing to take early retirement to assist with Gladys' children.

- Cynthia, Gladys' sister, was also very supportive and accepting of Gladys and wanted to be there for her and the children.

- Darrel, Gladys' oldest son, was very upset after finding out she was HIV positive. He refused to go to visit a counselor, started skipping school, and didn't want to talk to Gladys about the issue.

- Robert, Gladys' youngest son, was upset to learn his mother was HIV positive and started coming home early from school and wouldn't play with other children. Gladys got Robert into counseling and he started to learn how to deal with having an HIV positive parent.

- Shana Pearl is Gladys' daughter who was born after she learned she was HIV positive. Shana was not HIV positive and was celebrating her first birthday. 


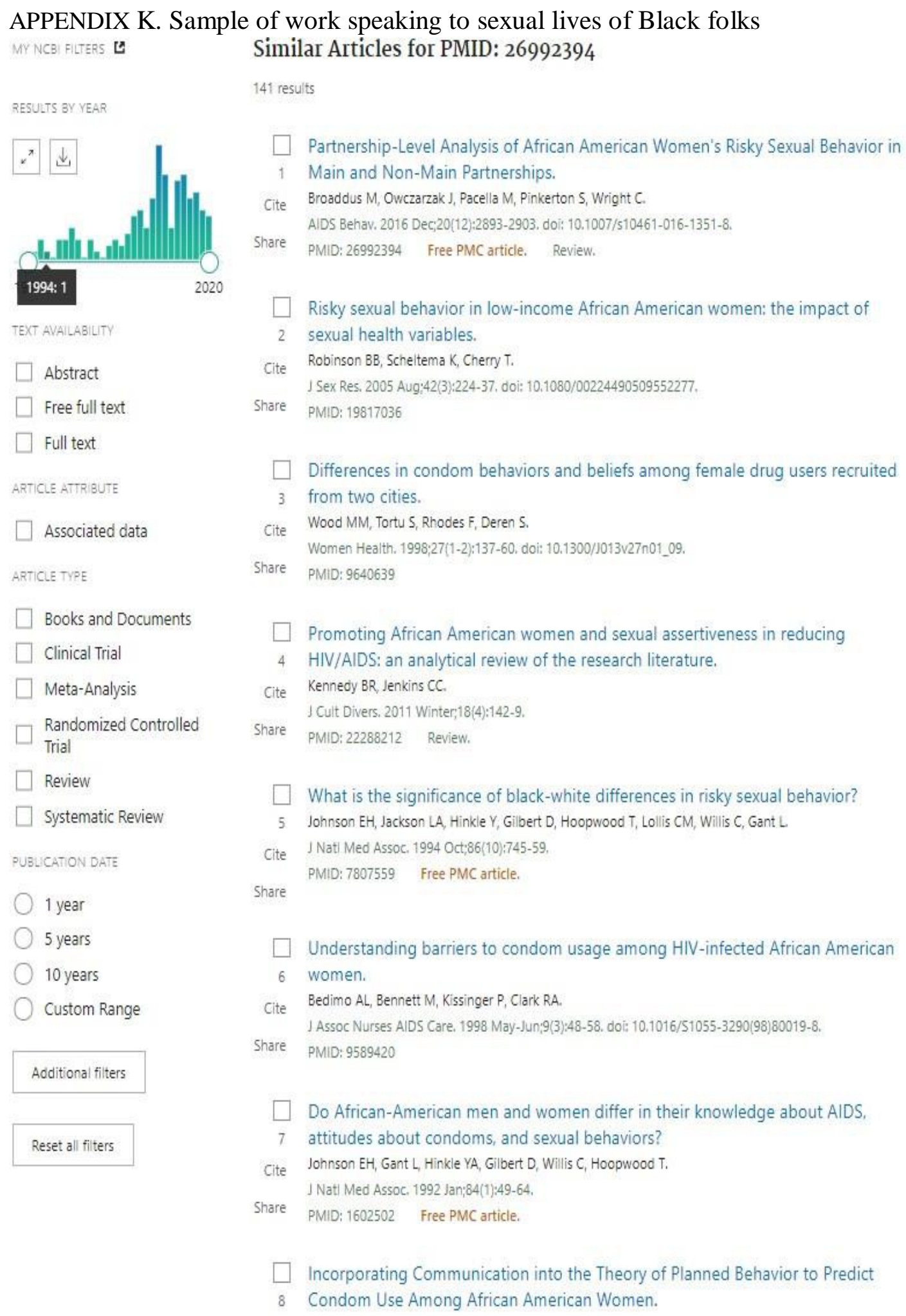


SISTA in Compendium

\section{A Randomized Controlled Trial of an HIV Sexual Risk- reduction Intervention for Young African- American Women}

DiClemente, R.J., \& Wingood, GM. (1995).

Journal of the American Medical Association, 274(16), 1271 - 1276

Intervention Goal(s): To determine the effects of a small group intervention to increase consistent condom use and prevent HIV infection.

Intervention Setting: Community center."
Description of Intervention: Social Skills Training

Social Cognitive Theory and theories of gender and power were used as models to guide the development of this social skills intervention. The intervention consisted of five weekly 2-hour group sessions led by trained African-American peer educators in the Bayview-Hunter's Point community of San Francisco, California. Each session had a specific topic and planned activities for modeling and assessing skills.

Session 1: Gender and ethnic pride. The women discussed positive attributes of being an African-American woman

Session 2: Personal responsibility for sexual decision making. The women watched an HIV prevention video and had discussion.

Session 3: Sexual assertiveness and communication training. Role-playing exercises were used to practice managing risky sexual situations.

Session 4: Condom use. The women concentrated on building skills and changing social norms for proper condom use.

Session 5: Cognitive coping skills. Participants developed skills such as sexual self-control.

Population: Among the 128 sexually active African-American women from an economically disadvantaged neighborhood who participated in the study, the average age was 23 years, ranging from 18-29 years.

Comparison Condition: The intervention was given to comparison participants at a later time.

Behavioral/Health Findings: Women who participated in the intervention were significantly more likely than women in the comparison condition to report consistent condom use with their partners, negotiating condom use, and not having sex when a condom was not available.

\section{Contact:}

Ralph DiClemente, $\mathrm{PhD}$

Phone: $\quad 404-727-0237$

Rollins School of Public Health

Fax:

Emory University

1518 Clifton Road

Atlanta, GA 30022

§Information obtained from related reports or author. 


\section{How the Compendium Is Organized}

The Compendium is organized into four sections:

Section One: Summaries of Prevention Interventions

This section provides "one-pagers" or Summaries of each effective intervention. These are written to emphasize the intervention content and methods, based on information provided in the report. Summaries are grouped by target populations:
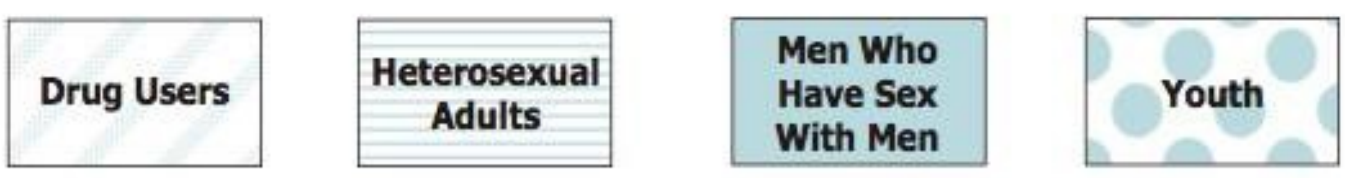

Within groups, Summaries are ordered alphabetically by author.

\section{Section Two: Tables}

For all interventions, Table 1 highlights characteristics of the populations and interventions.

For selected interventions, Table 2 provides information about access to intervention materials.

\section{Section Three: Intervention Checklist}

The Intervention Checklist is a tool for intervention assessment. It is designed to clarify aspects of existing interventions that can be strengthened.

\section{Section Four: Appendices}

Appendix A describes the aims of CDC's HIV/AIDS Prevention Research Synthesis (PRS) project, the criteria used to select PRS relevant and rigorous studies, and the additional criteria used to select a subset of relevant and rigorous studies for the Compendium.

Appendix $B$ contains the bibliography, which references each study in the
Compendium, along with additional or supplemental citations that pertain to that study. 
APPENDIX L: Patricia Hill Collis’ Controlling images (1991).

\begin{tabular}{|c|c|c|c|}
\hline & Who is she? & Why was she created & What is the effect? \\
\hline mammy & $\begin{array}{l}\text {-the faithful, obedient } \\
\text { domestic servant }\end{array}$ & $\begin{array}{l}\text {-created to justify the economic } \\
\text { exploitation of house slaves, sustained } \\
\text { to explain Black women's } \\
\text { longstanding restriction to domestic } \\
\text { service, represents the normative } \\
\text { yardstick used to evalluate all Black } \\
\text { women's behavior. By loving, } \\
\text { nurturing, and caring for her white } \\
\text { children and "family" better than her } \\
\text { own, the mammy symbolizes the } \\
\text { dominant group's perception of the } \\
\text { ideal Black female relationship to elite } \\
\text { white male power. }\end{array}$ & $\begin{array}{l}\text {-even though she may be } \\
\text { well-loved and may wield } \\
\text { considerable authority in } \\
\text { her white "family," the } \\
\text { mammy still knows her } \\
\text { "place" as obedient } \\
\text { servant. } \\
\text {-she has accepted her } \\
\text { subordination }\end{array}$ \\
\hline $\begin{array}{l}\text { welfare } \\
\text { mother }\end{array}$ & $\begin{array}{l}\text {-tied to Black women's } \\
\text { increasing dependence } \\
\text { on the post-World War } \\
\text { II welfare state. } \\
\text {-also, an updated } \\
\text { version of the breeder - } \\
\text { woman image a woman } \\
\text { of low morals and } \\
\text { uncontrolled sexuality, }\end{array}$ & $\begin{array}{l}\text { this image provides an ideological } \\
\text { justification for efforts to harness } \\
\text { Black women's fertility to the needs of } \\
\text { a changing political economy. } \\
\text {-her treatment reinforces the dominant } \\
\text { gender ideology positing that a } \\
\text { woman's true worth and financial } \\
\text { security should occur through } \\
\text { heterosexual marriage. } \\
\text {-creating the controlling image of the } \\
\text { welfare mother and stigmatizing her as } \\
\text { the cause of her own poverty and of } \\
\text { African Americans shifts the angle of } \\
\text { vision away from structural sources of } \\
\text { poverty and blames the victims } \\
\text { themselves. }\end{array}$ & $\begin{array}{l}\text { Like the matriarch, the } \\
\text { welfare mother is labeled } \\
\text { a bad mother. But unlike } \\
\text { the matriarch, she is not } \\
\text { too aggressive-on the } \\
\text { contrary, she is not } \\
\text { aggressive enough. } \\
\text { - the image of the welfare } \\
\text { mother provides } \\
\text { ideological justifications } \\
\text { for interlocking systems } \\
\text { of race, gender, and class } \\
\text { oppression. }\end{array}$ \\
\hline matriarch & $\begin{array}{l}\text { represents the sexually } \\
\text { aggressive woman, one } \\
\text { who emasculates Black } \\
\text { men because she will } \\
\text { not permit them to } \\
\text { assume roles as Black } \\
\text { patriarchs. }\end{array}$ & & \\
\hline $\begin{array}{l}\text { the } \\
\text { Jezebel, }\end{array}$ & $\begin{array}{l}\text { whore, sexually } \\
\text { aggressive woman }\end{array}$ & & $\begin{array}{l}\text { connecting all } 3 \text { is the } \\
\text { common theme of Black } \\
\text { women's sexuality. -each } \\
\text { image transmits messages } \\
\text { about proper links among } \\
\text { female sexuality, fertility, } \\
\& \text { Black women's roles } \\
\text { in the political economy. }\end{array}$ \\
\hline
\end{tabular}




\title{
APPENDIX M- Verbal script for recruitment
}

\section{S Portland State}

\author{
Email recruitment Form - Facilitators
}

Project Title: [Decolonizing HIV/AIDS prevention programs: A Black Feminist Analysis of the SISTA HIV/AIDS intervention]

Researcher: Joy Mutare, [Sociology]

Portland State University

Researcher Contact: jmutare@pdx.edu / 315-436-4837

My name is Joy Mutare from Portland State. I have been working on a study just to see how sisters experience the SISTA training and was wondering if you could share your thoughts with us regarding this program. We are interested SISTA's impact on the African American community as well as the ways you are addressing the gap now that SISTA has been defunded.

We are available at your convenience. Please see the attached consent for. We would like it for you to sign it and return to us. If this is not possible, please note that we can obtain consent from you on the day of the interview. Your recorded verbal consent will be held with the same regard. We would also love to speak to other facilitators who ran this program. If you could point us towards these sisters, we would be most grateful. The interview can be in person or over the phone. We expect the interviews to last between 45 minutes to one hour.

If you have questions, concerns please, or have experienced a research related injury, contact the research team at:

Aaron Roussell, Advisor and Dissertation

9499439860

roussell@pdx.edu

You are also welcome to contact the Portland State University Institutional Review Board ("IRB") who are overseeing this research. The IRB is a group of people who independently review research studies to ensure the rights and welfare of participants are protected. The Office of Research Integrity is the office at Portland State University that supports the IRB. If you have questions about your rights, or wish to speak with someone other than the research team, you may contact:

Office of Research Integrity

PO Box 751

Portland, OR 97207-0751

Phone: (503) 725-5484

Toll Free: 1 (877) $480-4400$

Email: hsrrc@pdx.edu 